\title{
Solid and Solid-Like Composite Electrolyte for Lithium Ion Batteries: Engineering the Ion Conductivity at Interfaces
}

\author{
Xubin Chen and Philippe M. Vereecken*
}

The development of solid composite electrolytes or solid composite electrolytes (SCEs) consisting of an ionic conductor and a dielectric matrix offers an elegant strategy to enhance the ionic conductivity of electrolytes by engineering the interface conduction. At the conductor/matrix interface, the ionic conductivity can be enhanced by the enriched charge carrier concentration and/or the changed molecular structure of the ionic conductor. This review deals with the interfacial ion conduction mechanisms of the inorganic particle-based SCE, polymer-SCE, and ionic liquid electrolytebased SCE (ILE-SCE). In the first part of this review, an overview is given of the space-charge theory developed to describe the increased vacancy concentration at the interface of inorganic particle-based SCE. In the second part, the proposed interface interactions and structural changes associated with interface conduction for the polymer-SCE and ILE-SCE are reviewed. For the ILE-SCE, the preparation methods and interface characterization are discussed together with the proposed conductivity models. The use of mesoporous matrix materials with high internal surface area for ILE-SCE is reviewed here for the first time.

\section{Introduction}

\subsection{The Rapid Evolution in Li-Ion Batteries}

The Li-ion galvanic cell is the technology of choice for rechargeable battery applications, as the Li-ion electrode chemistries provide the highest volumetric and gravimetric energy density known. The evolution of Li-ion cell technology was initially driven primarily by the portable electronics industry. The large energy density of the Li-ion batteries enabled the miniaturization of electronic devices and the emergence of smart phones and tablets. The improvements in the Li-ion technology has subsequently prompted the developments in the last 10 years toward electric vehicles (EV), mainly plug-in EV and full $\mathrm{EV}^{[1]}$

Dr. X. Chen, Prof. P. M. Vereecken

imec

Kapeldreef 75, B-3001 Leuven, Belgium

E-mail: vereeck@imec.be

Dr. X. Chen, Prof. P. M. Vereecken

$\mathrm{M}^{2} \mathrm{~S}$ Department

Centre for Surface Chemistry and Catalysis

KU-Leuven (Leuven University)

Kasteelpark Arenberg 23, B-3001 Leuven, Belgium

The ORCID identification number(s) for the author(s) of this article can be found under https://doi.org/10.1002/admi.201800899.

DOI: 10.1002/admi.201800899 which are expected to consume over half of total lithium ion battery product. ${ }^{[2,3]}$ For these applications, energy density and power density are the main drivers. Presently, the demand of stationary storage and then mainly the application of local or home storage drives R\&D also toward cost reduction, increased life-time, and safety.

Since its first introduction on the market by Sony in 1991, the energy density of the (high energy) Li-ion battery has doubled from $100 \mathrm{Wh} \mathrm{kg}^{-1}\left(250 \mathrm{Wh} \mathrm{L}{ }^{-1}\right)$ to $250 \mathrm{Wh} \mathrm{kg}^{-1}\left(600 \mathrm{Wh} \mathrm{L}^{-1}\right)$ mainly through the introduction of new electrode chemistries with higher Li-ion capacity and the improvement of the accessible capacity by improvement of electrode formulations. Today, lithium cobalt oxide $\left(\mathrm{LiCoO}_{2} \text { or } \mathrm{LCO}\right)^{[4]}$ and lithium nickelcobalt-manganese oxide $\left(\mathrm{LiNi}_{x} \mathrm{Mn}_{\gamma} \mathrm{Co}_{z} \mathrm{O}_{2}\right.$ (with $x+y+z=1$ ) or NMC) ${ }^{[5]}$ are the most used positive electrode materials followed by lithium-iron phosphate $\left(\mathrm{LiFePO}_{4}\right.$ or LFP), ${ }^{[6]}$ lithium-manganese oxide $\left(\mathrm{LiMn}_{2} \mathrm{O}_{4}\right.$ or LMO), and lithium-nickel-cobalt-aluminum oxide $\left(\mathrm{LiNi}_{0.8} \mathrm{Co}_{0.15} \mathrm{Al}_{0.05} \mathrm{O}_{2}\right.$ or NCA). ${ }^{[7,8]}$ For the negative electrode specialty, graphite $\left(\mathrm{LiC}_{6}\right)$ is still most commonly used (>90\% market share), ${ }^{[9]}$ even though higher capacity composites of graphite and silicon are now entering the market. Lithium-titanium oxide $\left(\mathrm{Li}_{4} \mathrm{Ti}_{5} \mathrm{O}_{12}\right.$ or LTO) is used specifically for safety and high-power applications, for example, for hybrid electric vehicles. ${ }^{[10]}$ An average growth rate of $10 \mathrm{Wh} \mathrm{kg}^{-1}$ per year is expected to continue over the next 10 years through further improvement of electrode materials, e.g., by the introduction of nanomaterials and higher voltage materials. ${ }^{[1]}$

One way to increase the energy density of the Li-ion battery is to increase the cell voltage altogether. ${ }^{[12]}$ The introduction of higher voltage positive electrodes such as lithiummanganese-nickel oxide $\left(\mathrm{LiMn}_{1.5} \mathrm{Ni}_{0.5} \mathrm{O}_{4}\right.$ or LMNO with electrode potential of $\left.4.7 \mathrm{~V} \mathrm{vs} \mathrm{Li}^{+} / \mathrm{Li}\right)^{[10]}$ is hindered by a lack of electrolytes with positive enough voltage windows. The currently employed carbonate-based solvents decompose at voltages $\approx 4.4 \mathrm{~V}$ and are therefore not compatible with these high voltage positive electrodes without suitable additives or protective coatings. ${ }^{[13-15]}$ Certain ionic liquid electrolytes (ILE) such as lithium bis(trifluoromethanesulfonyl)imide (Li[TFSI]) in 1-butyl-1-methylpyrrolidinium bis(trifluoromethylsulfonyl)imide ([BMP][TFSI]) are more stable against these $5 \mathrm{~V}$ cathodes but not against $\mathrm{Li}$ or carbon anodes.. ${ }^{16]}$ Solid-state electrolytes can provide the necessary electrochemical window 
(e.g., lithium phosphate glass doped with nitrogen or LiPON

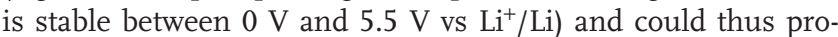
vide a viable alternative. ${ }^{[17,18]}$ Unfortunately, the lack of solid electrolyte materials with both sufficiently high Li-ion conductivity $\left(>10 \mathrm{mS} \mathrm{cm}^{-1}\right)$ and wide enough electrochemical window $(<0.2$ and $>4.5 \mathrm{~V})$ has been the main bottle neck for the introduction of solid-state electrolytes. LiPON ${ }^{[19]}$ for example, has an ionic conductivity of only $10^{-7}$ to $10^{-6} \mathrm{~S} \mathrm{~cm}^{-1}$ and is therefore only applicable in all-solid-state thin-film microbatteries where the sub-micrometer electrolyte film thickness allows low enough cell resistance. ${ }^{[20,21]}$ Recently, significant progress has been made also in the area of solid-state electrolytes for the large capacity powder-based batteries. Researchers from Tokyo Institute of Technology and Toyota corporation reported on a novel crystalline sulfide superionic conductor with Li-ion conductivity exceeding $20 \mathrm{mS} \mathrm{cm}{ }^{-1}$ at room temperature. ${ }^{[22]}$

\subsection{Solid Electrolytes}

Replacement of the liquid electrolyte by a solid electrolyte in lithium ion batteries (LIB) could solve several key issues which are limiting battery performance today. First, battery safety would most notably benefit from the removal of the volatile and flammable carbonate solvents, whose decompositions can release more than $2000 \mathrm{~J} \mathrm{~g}^{-1}$ energy, increasing the cell temperature up to $600{ }^{\circ} \mathrm{C} .{ }^{[23,24]}$ Solid electrolytes are more resistant to such thermal decomposition. Second, much longer cycle lifetimes are expected for the all solid-state batteries as performance degrading side reactions at the electrode/electrolyte interface are significantly reduced or nonexisting. Battery life-time over 10000 cycles has indeed been demonstrated already in thin-film microbatteries, such as $\mathrm{Li} / \mathrm{LiPON} / \mathrm{LiCoO}_{2}{ }^{[25]}$ and $\mathrm{Li} / \mathrm{LiPON} /$ $\mathrm{LiNi}_{0.5} \mathrm{Mn}_{1.5} \mathrm{O}_{4} \cdot{ }^{[26]}$ However, for large capacity batteries with $100 \mu \mathrm{m}$ thick powder electrodes, the structural integrity of the electrode particle/electrolyte interface might compromise the cyclability. ${ }^{[25]}$ Interestingly, and often not yet recognized, is that the absence of parasitic side-reactions enables the introduction of nanostructured active electrode materials which should significantly increase the (dis)charging rate of the all-solid electrodes and cells. ${ }^{[27]}$ The kinetic advantage of large surface area nanoparticle electrodes is, for example, well-known for high power spinel Li-ion cells where the nanoparticle $\mathrm{Li}_{4} \mathrm{Ti}_{5} \mathrm{O}_{12}$ or LTO negative electrodes do not suffer from side-reactions with the carbonate solvent due to their relatively high electrode potential of $1.55 \mathrm{~V}$ versus $\mathrm{Li}^{+} / \mathrm{Li}^{.}{ }^{[28,29]}$ Another advantage of solid electrolytes is their high $\mathrm{Li}^{+}$transport number, which is typically close to 1 for inorganic materials where the counter charge is fixed in the crystal lattice. Finally, the rigid solid electrolyte component could be made thinner than the currently used separator membrane with a standard $25.4 \mu \mathrm{m}$ thickness, ${ }^{[30]}$ resulting in more compact cells and a simplified battery design thus increasing the effective energy and power density of the battery.

The introduction of large capacity all-solid-state batteries has been held back by the quest for suitable solid electrolyte materials with both high ion conductivity and wide electrochemical window. ${ }^{[31,32]}$ The Li-ion conductivities of the carbonate-based liquid electrolytes are in the range of $10 \mathrm{mS} \mathrm{cm}^{-1}$ (e.g., $10.7 \mathrm{mS} \mathrm{cm}^{-1}$ for $\mathrm{LiPF}_{6}$ in 1:1 mixture of ethylene carbonate

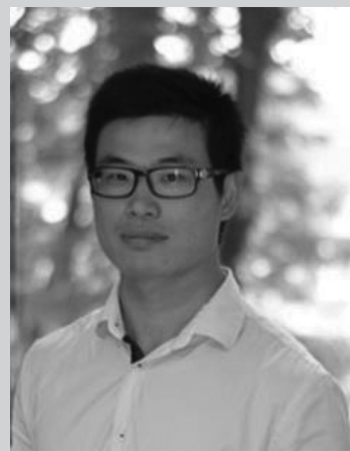

Xubin Chen is a researcher at IMEC, Belgium. He received his Bachelor and Master degree in material science and engineering from Xiamen university and Zhejiang university, China, respectively. He then obtained his Ph.D. from KU-Leuven and imec in 2018, working on solid composite electrolytes for lithium ion batteries. His research

focusses on the synthesis of nanocomposite materials as solid electrolytes, conduction mechanisms in composite electrolytes, and on the integration of solid electrolytes into all-solid-state batteries.

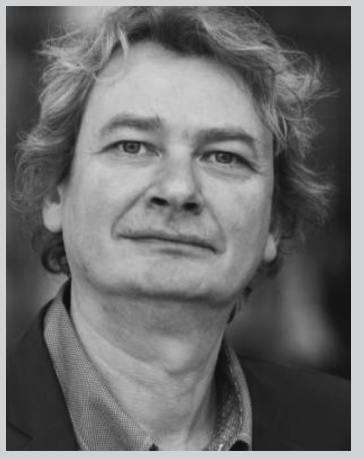

Philippe Vereecken is Distinguished Member of Technical Staff at imec and part-time professor at the University of Leuven (KU-Leuven). His main expertise lays in the combination of electrochemistry and nanomaterials and specifically in its use in semiconductors, energy conversion, electrochemical storage, and nanomaterials synthesis. Dr. Vereecken received his Ph.D. in Physical Chemistry at Ghent University (Belgium) in 1998. He then spent 7 years in the US, first as a postdoctoral associate at The Johns Hopkins University in Baltimore, MD (1998-2001) and subsequently as a Research Staff Member (RSM) at IBM T.J. Watson Research Center in Yorktown Heights, NY (2001-2005). In 2009, Dr. Vereecken started up the electrochemical storage activities in imec. His current focus lays in the development of novel solid-state nanocomposite electrolytes and thin-film protective coatings for next generation solid-state Li-ion batteries. Other interests include thin-film batteries and photo-electrochemical generation of solar fuels for sustainable energy production.

and dimethyl carbonate).$^{[15]}$ Good progress has been made both for inorganic ${ }^{[33]}$ and polymer solid electrolyte ${ }^{[34-36]}$ chemistries over the last decade. The threshold value of $10 \mathrm{mS} \mathrm{cm}^{-1}$ was only recently breached with the discovery of a new type of crystalline sulfide materials with high $\mathrm{Li}$ content, e.g., $\mathrm{Li}_{10} \mathrm{GeP}_{2} \mathrm{~S}_{12} \cdot{ }^{[37]}$

Solid electrolytes for Li-ion batteries can be divided into 3 categories: inorganic electrolytes, polymer electrolytes, and composite electrolytes. Several reviews ${ }^{[17,33,38]}$ and books ${ }^{[25]}$ are already available on the first two categories and an overview of the most important solid electrolyte systems with typical ranges of reported Li-ion conductivity is shown in Table 1.

The inorganic electrolytes can be further divided into crystalline materials and glasses. The crystal materials further include 
Table 1. Overview of solid electrolyte materials for lithium ion batteries. ${ }^{[17,33,38,42]}$

\begin{tabular}{|c|c|c|}
\hline Electrolyte & Composition & Conductivity at RT $\left[\mathrm{S} \mathrm{cm}^{-1}\right]$ \\
\hline $\begin{array}{l}\text { Sulfide crystal (thio-LISICON } \\
\text { and argyrodite) }\end{array}$ & $\begin{array}{c}\mathrm{Li}_{10} \mathrm{MP}_{2} \mathrm{~S}_{12}(\mathrm{M}=\mathrm{Si}, \mathrm{Ge}, \mathrm{Sn}) \\
\mathrm{Li}_{11} \mathrm{SiPS}_{12} \\
\mathrm{Li}_{3+x}\left(\mathrm{P}_{1-x} \mathrm{Si}_{x}\right) \mathrm{S}_{4} \\
\mathrm{Li}_{6} \mathrm{PS}_{5} \mathrm{X}(\mathrm{X}=\mathrm{Cl}, \mathrm{Br}, \mathrm{I})\end{array}$ & $10^{-6}-10^{-2}$ \\
\hline LISICON & $\begin{array}{c}\mathrm{Li}_{2+2 x} \mathrm{Zn}_{1-x} \mathrm{CeO}_{4} \\
\mathrm{Li}_{4 \pm x} \mathrm{Si}_{1-x} \mathrm{X}_{x} \mathrm{O}_{4}(\mathrm{X}=\mathrm{P}, \mathrm{Al} \text {, or } \mathrm{Ce})\end{array}$ & $10^{-7}-10^{-4}$ \\
\hline NASICON-like & $\begin{array}{c}\mathrm{Li}_{1+6 x} \mathrm{M}^{4+}{ }_{2-} \mathrm{M}^{\prime 3+}{ }_{x}\left(\mathrm{PO}_{4}\right)_{3}(\mathrm{M}=\mathrm{Ti}, \mathrm{Ge}, \mathrm{Sn}, \mathrm{Hf} \\
\left.\text { or } \mathrm{Zr} \text { and } \mathrm{M}^{\prime}=\mathrm{Cr}, \mathrm{Al}, \mathrm{Ga}, \mathrm{Sc}, \mathrm{Y}, \mathrm{In} \text {, or } \mathrm{La}\right)\end{array}$ & $10^{-10}-10^{-3}$ \\
\hline Garnet & $\begin{array}{c}\mathrm{Li}_{3} \mathrm{Ln}_{3} \mathrm{Te}_{2} \mathrm{O}_{12}(\mathrm{Ln}=\mathrm{Y}, \mathrm{Pr}, \mathrm{Nd}, \mathrm{Sm}-\mathrm{Lu}) \\
\mathrm{Li}_{5} \mathrm{La}_{3} \mathrm{M}_{2} \mathrm{O}_{12}(\mathrm{M}=\mathrm{Nb}, \mathrm{Ta}, \mathrm{Sb}) \\
\mathrm{Li}_{6} \mathrm{ALa}_{2} \mathrm{M}_{2} \mathrm{O}_{12}(\mathrm{~A}=\mathrm{Mg}, \mathrm{Ca}, \mathrm{Sr}, \mathrm{Ba} ; \mathrm{M}=\mathrm{Nb}, \mathrm{Ta}) \\
\mathrm{Li}_{7} \mathrm{La}_{3} \mathrm{M}_{2} \mathrm{O}_{12}(\mathrm{M}=\mathrm{Zr}, \mathrm{Sn})\end{array}$ & $10^{-6}-10^{-3}$ \\
\hline $\mathrm{Li}_{3} \mathrm{~N}$ & $\mathrm{Li}_{3} \mathrm{~N}$ & $10^{-3}$ \\
\hline Li- $\beta$-alumina & $1.13 \mathrm{Li}_{2} \mathrm{O}-11 \mathrm{Al}_{2} \mathrm{O}_{3}$ to $1.13 \mathrm{Li}_{2} \mathrm{O}-11 \mathrm{Al}_{2} \mathrm{O}_{3}$ & $10^{-4}-10^{-3}$ \\
\hline $\mathrm{Li}_{2} \mathrm{O}-\mathrm{Al}_{2} \mathrm{O}_{3}-\mathrm{SiO}_{2}$ glass & $\mathrm{LiAlSiO}_{4}$ & $10^{-5}$ \\
\hline LiPON & $\mathrm{Li}_{x} \mathrm{PO}_{y} \mathrm{~N}_{z}$ & $10^{-7}-10^{-6}$ \\
\hline Sulfide glass & $\begin{array}{c}\mathrm{Li}_{2} \mathrm{~S}_{-} \mathrm{P}_{2} \mathrm{~S}_{5} \\
\mathrm{Li}_{2} \mathrm{~S}-\mathrm{Si}_{2} \mathrm{~S}_{5}-\mathrm{Li}_{4} \mathrm{SiO}_{4} \\
\mathrm{Li}_{7} \mathrm{P}_{3} \mathrm{~S}_{11} \\
\mathrm{Li}_{2} \mathrm{~S}_{-} \mathrm{P}_{2} \mathrm{~S}_{5}-\mathrm{Lil} \\
\mathrm{Li}_{2} \mathrm{~S}_{-} \mathrm{P}_{2} \mathrm{~S}_{5}-\mathrm{LiBH}_{4} \text {, etc. }\end{array}$ & $10^{-5}-10^{-2}$ \\
\hline Solid polymer electrolyte & PEO-LiX, $\left(\mathrm{X}=\mathrm{BF}_{4}^{-}, \mathrm{TFSI}^{-}, \mathrm{PF}_{6}^{-}, \mathrm{ClO}_{4}^{-}\right.$, etc. $)$ & $10^{-8}-10^{-4}$ \\
\hline solid composite electrolyte & $\begin{array}{c}\text { Oxide/lithium salt } \\
\text { Oxide/polymer } \\
\text { Oxide/ionic liquid electrolyte }\end{array}$ & $10^{-8}-10^{-2}$ \\
\hline
\end{tabular}

material classes such as LISICON-type electrolytes $\left(\mathrm{Li}_{2+2 x} \mathrm{Zn}_{1-x}\right.$ $\left.\mathrm{GeO}_{4}\right)$, ${ }^{[39]}$ lithium-perovskites $\left(\mathrm{Li}_{3 x} \mathrm{La}_{2 / 3-x} \mathrm{TiO}_{3}\right),{ }^{[40]}$ lithiumargyrodites $\left(\mathrm{Li}_{6} \mathrm{PS}_{5} \mathrm{X}, \mathrm{X}=\mathrm{Cl}, \mathrm{Br}, \mathrm{I}\right),{ }^{[11]}$ sodium super ionic conductor (NASICON)-like materials ${ }^{[6]} \quad\left(\mathrm{Li}_{1+6 x} \mathrm{M}_{4+2 \times 3+x}^{\prime}\left(\mathrm{PO}_{4}\right)_{3}\right.$, $\mathrm{M}=\mathrm{Ti}, \mathrm{Ge}, \mathrm{Sn}, \mathrm{Hf}$, or $\mathrm{Zr}$ and $\mathrm{M}^{\prime}=\mathrm{Cr}, \mathrm{Al}, \mathrm{Ga}, \mathrm{Sc}, \mathrm{Y}, \mathrm{In}$, or $\left.\mathrm{La}\right)$, and lithium garnet $\mathrm{Li}_{5} \mathrm{La}_{3} \mathrm{M}_{2} \mathrm{O}_{12}(\mathrm{M}=\mathrm{Nb}, \mathrm{Ta}) .{ }^{[42]}$ The lithium super ionic conductor (LISICON) and NASICON (as it was first explored as an electrolyte for Na-ions) are two different types of Li-ion electrolytes which, though predicted to achieve high performance, are only able to attain Li-ion conductivities of about $10^{-3} \mathrm{~S} \mathrm{~cm}^{-1}$. The new thio-LISICON materials with general composition $\mathrm{Li}_{10}\left(\mathrm{M}_{1-x} \mathrm{~N}_{x}\right) \mathrm{P}_{2} \mathrm{~S}_{12}(\mathrm{M}, \mathrm{N}=\mathrm{Ge}, \mathrm{Si}, \mathrm{Sn})$ reach conductivities close to $10 \mathrm{mS} \mathrm{cm} \mathrm{cm}^{-1}$ and can be increased even higher by doping with, e.g., Cl. ${ }^{[22]}$ Inorganic glass electrolytes are often mixtures of several amorphous compounds, e.g., $\mathrm{Li}_{3} \mathrm{PO}_{4}-\mathrm{Li}_{2} \mathrm{~S}-\mathrm{SiS}_{2}{ }_{2}^{[43]}$ and $\mathrm{Li}_{2} \mathrm{~S}-\mathrm{P}_{2} \mathrm{~S}_{5} \cdot{ }^{[44]}$ Whereas $\mathrm{Li}_{3} \mathrm{PO}_{4}$ and $\mathrm{Li}_{2} \mathrm{~S}$ have a room temperature conductivity of only $10^{-9[45]}$ and $10^{-13} \mathrm{~S} \mathrm{~cm}^{-1[46]}$ respectively, the composite glasses above have a conductivity of $1.5 \times 10^{-3}$ and $8 \times 10^{-5} \mathrm{mS} \mathrm{cm}^{-1}$, respectively.

Polymer electrolytes are composed of a polymer and a lithium salt-typically polyethylene oxide (PEO) with a commonly used lithium salts like $\mathrm{LiClO}_{4},{ }^{[47]} \mathrm{LiBF}_{4},{ }^{[48]} \mathrm{LiPF}_{6},{ }^{[49]}$ and $\mathrm{Li}[\mathrm{TFSI}]^{[50]}$ — where the lithium salt is solvated by the polymer chain. Efforts have mainly focused on increasing the conductivity of the solid electrolyte.

The focus of this introduction will be, on solid composite electrolytes or solid composite electrolyte (SCE) where seemingly inactive inorganic oxides mixed with organic, inorganic, or polymer Li-ion electrolytes results in an enhancement of the electrolyte conductivity. Nanocomposites of an ionic liquid electrolyte confined within an oxide porous matrix, sometimes also referred to as ionogels, are also included in this category. Recently, we have shown that for these nanocomposite electrolytes enhancement can also be obtained by careful control of the surface functionalization which opens the door for engineering of new materials. ${ }^{[51]}$ Note that whereas ionic liquid electrolytes are typically in the liquid state at room temperature, the ionic liquid electrolyte in nanoconfined spaces becomes solid or solid-like due to the complete or particle adsorption on the pore wall surface. Indeed, it is this adsorption which also leads to the enhanced interfacial ion conductivity of the nanocomposites.

\subsection{Ionic Conduction in Solid Electrolytes}

In general, the ionic conductivity, $\sigma$, can be expressed as the sum of all the moving charged species, $i$, through the electrolyte according to ${ }^{[52]}$

$\sigma=\sum_{i} q_{i} c_{i} u_{i}$

where $q_{i}$ is the charge number, $c_{i}$ is the concentration, and $u_{i}$ is the mobility of the charged species. Lithium ions can move through solid electrolytes following different mechanisms. In inorganic crystal electrolytes, lattice defects such as vacancies and interstitials exist. Also in glass electrolytes such as $\mathrm{Li}_{3} \mathrm{PO}_{4}$ there are so-call "charged defects" where ions are missing from their regular sites. ${ }^{[53]} \mathrm{Li}^{+}$ions hop through these defects. The probability, $\mathrm{P}$, for an ion to jump to its neighboring site is ${ }^{[52]}$

$P=z(1-c / N) f v$

where $z$ is the number of the nearest neighboring sites; $f$ is a geometrical factor of order unity that depends on the jump path; $N$ is the number of normal sites per unit volume (i.e., $c / N$ is the fraction of defects); $v$ is the hopping frequency which is expressed as

$v=v_{0} \exp \left(-\frac{\Delta G_{\mathrm{m}}}{k T}\right)$

where $v_{0}$ is the attempt frequency $\left(\approx 10^{12} \mathrm{~Hz}\right), k$ is the Boltzmann constant; $T$ is temperature; and $\Delta G_{\mathrm{m}}$ is the motional free energy which describes the energy barrier for the ion motion

$\Delta G_{\mathrm{m}}=\Delta H_{\mathrm{m}}-T \Delta S_{\mathrm{m}}$

with $\Delta H_{\mathrm{m}}$ and $\Delta S_{\mathrm{m}}$ the motional enthalpy and entropy, respectively. Under an electrical field, the possibility of the ion motion along this field becomes 
$P^{\prime}=z(1-c / N) f v_{0}\left(\exp \left(-\frac{\Delta G_{\mathrm{m}}-q E l / 6}{k T}\right)-\exp \left(-\frac{\Delta G_{\mathrm{m}}+q E l / 6}{k T}\right)\right)$

where $E$ is the electrical filed; $l$ is the distance between neighboring sites; and " 6 " means ions move in three dimensions. Therefore, the drift velocity, $V$, of ions is

$V=P^{\prime} \frac{l}{2}$

As $q E l / 6 \ll k T$ holds for the temperature where ions are mobile, ${ }^{[52]}$ Equation (6) becomes

$V=\frac{l}{2} z(1-c / N) f v_{0} \exp \left(-\frac{\Delta G_{\mathrm{m}}}{k T}\right) \frac{q E l}{3 k T}$

The mobility of ions is defined as

$u=\frac{V}{E}$

Comparison of Equations (7) and (8) gives

$u=l z(1-c / N) f v_{0} \exp \left(-\frac{\Delta G_{\mathrm{m}}}{k T}\right) \frac{q l}{6 k T}$

Substitution of Equation (9) into Equation (1) yields the conductivity of $\mathrm{Li}^{+}$in the electrolyte

$\sigma=\frac{q^{2} l^{2} z c(1-c / N) f v_{0}}{6 k T} \exp \left(-\frac{\Delta G_{\mathrm{m}}}{k T}\right)$

Equation (10) can be rewritten as

$\sigma=\frac{\sigma_{0}}{T} \exp \left(\frac{-E_{\mathrm{a}}}{k T}\right)$

where $E_{\mathrm{a}}$ is the activation energy, and $\sigma_{0}$ is a pre-exponential factor. Obviously, they can be expressed as

$E_{\mathrm{a}}=\Delta H_{\mathrm{m}}$

$\sigma_{0}=\frac{q^{2} l^{2} z c(1-c / N) f v_{0}}{6 k} \exp \left(\frac{\Delta S_{\mathrm{m}}}{k}\right)$

Equation (11) is known as Arrhenius equation. If the defect concentration depends on temperature, it follows

$c=N \exp \left(-\frac{\Delta G_{c}}{k T}\right)$

in which $\Delta G_{c}=\Delta H_{c}-T \Delta S_{c}$ is the free energy of defect formation. In this case, substitution of Equation (14) into Equation (10) gives

$E_{\mathrm{a}}=\Delta H_{\mathrm{m}}+\Delta H_{\mathrm{c}}$

$\sigma_{0}=\frac{q^{2} l^{2} z N(1-c / N) f v_{0}}{6 k} \exp \left(\frac{\Delta S_{\mathrm{m}}+\Delta S_{\mathrm{c}}}{k}\right)$ where $\Delta H_{\mathrm{c}}$ and $\Delta S_{\mathrm{c}}$ are, respectively, the enthalpy and entropy of defect formation. The activation energy comprises of Coulombic binding energy, $E_{c}$, and volumetric strain energy caused by the ions' motion, $E_{\mathrm{s}} \cdot{ }^{\left[{ }^{[} 4\right]}$ The former is inversely proportional to the ion size, while the latter is expected to increase as the ion size increases. ${ }^{[55]}$

In solid polymer electrolytes, $\mathrm{Li}^{+}$ions conduct by the migration of defects which is coupled with the deformation of the polymer chain. ${ }^{[53]}$ Typically, $\mathrm{Li}^{+}$ions are coordinated by the ether moieties of the polyethylene oxide chain which are wrapped around the ions. $\mathrm{Li}^{+}$ions then migrate along the poly-ether chain by exchanging one coordination center with another further along the motion path. In this second mechanism, the temperature dependence of the conductivity is expressed as ${ }^{[53]}$

$\sigma=\frac{\sigma_{0}}{T^{1 / 2}} \exp \left(-\frac{B}{T-T_{0}}\right)$

where $B$ is the so-called pseudoactivation energy, $T_{0}$ is related to the glass transition temperature of the polymer $T_{\mathrm{g}}$ as $T_{0} \cong T_{\mathrm{g}}-50 \mathrm{~K}$; and $\sigma_{0}$ is the pre-exponential factor which is a function of the charge carrier concentration.

It is useful to relate the conductivity to the diffusion coefficient, $D$, as the latter can be characterized with many nonelectrochemical techniques. ${ }^{[56]}$ The electrochemical potential of an ion, $\tilde{\mu}$, is

$\tilde{\mu}=\mu+q \varphi$

where $\varphi$ is the electrostatic potential and $\mu$ is the chemical potential. The latter follows

$\mu=\mu_{0}+k T \ln c$

with $\mu_{0}$ the standard chemical potential. A deviation of the electrochemical potential in the electrolyte exerts a force $F_{\mathrm{i}}$ on charges

$F_{\mathrm{i}}=-\nabla \tilde{\mu}=-\nabla(\mu+q \varphi)$

This force results in an ion flux, $j_{j}$, comprised of a diffusion flux $j_{\mathrm{d}}$ and an electrical drift $j_{\mathrm{e}}$. These two parts are, respectively, expressed as

$j_{\mathrm{d}}=-D \nabla c$

$j_{\mathrm{e}}=c u E$

where $E$ is the electrical field, which equals $-\nabla \varphi$. Equation (21) is from Fick's law. ${ }^{[33]}$ At equilibrium, the net ion flux is zero. This means

$j_{\mathrm{d}}+j_{\mathrm{e}}=-D \nabla c+c u E=0$

According to Boltzmann distribution, the concentration of a charge is

$c=c_{0} \exp \left(\frac{q \varphi}{k T}\right)$ 
where $c_{0}$ is a constant. Substitution of Equation (24) in to Equation (23) yields ${ }^{[52]}$

$u=D q / k T$

The conductivity of the solid electrolyte can accordingly be improved by increasing the $\mathrm{Li}^{+}$concentration, the defect concentration, and by lowering the activation energy for diffusion or migration. The activation energy for inorganic crystals can be lowered, for example, by widening the narrowest passage or bottle neck for $\mathrm{Li}^{+}$transport in the lattice by the introduction of large equivalent atoms by doping or even total replacement. For example, in the case of $\mathrm{Li}_{0.34} \mathrm{Nd}_{0.55} \mathrm{TiO}_{3}$, replacing the $\mathrm{Nd}^{3+}$ with $\mathrm{La}^{3+}$ resulted in a lowering of $E_{\mathrm{A}}$ from 0.5 to $0.4 \mathrm{eV}$ for the equivalent $\mathrm{Li}_{0.34} \mathrm{La}_{0.55} \mathrm{TiO}_{3}{ }^{[33]}$ Alternatively, the $\mathrm{Li}^{+}$and vacancy concentrations can be increased by aliovalent substitution where a higher valence element is substituted by a lower valence one and additional $\mathrm{Li}^{+}$to compensate the valence difference as, for example, in the case of $\mathrm{Li}_{3+x}\left(\mathrm{P}_{1-x} \mathrm{Si}_{x}\right) \mathrm{O}_{4}$ where $\mathrm{P}^{5+}$ is partially substituted by $\mathrm{Si}^{4+}$ and $\mathrm{Li}^{+} .[33,57,58]$

\subsection{Heterogeneous Doping in SCE}

Heterogeneous doping typically refers to the phenomena of increased ionic conductivity at the interfaces between an inert solid phase, such as silica or alumina oxide particles, and an electrolyte. ${ }^{[59]}$ Conductivity enhancement in two-phase composite systems has been known for almost 90 years ${ }^{[60]}$ however, the phenomena picked up little interest until a 100 times enhancement in $\mathrm{Li}^{+}$conductivity at room temperature was reported, simply by dispersing $\mathrm{Al}_{2} \mathrm{O}_{3}$ particles in LiI. ${ }^{[61]}$ Since then, an ionic conductivity enhancement of up to four orders of magnitude (but still $<1 \mathrm{mS} \mathrm{cm}{ }^{-1}$ ) has been reported for solid composite electrolyte systems with well-controlled nanoconfinement of the Li-salt. ${ }^{[62]}$ The concept of using interfaces to engineer ion conductivity has also been termed "nanoionics." [63]

The increased conductivity by heterogeneous doping is believed to be the result of a significant increase in the defect concentration (Li-ion vacancies) at the interface between the dopant (oxide) and the electrolyte. The ions in the electrolyte adsorb on the oxide surface to form an electrical double layer and as such leave their lattice positions, thus creating a layer rich in vacancies at the interface between the electrolyte and the dopant (Figure 1). Several Li-ion SCEs have been demonstrated since the first report of the $\mathrm{LiI} / \mathrm{Al}_{2} \mathrm{O}_{3}$ SCE which has been applied in commercial Li/LiI pacemaker batteries later. ${ }^{[64-66]}$ Li-ion solid composite electrolytes or SCE are made by mixing a simple solid lithium salt such as $\mathrm{LiI},{ }^{[67]} \mathrm{LiClO}_{4},{ }^{[68]} \mathrm{Li}_{3} \mathrm{PO}_{4},{ }^{[69]}$ $\mathrm{LiF},{ }^{[70]}$ and $\mathrm{Li}_{2} \mathrm{CO}_{3}{ }^{[71]}$ with a dielectric matrix material which is typically $\mathrm{Al}_{2} \mathrm{O}_{3}{ }^{[72]}$ or $\mathrm{SiO}_{2}{ }^{[73]}$ (see Table 2). The oxide matrix is usually supplied in the form of solid nanoparticles (Figure 1a) or mesoporous micron particles (Figure 1b). Even though impressive enhancements in conductivity up to 10000 -fold ${ }^{[74]}$ have been shown for these simple salt/oxide solid particle-particle composites with purely inorganic solid/solid interfaces, the room temperature Li-ion conductivities do not exceed $10^{-5} \mathrm{~S} \mathrm{~cm}^{-1}$, i.e., still several orders of magnitude too low for application in large capacity LIBs (the conductivities of liquid electrolytes are about $10 \mathrm{mS} \mathrm{cm}^{-1}$ ). The inorganic Li-salt/oxide systems form the first category of solid composite electrolytes which will be reviewed here in Section 2 for SCE with solid/ solid interface.

Composites with oxide nanoparticles are also known as solid polymer electrolytes. ${ }^{\left[{ }^{[0-84]}\right.} \mathrm{Li}$-ion conductivity enhancement was also found in SCEs where $\mathrm{Al}_{2} \mathrm{O}_{3}, \mathrm{TiO}_{2}$ and $\mathrm{SiO}_{2}$ nanoparticles were mixed with $\mathrm{LiClO}_{4}$-PEO polymer electrolyte (see Tables 5 and 6). Hence, heterogeneous doping or conduction promoting interface interactions are also prevalent for composites with solid electrolyte solutions as the $\mathrm{Li}^{+}$ions in the polymer electrolyte are effectively solvated by four ether moieties of the polyethylene oxide chain. In this case, the explanation of a vacancy enriched layer as for the inorganic solid/solid, i.e.; Li-salt/oxide SCE, is no longer valid. In this case the interface is solvent-like: the $\mathrm{Li}^{+}$ions are solvated at the interface, as in a liquid electrolyte. Even so, an electrical double layer will still form at the interface which is in this case governed by the more standard Helmholtz-layer and Stern-layer models for electrolyte solutions. In addition, chemical and dipole interactions can provide molecular ordering and/or adsorption on the oxide surface area. In this regard, there are several publications where the oxide particle surface has been intentionally functionalized with, for example, self-assembled monolayers or self-assembled monolayers (SAMs) to engineer the Li-ion conduction at the oxide interface. ${ }^{[85]}$ The interface conduction phenomena on the polymer-SCE will be covered in Section 3.

More recently, attempts have also been made to increase the Li-ion conductivity of ILE by the addition of oxide particles resulting in viscous to gel-type composites. ${ }^{[51,86,87]}$ However, in these cases, the ion conductivity hardly exceeded that of the bulk ILE. As for the solid composite polymer electrolytes, solvent-like interfaces are also formed here. In addition, evidence suggests that ionic liquid molecules do adsorb on oxides into ordered molecular structure. ${ }^{[88]}$

An interesting new approach for the fabrication of solid composite electrolytes with ionic liquid electrolytes is a sol-gel process where the oxide matrix is made by a hydrolysis-condensation reaction (e.g., porous silica from tetraethyl orthosilicate (TEOS) precursor) with an ionic liquid electrolyte added to the sol-gel solutions. The ionic liquid electrolyte is entrapped inside the nanoporous structure of the oxide matrix after curing and the product can be a powder or solid monolith. This material has also been nicknamed "ionogel."[89,90] The main advantage of these sol-gel derived ionic liquid electrolyte based solid composite electrolytes (ILE-SCEs) is that they can form an interconnected oxide matrix under the right synthesis conditions. These interconnected oxide surfaces have the potential for harvesting the most out of the interface conduction enhancement. Indeed, whereas for interconnected silica pores, the ions can move along the surface from one end of the monolith all the way to the other end of the monolith, the particle composites have to rely on percolation through an ILE layer, in between the particles, as schematically shown in Figure 1a. In addition, the nanoconfined ILE is expected to have different properties than bulk ILE and the interface interactions can be maximized by decreasing the pore size. The concept of ILE-SCE is relatively new and has not been reviewed yet. In Section 4, the preparation, the interface structure, and conduction models 


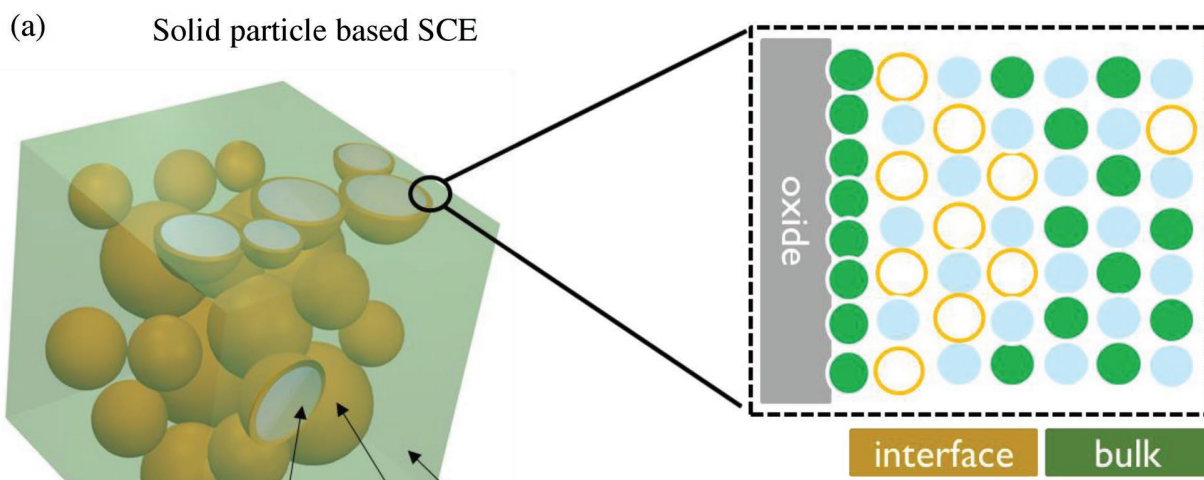

(b)
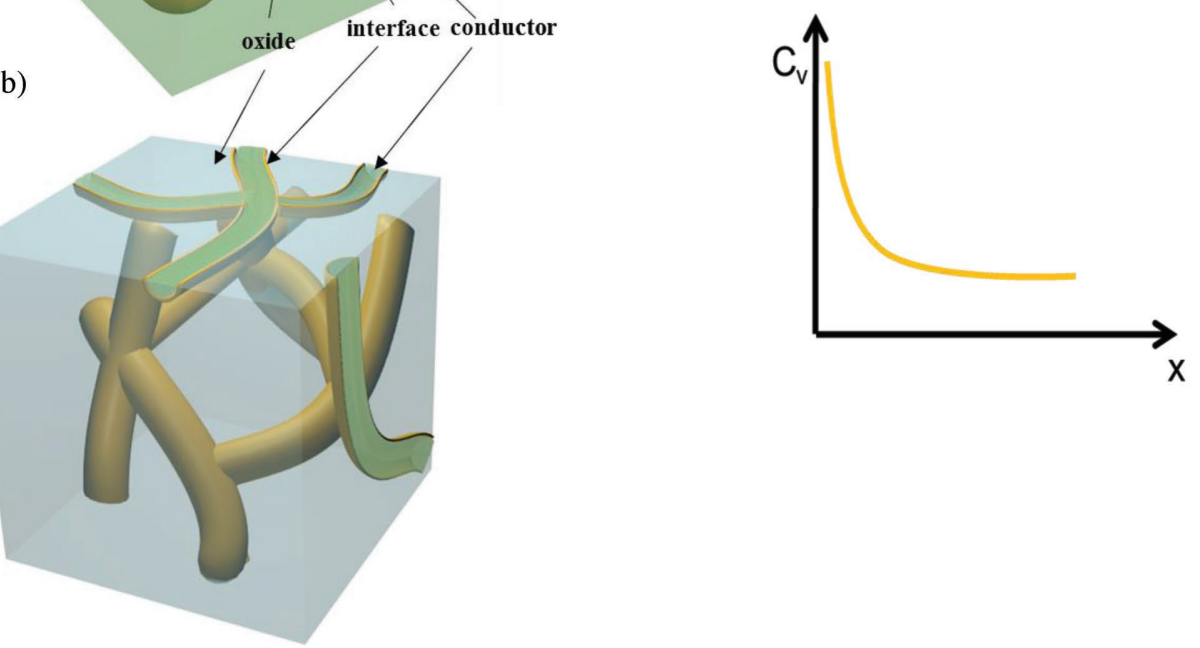

SCE with porous matrix

Figure 1. Schematic of SCEs with solid particles with point-to-point contacts as matrix dispersed in a conductor a), and SCEs with porous oxides as matrix where the interconnected pores are filled with the conductor b); the gray, yellow, and green parts represent the oxide, interface, and conductor, respectively; top right is a schematic of the space charge layer at the interface of the SCE. Ions (green and blue dots) can absorb on the surface of the matrix thus creating defects (yellow circles); bottom right is a diagram of the increased defect concentration $\left(C_{v}\right)$ at the interface.

of the ILE-SCE will be covered with a focus on the effect of the interface structure on the conduction. The role of the key factors, such as the surface chemistry of the matrix, the salt, and the functional group in the interface interaction will be

Table 2. Some SCEs developed for lithium ion batteries. ${ }^{[71]}$

\begin{tabular}{|c|c|c|c|c|}
\hline SCE & $\begin{array}{l}\text { Ionic conductivity } \\
\qquad\left[\mathrm{S} \mathrm{cm}^{-1}\right]\end{array}$ & $\begin{array}{c}\text { Measurement } \\
\text { temperature }\left[{ }^{\circ} \mathrm{C}\right]\end{array}$ & $\begin{array}{l}\text { Conductivity } \\
\text { enhancement }\end{array}$ & Ref. \\
\hline $\mathrm{Lil} / / \mathrm{Al}_{2} \mathrm{O}_{3}$ & $1.2 \times 10^{-5}$ & 25 & 50 & [61] \\
\hline $\mathrm{Lil} / \mathrm{SiO}_{2}$ & $2 \times 10^{-4}$ & 220 & 10 & [67] \\
\hline $\mathrm{Lil} / \mathrm{Li}_{3} \mathrm{~N}$ & $3.5 \times 10^{-7}$ & 25 & - & [75] \\
\hline $\mathrm{LiClO}_{4} / \mathrm{Al}_{2} \mathrm{O}_{3}$ & $2.5 \times 10^{-2}$ & 200 & 1000 & [76] \\
\hline $\mathrm{LiClO}_{4} / \mathrm{Al}_{2} \mathrm{O}_{3}$ & $2.5 \times 10^{-6}$ & 100 & 200 & [77] \\
\hline $\mathrm{LiClO}_{4} / \mathrm{SiO}_{2}$ & $\approx 10^{-5}$ & 40 & 10000 & [74] \\
\hline $\mathrm{Li}_{3} \mathrm{PO}_{4} / \mathrm{Al}_{2} \mathrm{O}_{3}$ & $1.5 \times 10^{-6}$ & 393 & 10 & [78] \\
\hline $\mathrm{Li}_{2} \mathrm{SO}_{4} / / \mathrm{Al}_{2} \mathrm{O}_{3}$ & $4.3 \times 10^{-5}$ & 253 & 1000 & [79] \\
\hline $\mathrm{LiF} / \mathrm{Al}_{2} \mathrm{O}_{3}$ & $3.6 \times 10^{-8}$ & 300 & - & [70] \\
\hline $\mathrm{Li}_{2} \mathrm{CO}_{3} / \mathrm{Al}_{2} \mathrm{O}_{3}$ & $5.6 \times 10^{-8}$ & 150 & 80 & [71] \\
\hline
\end{tabular}

summarized to guide the design of ILE-SCEs with solvent-like interface.

\section{SCEs with Solid-Solid Interface}

\subsection{The Space Charge Layer Theory}

The "space-charge layer" theory is generally accepted to explain the interface conduction in the solid-solid composite electrolyte. ${ }^{[63,91-93]}$ Figure 1 shows a schematic of the space charge layer formed at the SCE solid/solid interface. In general, for oxides with higher work functions (or lower Fermi energy) than the MX salt compound, the $\mathrm{M}^{+}$cations will move from the ionic conductor toward the oxide surface. The resulting electrical double layer then compensates the work function difference so that the Fermi levels are aligned at equilibrium. In doing so, the cations leave behind vacancies and anions with uncompensated charge distributed over a layer near the interface. This process can be described by the following defect equilibrium reaction ${ }^{[94]}$

$M_{\mathrm{M}}+V_{\mathrm{s}} \leftrightarrow M_{\mathrm{s}}^{\cdot}+V_{\mathrm{M}}^{\prime}$ 
where $M_{M}$ is a metal ion at regular lattice site, $V_{\mathrm{S}}$ is an unoccupied interface site, $M_{\mathrm{s}}^{*}$ is the metal ion at the interface site, and $V^{\prime}{ }_{M}$ is the metal ion vacancy left behind by the metal ion $M_{\mathrm{M}}$. The ease for this solid-state exchange reaction to happen depends on the standard free energy of the reaction, $\Delta G^{\circ}$, and the concentration of each species ( $\Delta G=0$ at equilibrium). To include the effect of the electrostatic potential as a result of uncompensated charges, one has to consider the electrochemical potential. At equilibrium, the distribution of vacancies satisfies the condition that the deviation of the electrochemical potential, $\mu_{i}(x)$, of charged species is zero

$$
\nabla \tilde{\mu}_{i}(x)=\nabla\left(\mu_{i}(x)+q_{i} \varphi(x)\right)=0
$$

where $\mu_{i}(x)$ is the chemical potential of the charged species which is a function of their effective concentration at a distance, $x$, away from the interface boundary of the two phases; $q_{i}$ is the charge of the species; $\varphi(x)$ is the electrostatic potential at a distance $x$ and it is related to the concentration of charged species through the Poisson equation. The vacancy, or more general, the defect concentration enhancement $\zeta_{i}$ after the equilibrium, defined as the ratio of the defect concentration at the interface and in the bulk, $c_{\infty}$, can be expressed as ${ }^{[95]}$

$\zeta_{i}\left(\frac{x}{\lambda}\right)=\left[1+\exp \left(-\frac{x}{\lambda}\right) \theta_{i}\right]^{2} /\left[1-\exp \left(-\frac{x}{\lambda}\right) \theta_{i}\right]^{2}$

where $\lambda$ is the so-called Debye length which characterizes the dimension of the space charge layer, and is defined as

$\lambda=\left(\frac{\varepsilon \varepsilon_{0} R T}{2 F^{2} c_{\infty}}\right)^{1 / 2}$

where $F, R$, and $\varepsilon \varepsilon_{0}$ are, respectively, Faradaic constant, gas constant, and the dielectric permittivity of the ionic conductor. The contribution of surface properties on the interface enhancement is captured by $\theta_{i}$ defined as ${ }^{[96]}$

$\theta_{i}=\left[\zeta_{i, x=0}^{0.25}-\zeta_{i, x=0}^{-0.25}\right] /\left[\zeta_{i, x=0}^{0.25}+\zeta_{i, x=0}^{-0.25}\right]$

The surface acidity or basicity is a good example of a surface property that strongly affects the interface layer and thus the interface conduction. For example, Maier ${ }^{[96]}$ showed that by changing the surface of the alumina from $-\mathrm{OH}$ to $-\mathrm{OLi}$ terminated, the conductivity enhancement of the $\mathrm{LiI} / \mathrm{Al}_{2} \mathrm{O}_{3}$ composite increased from 30 times to 200 times. It was also reported that the surface conductivity of a $\mathrm{AgCl}$ film changed with the measurement ambient. When measured in $\mathrm{NH}_{3}$, a Lewis base that can interact with $\mathrm{Ag}^{+}$, the conductivity of the $\mathrm{AgCl}$ film was higher than when obtained in $\mathrm{N}_{2}$, a rather inert gas considered to attract no $\mathrm{Ag}^{+} \cdot{ }^{[97]}$ Uvarov and co-workers ${ }^{[76,77]}$ showed that the activation energies of Li-ion diffusion for composites of $\mathrm{LiClO}_{4}$ with $\gamma-\mathrm{Al}_{2} \mathrm{O}_{3}$ and $\gamma-\mathrm{LiAlO}_{2}$ were lower than those for the composites with $\alpha-\mathrm{Al}_{2} \mathrm{O}_{3}$ and $\alpha-\mathrm{LiAlO}_{2}$. This difference was attributed to the difference in the arrangement of the surface atoms of the matrix (although the work function may also be different). However, it is noted that it is not easy to extract the surface effect only, as the particles in the composite itself likely have changed as well, e.g., particle size distribution, particle morphology, particle-to-particle distance, and average contact area. The reader is referred to the following review paper $^{[71]}$ for more specifics on the particle-to-particle interaction in these all-solid particle composite electrolytes.

Calculation of overall conductivity enhancement at the oxide/ ionic conductor interface is hence not straight forward. Even so, the theoretical treatment above indicates that the conductivity enhancement will be largest when the free energy of the interface interaction is most negative (Equation (26)). Hence, it seems the introduction of negative surface charge is expected to enhance the cation ion conduction, either as the result of an intrinsic material property (work function and surface termination) or introduced by surface functionalization. Furthermore, the interface layer $(\lambda)$ will be wider (more lanes on the highway of vacancies) when the dielectric constant is smaller (Equation (29)). Because the interfaces in the particle-particle SCE are interwoven into a complicated, torturous network with matrix particles and bulk-phase lithium compounds embedded inside, the calculation of the interface conduction is difficult.

A layered thin-film SCE can be used as a model system to study the interface conduction. Figure 2a illustrates a schematic of such a layered thin-film SCE. This model planar SCE consists of an ionic conductor layer deposited over the planar matrix substrate, usually an oxide which is measured with foreseen of interdigitated or comb electrodes. The conductance $Y$, typically measured between two opposing electrodes, is the sum of the conduction along the interface layer and the conductor layer. Plotting $Y$ as a function of the thickness of the conductor layer $L$, as shown in Figure 2b, reveals whether there is interface conductivity enhancement and how strong the enhancement is. ${ }^{[95]}$ In the absence of interface conduction, the conductance varies proportionally with conductor layer thickness (in case of no grain boundary contribution). In case of interface contribution, the conductivity curves will rise above this line. In addition, the width of the space charge layer, $\lambda$ can be determined using this conductance versus thickness plot.

The layered thin-film SCE method has been used also to support the space charge layer theory. ${ }^{[98,99]}$ However, extraction of quantitative parameters such as the thickness of space-charge layer or Debye length, $\lambda$, turned out not to be straightforward. One of the first attempts was done by Schreck et al. ${ }^{[100]}$ who measured the interface conduction of 5-300 $\mathrm{nm}$ thin LiI films thermally evaporated on a sapphire substrate. The conductance versus thickness plot of the SCEs, as shown in Figure 3a, indeed showed the profile expected for strong contribution of interface conduction. From their proposed model, they calculated an interface width or Debye length as $\lambda=30 \mathrm{~nm}$ for a 7-fold conductivity enhancement at the interface. A few years later, using the same data set, Maier ${ }^{[94]}$ derived a 20-fold conductivity enhancement for $\lambda=62 \mathrm{~nm}$ using their model. Figure $3 \mathrm{~b}$ shows an example using a modified approach whereby multilayer stacks are used to increase the number of interfaces while the thickness of the lamella is decreased. They ${ }^{[101]}$ found that the conductivity of 2-500 $\mathrm{nm}$ thin $\mathrm{BaF}_{2} / \mathrm{CaF}_{2}$ layers, fabricated by molecular beam epitaxy (MBE), increased by two orders of magnitude as the individual layer thinned (Figure $3 b$ ) due to the contribution of interface conduction. The Debye length $\lambda$ was calculated to be $10 \mathrm{~nm}$, which agreed well with the experimental 
(a)

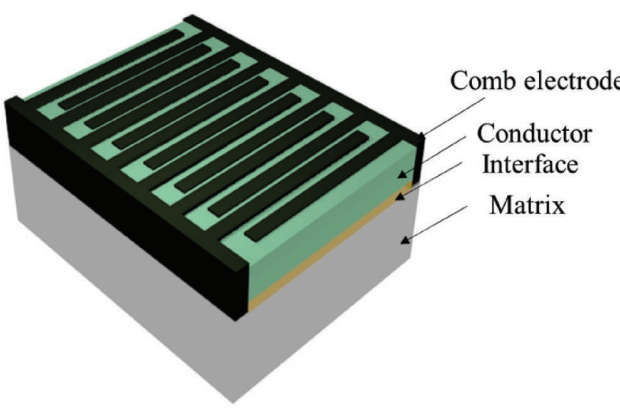

(b)

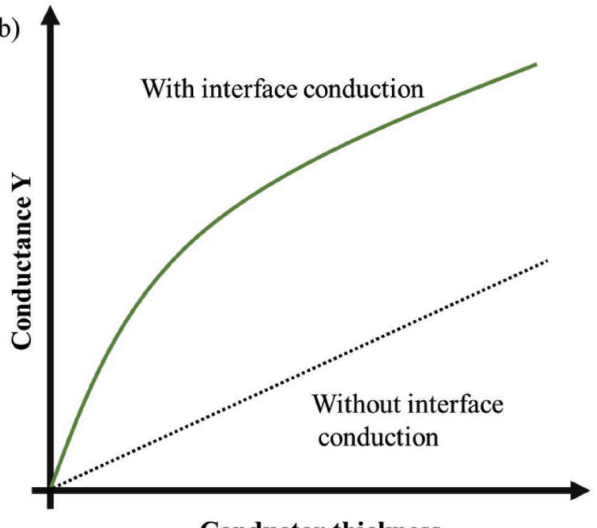

Figure 2. a) Schematic of a layered thin-film SCE for the characterization of interface conduction. The green, yellow and gray parts stand for the ionic conductor, the interface and the oxide matrix, respectively. Black blocks represent comb/interdigitated electrodes for the conductivity measurement; b) projected conductance $(Y$ versus conductor thickness (vertical to the conductor/matrix interface) plot of the layered thin-film SCE with (green line) and without (black dotted line) interface conduction; b) Adapted with permission. ${ }^{[94]}$ Copyright 1985, Elsevier.

observation that the conductivity of the layer increased sharply as the layer thickness approached $4 \lambda$.

In contrast, some studies using layered thin-film SCEs have challenged the space charge theory. ${ }^{[102-105]}$ For example, Mühlherr et al. ${ }^{[104]}$ attributed a 1000-fold conductivity enhancement for a $\mathrm{AgCl} / \mathrm{Al}_{2} \mathrm{O}_{3}$ layered thin-film SCE to grain boundaries and dislocations, rather than to the space charge layer. They based their arguments on the fact that the Debye length determined using the space charge theory $(180 \mathrm{~nm})$ was about ten times larger than the initial rising part in the conductance versus conductor layer thickness plot. Likewise, Modine et al. ${ }^{[03]}$ observed that the conductivity enhancements of the $\mathrm{LiI} / \mathrm{Al}_{2} \mathrm{O}_{3}$ layers thermally deposited at 27 and $100{ }^{\circ} \mathrm{C}$ were, respectively, 40 times and none. Furthermore, this 40-time enhancement was found to decay over time, indicating grain growth or defect annihilation. The author thus assumed that dislocations, which were generally thermally unstable at the interface, caused the conductivity enhancement.

In general, only a few reports on layered thin-film SCEs have been published, possibly because of the need for smooth ultra-thin films with uniform thickness and of micropatterning capabilities. Indeed, the thickness of the interface layer, characterized by the Debye length, can be less than $10 \mathrm{~nm}$ in some cases. To perform a good measurement, one has to be able to scale the film thickness at least down to the Debye length. The most used deposition techniques in literature were thermal evaporation techniques which are not well-suited for deposition of continuous and smooth films of sufficient thinness. For
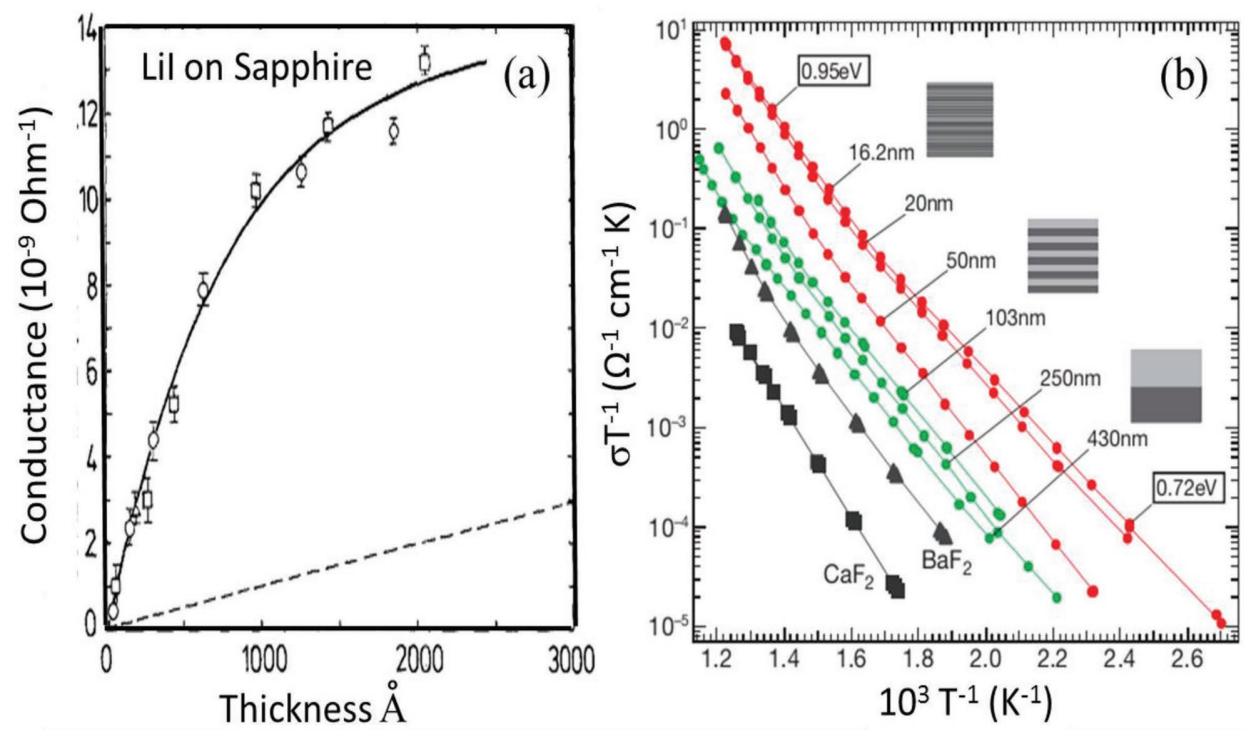

Figure 3. a) Reported conductance of the Lil/sapphire layered thin-film SCE versus Lil thickness (dots). The dashed line represents the projected conductance of the Lil without interface conduction. Reprinted with permission. ${ }^{100]}$ Copyright 1986, Springer. b) Reported conductivity of the BaF $2 /$ $\mathrm{CaF}_{2}$ layered thin-film SCEs of different thicknesses. The conductivity of the SCEs increases as the thickness of the individual layer decreases. Inserts are schematics of the SCEs. Reprinted with permission. ${ }^{[101]}$ Copyright 2000, Nature Publishing Group. 
example, the $15 \mathrm{~nm}$ "films" deposited by MBE in ref. ${ }^{[101]}$ were in fact reported to be islands instead of continuous films. This discontinuity of the films obviously affects the conductivity, thus making the determination of the interface conduction inaccurate. Also, Furusawa et al. ${ }^{[106]}$ concluded that the conductivities of thermally deposited lithium alumino-silicate on $\mathrm{SiO}_{2}$ and $\mathrm{Al}_{2} \mathrm{O}_{3}$ substrates were not suited to derive the interface condition because the films were too thick. To overcome this difficulty, deposition techniques such as atomic layer deposition (ALD) that can control the film thickness at the atomic level and cover the surface profile of the interdigitated electrodes with excellent conformity could be employed. Another issue can be the very large resistances associated with these thin films. As the conductivities of the investigated films are typically below $10^{-6} \mathrm{~S} \mathrm{~cm}^{-1}$, in some cases even below $10^{-9} \mathrm{~S} \mathrm{~cm}^{-1}$, the resistance of a $10 \mathrm{~nm}$ film can easily exceed $10^{9}-10^{12} \Omega$ for interdigitated electrodes where the total length of the comb electrode is 1000 times that of the distance between the electrodes. Measurement of such high resistance can have an error of more than $35 \% .{ }^{[103]}$ Hence, for accurate determination of resistance, the availability of good micropatterning capabilities is required to maximize the length of the comb electrodes and minimize the distance between the electrodes.

\subsection{Conductivity Models for the Particle-Based SCEs}

In particle-based SCEs, the interface layer and bulk conductor form a conduction network where ions percolate from particle to particle through the composite (Figure 1a). As such, the overall conductivity of the composite depends on the distribution of the conductor and matrix particles. Indeed, the conductivity was observed to vary with the volume fraction of the matrix as shown in Figure $4 \mathrm{a}$ (for $\mathrm{LiI} / \mathrm{Al}_{2} \mathrm{O}_{3} \mathrm{SCEs}$ ). The ion conductivity increases with increasing content of oxide matrix until a maximum is reached which corresponds to the optimum distribution of percolation paths. Beyond this point, existing paths are blocked by the additional volume of the matrix. In general, the conductivity of the SCE can be described as follows (assuming the matrix is ionically and electronically insulating $)^{[94]}$

$\sigma=\beta_{\infty}\left(1-x_{\mathrm{V}}\right) \sigma_{\mathrm{b}}+\beta_{\text {in }} x_{\mathrm{V}, \text { in }} \sigma_{\text {in }}$

where $x_{\mathrm{V}}$ and $x_{\mathrm{V} \text {,in }}$ are the volume fractions of the matrix and interface, respectively; $\beta_{\infty}$ and $\beta_{\text {in }}$ are parameters representing the influence of the distribution and morphology of the particles and interface; and $\sigma_{\mathrm{b}}$ and $\sigma_{\mathrm{in}}$ are the bulk and interface conductivity, respectively. Several models have been proposed which differ in their derivation of the parameters in Equation (31). Each of these models manages to fit experimental data of some specific electrolyte/oxide systems, but so far, no generally applicable model for the conductivity of the SCE exists. From the fits, parameters such as the width of the space charge region, the critical volume fraction where enhanced conductivity is likely to be maximal, or where the conductivity is expected to steeply decline have been extracted.

\subsubsection{Resistor Network Model}

In this model, the matrix and conductor are assumed to be cubic particles in contact with each other and the SCE is represented by an electrical circuit with resistors connected in parallel and in series. ${ }^{[107,108]}$ The conductivity of the SCE is given by

$\sigma=\left\{\begin{array}{c}\sigma_{\mathrm{b}}+\sigma_{\text {in }}\left[\frac{x-a / 2}{t}\right]^{m} ; a / 2<x<a / 2+t \\ \sigma_{\mathrm{b}}+\sigma_{\text {in }} \mathrm{e}^{-\frac{(x-a / 2-t)}{s}} ; x>a / 2+t\end{array}\right.$

with $\sigma_{\mathrm{b}}$ the conductivity of the bulk conductor, $\sigma_{\text {in }}$ the interface conductivity, $x$ the distance from the center of the cubic
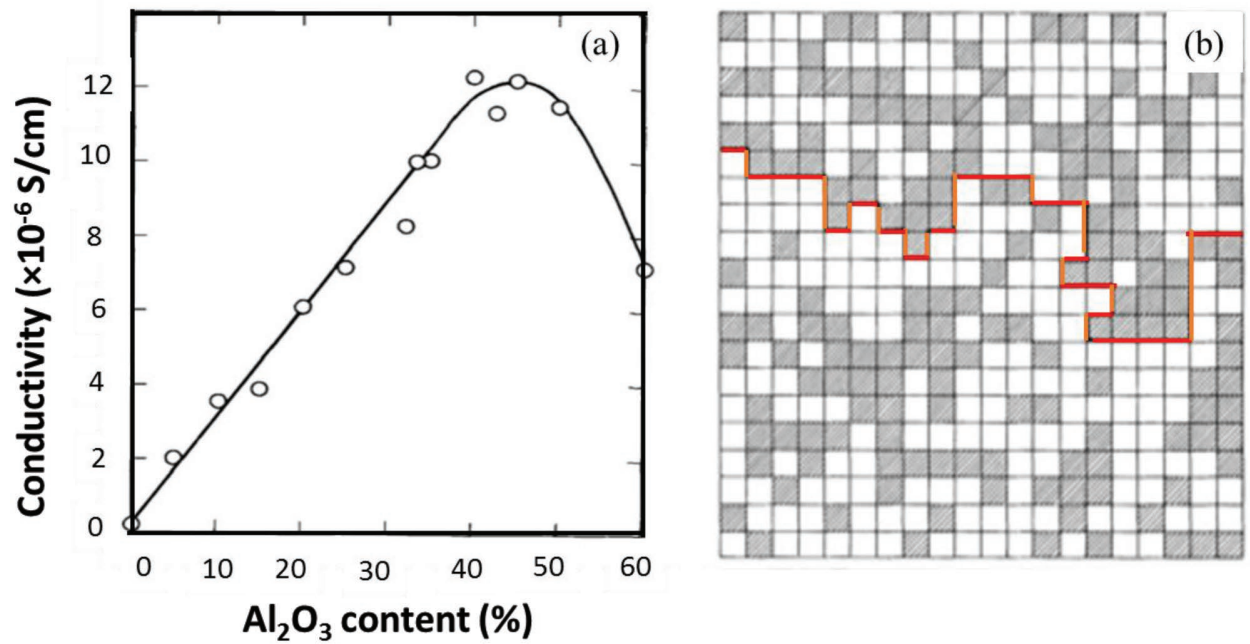

Figure 4. a) conductivity versus $\mathrm{Al}_{2} \mathrm{O}_{3}$ volume content of the $\mathrm{Lil} / \mathrm{Al}_{2} \mathrm{O}_{3} \mathrm{SCE}$. Reprinted with permission. ${ }^{[6]]}$ Copyright 1973, The Electrochemical Society. b) A schematic of the percolation model for the SCE, with the filled and unfilled sites corresponding to the matrix and lithium conductor, respectively. The red lines represent the percolation of the interface. Reprinted with permission. ${ }^{[10]}$ Copyright 1985, American Physical Society. 
particles, $a$ the size of the cubic particle, $t$ the thickness of interface layer, and $s$ and $m$ fitting parameters.

This model manages to describe the effect of particle size on the conductivity. Using this model, a good fit for the experimental data of the $\mathrm{LiI}-\mathrm{Al}_{2} \mathrm{O}_{3}$ system was achieved without making a priori predictions for the parameters. However, this model neglects the random distribution of oxide particles, and is therefore mostly suited for systems in which the matrix particles have an ordered structure.

\subsubsection{Percolation Model}

In the percolation model, the matrix and conductor particles are simulated as two-dimensional squares randomly filling in the positions of the planar lattice ${ }^{[109-111]}$ (Figure 4b). The interfaces between two squares are represented by a resistor: the matrix-matrix interface has zero conductance and, the conductor-conductor and matrix-conductor interfaces have bulk and interface conductance, respectively. ${ }^{[112-114]}$

The percolation theory can predict the dependence of the conductivity on the volume fraction of the matrix phase. It could express low conductivity at the two ends of the volume fraction and a maximum of the conductivity near the middle of the volume fraction (Figure 4a). Jiang and Wagner ${ }^{[115]}$ further improved the percolation model by adding a specific thickness for the space charge region. Moreover, by allowing the particles of both phases to agglomerate to create a nonideal random distribution, its accuracy was improved. Qualitatively, it explains the conductivity dependence on particle size, the shift of optimum oxide concentration for nonideal random distributions and the influence of the increase in defect density on the conductivity. The model fits the experimental data of the LiI- $\mathrm{Al}_{2} \mathrm{O}_{3} \mathrm{SCE}$ quite well over the entire volumetric range, and the conductivity of the $\mathrm{CuCl}-\mathrm{Al}_{2} \mathrm{O}_{3} \mathrm{SCE}$ with $\mathrm{Al}_{2} \mathrm{O}_{3}$ for less than 20 vol\%.[115]

\subsubsection{Effective Medium Model}

The effective medium model assumes that the matrix particles are uniformly distributed in the conductor phase, and describes the effect of the volume reduction of the conductor on the SCE conductivity. ${ }^{[116-119]}$ The first effective medium model applied to solid composite electrolytes was adapted from a model developed for binary metallic mixtures by Landauer ${ }^{[120]}$ As such, the model did not yet include the enhancement of the interface layer. Further improvement to the effective medium model for SCE was done by Nan and Smith ${ }^{[118]}$ for a three-phase system including the highly conductive interface layer. The model successfully predicted the variation of the conductivity enhancement with the volume fraction of the matrix; giving the onset of percolation, the concentration corresponding to the maximum conductivity and second percolation threshold where the isolation particles dominate the conductivity. In addition, it qualitatively describes the effect of the proportion of interface, and the oxide particle size on the conductivity. It can fit the conductivities of $\mathrm{Li}_{2} \mathrm{SO}_{4} / \mathrm{Al}_{2} \mathrm{O}_{3}$ and $\mathrm{LiCl}-\mathrm{Al}_{2} \mathrm{O}_{3}$ SCEs. ${ }^{70]}$

\subsection{Effect of Porous Matrix Structure on Conductivity of Particle-Based SCE}

The above models indicate that the matrix particle size plays an important role in the conductivity enhancement. Decreasing the particle size increases the specific surface area and thus the proportion of interface in the SCE. Hence, the SCE conductivity is expected to increase as the particle size deceases, which is indeed observed experimentally. For example, it was reported that the maximum conductivity of the $\mathrm{LiI} / \mathrm{Al}_{2} \mathrm{O}_{3} \mathrm{SCE}$ increased by 8 times as the surface area of the $\mathrm{A}_{2} \mathrm{O}_{3}$ enlarged from 20 to $140 \mathrm{~m}^{2} \mathrm{~g}^{-1}$. ${ }^{[96]}$ Similarly, with the size of $\mathrm{Al}_{2} \mathrm{O}_{3}$ particles ranging from 0.06 to $8 \mu \mathrm{m}, \mathrm{CuCl} / \mathrm{Al}_{2} \mathrm{O}_{3}$ SCEs showed the highest conductivity for the smallest $\mathrm{Al}_{2} \mathrm{O}_{3}$ particles, i.e., an increase from $\approx 10^{-7} \mathrm{~S} \mathrm{~cm}^{-1}$ for $60 \mathrm{~nm}$ particles, to $\approx 10^{-6} \mathrm{~S} \mathrm{~cm}^{-1}$ for $8 \mu \mathrm{m}$ particles. ${ }^{[121]}$ Very fine particles (e.g., $<10 \mathrm{~nm}$ ) may, however, cause a drop in conductivity of the SCE due to agglomeration. Indeed, these fine nanoparticles easily form agglomerates when dry, which can no longer be efficiently dispersed in liquids, ${ }^{[122-126]}$ and this agglomeration tends to decrease the surface area of particles. ${ }^{[127]}$ For example, the surface area of $14 \mathrm{~nm} \mathrm{TiO}{ }_{2}$ particles reduces from 100 to $30 \mathrm{~m}^{2} \mathrm{~g}^{-1}$ as a result of agglomeration to powder. ${ }^{[128]}$ Agglomeration can also affect the distribution of the lithium salt and matrix particles in the SCE. If the two phases do not contact each other, no interface is formed. Therefore, the inefficient mixing can affect the interface and in turn decrease the overall conductivity of the SCE.

The above nanoparticle agglomeration issue can be resolved by using a nanoporous matrix instead. A nanoporous matrix can have interconnected pores with a diameter less than $10 \mathrm{~nm}$ resulting in a large effective or internal surface area. The nanoporous matrix can come in the form of particles with a few to tens of micrometer in size, thus mitigating the agglomeration. Moreover, if the nanoporous matrix is in the form of a monolith, ${ }^{[129,130]}$ such as nanoporous silica made by sol-gel processes, the interconnected pores can even extend through the whole monolith which can be of centimeter size. Such an interconnected pore structure provides the possibility for large continuous interfaces with undisrupted conduction paths in the SCE.

Many types of nanoporous materials have been developed, e.g., mesoporous (pore diameter $2-50 \mathrm{~nm}$ ) silica ${ }^{[131-133]}$ and alumina, ${ }^{[134]}$ microporous (pore diameter less than $2 \mathrm{~nm}$ ) alumina-silicate zeolites, ${ }^{[135,136]}$ and metal organic frameworks (MOFs). ${ }^{[137-139]}$ One of the most widely used nanoporous materials is mesoporous silica. It is typically prepared using so-called templated sol-gel methods. ${ }^{[140]}$ In a classic solgel method for silica, an alkyl silicate, e.g., TEOS, and $\mathrm{H}_{2} \mathrm{O}$ undergo a hydrolysis and condensation reaction forming silica in the presence of a catalyst such as acid (e.g., $\mathrm{HCl}^{[141]}$ ), base (e.g., $\mathrm{NaOH}^{[142]}$ ), or salt (e.g., $\mathrm{NaF}^{[143,144]}$ ). In the templated sol-gel method, a surfactant which is an amphiphilic compound, such as $\mathrm{C}_{n} \mathrm{H}_{2 n+1} \mathrm{~N}\left(\mathrm{CH}_{3}\right)_{3} \mathrm{Br}(\mathrm{CTAB}),{ }^{[145]}$ and a nonionic poly(alkylene oxide) block copolymer, ${ }^{[146,147]}$ is added into the solution to form circular-shaped micelles, and the silica grows around these micelle templates through a cooperative selfassembly. ${ }^{[131,148-150]}$ After removing the surfactant from the silica/surfactant composite, for example by heat treatment, ${ }^{[151]}$ liquid extraction, ${ }^{[141]}$ or by ultraviolent treatment, ${ }^{[152]}$ silica with 
Table 3. Typical porous silica materials prepared using templated solgel processes. MSU-J: Michigan State University material number J; SBA-1: Santa Barbara number 1.

\begin{tabular}{lcccc}
\hline Name & Surface area $\left[\mathrm{m}^{2} \mathrm{~g}^{-1}\right]$ & Pore shape & Pore size $[\mathrm{nm}]$ & Ref. \\
\hline MCM-41 & $\approx 1000$ & Cylinder & $1.6-10$ & {$[151]$} \\
SBA-15 & $630-1040$ & Cylinder & $5-30$ & {$[146]$} \\
MSU-J & $408-1127$ & Wormhole-like & $4.9-14.3$ & {$[158]$} \\
HMS & $1000-1150$ & Cylinder & $1.6-3.1$ & {$[159]$} \\
KIT-1 & Up to 1000 & Cylinder & $2.5-25$ & {$[160]$} \\
SBA-1 & $998-1187$ & Spherical & $1.4-2.7$ & {$[161]$} \\
\hline
\end{tabular}

pores of the same shape and similar size as the micelles form. Some commonly used mesoporous silica are listed in Table 3. The silica can have an internal surface area up to $1000 \mathrm{~m}^{2} \mathrm{~g}^{-1}$, much higher than that of the nanoparticles $\left(\approx 100 \mathrm{~m}^{2} \mathrm{~g}^{-1}\right)$. In addition, the surface can be readily modified with functional groups by introducing molecules containing these groups in the sol-gel solution, ${ }^{[153,154]}$ or by exposing the synthesized silica to a vapor or liquid phase with the functional-group-containing molecule. ${ }^{[155-157]}$ The rich surface chemistry could enable the design of the interface interaction thus tuning the conductivity of the SCE.

MOFs are another class of nanoporous materials of potential interest for SCE. MOFs are macromolecular compounds which consist of metal ions or clusters coordinated to organic ligands to form a porous scaffold with pore or cage sizes typically less than $2 \mathrm{~nm}$. MOFs can have a porosity up to $90 \%$ and a surface area up to $6000 \mathrm{~m}^{2} \mathrm{~g}^{-1} \cdot{ }^{[162]}$ Also, the functional chemistry in the pores or cages can be modified by, for example, postsynthesis modification. ${ }^{[139]}$

Porous materials have been used in SCEs soon after the concept of SCE was first introduced in 1973. ${ }^{[61]}$ For example, LiI/zeolite (pore size $<2 \mathrm{~nm}$ ) SCEs with a 10-time conductivity enhancement were reported by Khandkar et al. in 1986.[163] The conductivities of SCEs with a nanoporous matrix generally exceed those of the SCEs with solid (in the meaning of nonporous) particle matrixes. For example, LiI/mesoporous $\mathrm{Al}_{2} \mathrm{O}_{3}$ SCE (pore size of $\mathrm{Al}_{2} \mathrm{O}_{3}$ is $4 \mathrm{~nm}$,) by Maekawa et al. ${ }^{[164]}$ had a conductivity of 10 times that of the LiI/solid $\mathrm{Al}_{2} \mathrm{O}_{3}$ by Liang. ${ }^{[61]}$ Also, an astonishing 10 000-time conductivity enhancement of $\mathrm{LiClO}_{4} /$ mesoporous $\mathrm{SiO}_{2} \mathrm{SCE}$ was reported by Ulihin and co-workers, ${ }^{[74]}$ which has never been obtained by any SCE with solid particles. Some SCEs with porous microparticles as matrix are listed in Table 4.

\section{Polymer-SCEs}

Polymers such as $\mathrm{PEO},{ }^{[82]}$ polyacrylonitrile (PAN) ${ }^{[170]}$ polyimide ${ }^{[171]}$ and polymethylmethacrylate (PMMA) ${ }^{[172]}$ with coordinating groups, such as $-\mathrm{O}-$ and $=\mathrm{O}$, can solvate lithium salts with large anions favorable for the solvation such as $\mathrm{ClO}_{4}^{-},{ }^{-[7]}$ $\mathrm{BF}_{4}^{-},{ }^{[48]}$ and $\mathrm{N}\left(\mathrm{SO}_{2} \mathrm{CF}_{3}\right)_{2}{ }^{-}$(or TFSI anion) $)^{[173]}$ up to several mol $1^{-1} .{ }^{174,175]}$ This polymer $/ \mathrm{Li}^{+}$salt mixture is known as a polymer electrolyte. In the electrolyte, $\mathrm{Li}^{+}$cations are coordinated with the polar functional groups in the polymer chain, e.g., ethoxy group for PEO, while anions are generally considered as not
Table 4. Some typical SCEs with porous materials as matrix. Data was not available in the reference.

\begin{tabular}{lcccc}
\hline SCE & $\begin{array}{c}\text { Pore size of } \\
\text { the matrix }[\mathrm{nm}]\end{array}$ & $\begin{array}{c}\text { Specific surface area } \\
\text { of the matrix }\left[\mathrm{m}^{2} \mathrm{~g}^{-1}\right]\end{array}$ & $\begin{array}{c}\text { Conductivity } \\
\text { enhancement }\end{array}$ & Ref. \\
\hline $\mathrm{LiClO}_{4} / \mathrm{MCM}-41$ & $3-4$ & 970 & 10000 & {$[74]$} \\
$\mathrm{RbNO}_{3} / \mathrm{SBA}-15$ & 14 & 760 & 20 & {$[165]$} \\
$\mathrm{Agl}, \mathrm{AgBr} / \mathrm{Al}_{2} \mathrm{O}_{3}$ & 6.8 & 276 & 1000 & {$[62]$} \\
$\mathrm{Agl} / \mathrm{SiO}_{2}$ & 4 & - & 2 & {$[166]$} \\
$\mathrm{Lil}_{\mathrm{AAl}} \mathrm{O}_{3}$ & 4 & 315 & 260 & {$[164]$} \\
$\mathrm{Lil} / \mathrm{Vycor}$ glass & 4 & 250 & 70 & {$[167]$} \\
$\mathrm{Lil} / \mathrm{Al}_{2} \mathrm{O}_{3}$ & 2.7 & 1242 & 12 & {$[168]$} \\
$\mathrm{Agl} / \mathrm{SBA}-15$ & 5 & - & 20 & {$[169]$} \\
$\mathrm{Lil} / \mathrm{Zeolite}$ & - & - & 10 & {$[163]$} \\
\hline
\end{tabular}

solvated ${ }^{[176]}$ However, when the lithium ion concentration is high, the ions can form ion pairs or clusters where the cation associates also with the anion, as the dielectric constant of the polymer is low (e.g., 5-8 for PEO). ${ }^{[176]}$ The conduction of the $\mathrm{Li}^{+}$ion through the polymer electrolyte proceeds by both hopping of the $\mathrm{Li}^{+}$ions and the segmental motion of the polymer chain, the rate of which is related to the $T_{\mathrm{g}}$ of the polymer (Figure 5) ${ }^{[176]}$ Some typical polymer electrolytes for lithium ion batteries are listed in Table 5. The conductivities of polymer electrolytes are generally in the range from $10^{-8}$ to $10^{-4} \mathrm{~S} \mathrm{~cm}^{-1}$.

A polymer-SCE typically consists of inorganic particles, e.g., $\mathrm{SiO}_{2}$, and a polymer electrolyte. These two components are mechanically mixed or dispersed in a solvent which afterward evaporates. Some typical polymer-SCE pairs are listed in Table 6. The conductivity of the polymer-SCE generally exceeds that of the polymer electrolyte, and the electrolyte with inorganic particles and lithium salt only, i.e., solid-solid SCE. $[80,84,177,178]$

Recently, a polymer-SCE with a thin film mesoporous oxide has been reported. ${ }^{[179]}$ The $100 \mathrm{~nm}$ SCE was fabricated by first depositing the mesoporous oxide film by chemical vapor deposition (CVD) and then filling the pore with polymer electrolyte by spin-coating. Though the SCE film showed no conductivity enhancement, the conductance of such $100 \mathrm{~nm}$ thin SCE was comparable to that of a $1 \mu \mathrm{m}$ state-of-the-art LiPON film.

Polymer-SCE with $\mathrm{Li}^{+}$conductive ceramic or inorganic electrolyte particles as fillers, such as $\mathrm{Li}_{3} \mathrm{~N},{ }^{[180]}$ LLZO, ${ }^{[181]}$ NASICON,${ }^{[182]}$ and LATP, ${ }^{[183]}$ garnet ${ }^{[184]}$ have also been shown,

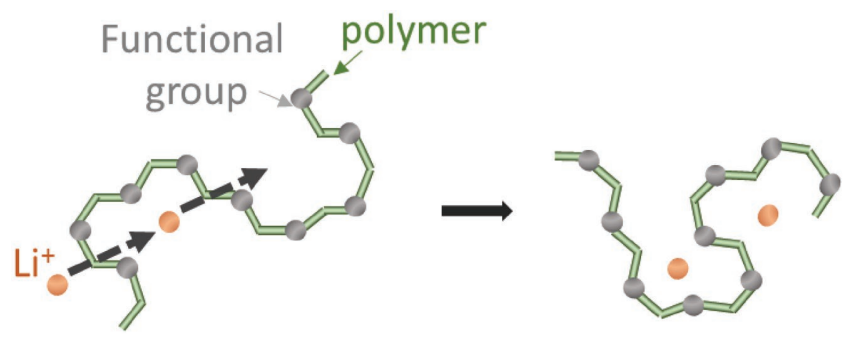

Figure 5. Schematic of $\mathrm{Li}^{+}$conduction in polymer electrolytes. The Green line connecting the gray dots the polymer chain, and the orange dots represent $\mathrm{Li}^{+}$ions solvated by the grey oxygen atoms. The anions are not included here. 
Table 5. Some typical polymer electrolytes for lithium ion batteries.

\begin{tabular}{lccc}
\hline Polymer electrolyte & lonic conductivity $\left[\mathrm{S} \mathrm{cm}^{-1}\right]$ & Measured temperature $\left[{ }^{\circ} \mathrm{C}\right]$ & Ref. \\
\hline $\mathrm{PEO} / \mathrm{Lil}$ & $6 \times 10^{-5}$ & 40 & {$[177]$} \\
$\mathrm{PEO} / \mathrm{LiClO}_{4}$ & $1 \times 10^{-7}$ & 27 & {$[190]$} \\
$\mathrm{PEO} / \mathrm{LiN}_{\left(\mathrm{SO}_{2} \mathrm{CF}_{3}\right)_{2}}$ & $1.5 \times 10^{-5}$ & 20 & {$[191]$} \\
$\mathrm{PEO} / \mathrm{LiBF}_{4}$ & $1 \times 10^{-6}$ & 25 & {$[192]$} \\
$\mathrm{PEO} / \mathrm{LiCF}_{3} \mathrm{SO}_{3}$ & $1 \times 10^{-9}$ & 40 & {$[193]$} \\
$\mathrm{PPO} / \mathrm{LiClO}_{4}$ & $1 \times 10^{-5}$ & 25 & {$[194]$} \\
$\mathrm{PPO} / \mathrm{LiN}_{\left(\mathrm{SO}_{2} \mathrm{CF}_{3}\right)_{2}}$ & $\approx 10^{-5}$ & 20 & {$[195]$} \\
\hline
\end{tabular}

though the research on this type of SCE is much less extensive compared to that on the SCE with nonconductive fillers, e.g., $\mathrm{SiO}_{2}$. This type of polymer-SCE has been reviewed recently. ${ }^{[25]}$ Different from the nonconductive filler based SCE which is typically designed to gain conductivity enhancement, the motivation for the development of these inorganic electrolyte SCE are to improve the contact or interface between the inorganic electrolyte particles and the active electrode particles, both of which are mechanically rigid, and in some cases also to prevent electrochemical reaction between the electrode material and certain conductive fillers, e.g., LATP. ${ }^{[25]}$ Indeed, the polymerSCE with $\mathrm{Li}^{+}$conductive fillers generally show conductivity lower than the filler itself, but much better as compared to the polymer electrolyte, which typically has inferior conductivity than the inorganic electrolyte. For example, the conductivity of an composite electrolyte consisting of $\mathrm{PEO}$ polymer, $\mathrm{LiCF}_{3} \mathrm{SO}_{3}$ salt, and $\mathrm{Li}_{3} \mathrm{~N}$ particles is 4 times lower than that of the $\mathrm{Li}_{3} \mathrm{~N}$ reference electrolyte. ${ }^{[180]}$ Likewise, the SCE comprised of PEO/ poly(propylene oxide) (PPO), $\mathrm{LiCF}_{3} \mathrm{SO}_{3}$, and LATP was reported to demonstrate a lower conductivity than LATP electrolyte. Also, Cui et al. observed a conductivity of $2 \times 10^{-4} \mathrm{~S} \mathrm{~cm}^{-1}$ for the electrolyte containing polyacrylonitrile- $\mathrm{LiClO}_{4}$ and 15 wt\% $\mathrm{Li}_{0.33} \mathrm{La}_{0.557} \mathrm{TiO}_{3}$, not higher than $\approx 10^{-3} \mathrm{~S} \mathrm{~cm}^{-1}$ for the $\mathrm{Li}_{0.33} \mathrm{La}_{0.557} \mathrm{TiO}_{3}$ ceramic. The decrease in the SCE conductivity, as compared to the conductive fillers, is generally attributed to the blocking polymer/filler interface. ${ }^{[25]}$ For example, by studying the impedance of $\mathrm{LiCF}_{3} \mathrm{SO}_{3} / \mathrm{PEO}_{20}$ layer coated on both sides of an $\mathrm{Li}_{3 x} \mathrm{La}_{2 / 3-x} \mathrm{TiO}_{3}$ (LLTO) pellet and laminated between two lithium metal electrodes, Abe et al. found that the polymer electrolyte/LLTO interface accounted for $83 \%$ of the total resistance of the polymer/inorganic stack. The ionically blocking nature of the polymer/filler interfaces was also supported by the fact that the conductivity of the polymer-SCE decreases as the size of the filler decreased; as a smaller filler particle size yields larger interfacial area in the SCE. ${ }^{[182,185]}$ For certain inorganic/polymer combinations, however, an additional interfacial resistance was not measured. For example, Tenhaeff et al. found that a $\mathrm{Li}_{2} \mathrm{O}-\mathrm{Al}_{2} \mathrm{O}_{3}-\mathrm{SiO}_{2}-\mathrm{P}_{2} \mathrm{O}_{5}-\mathrm{TiO}_{2}-\mathrm{GeO}_{2}$ mixed ceramic membrane laminated between a PEO based polymer electrolyte showed no interfacial resistance. ${ }^{[186]}$ These studies suggested that the distribution of the polymer and the fillers in the SCE and the formation of closed interfacial contacts are important aspects for the conduction of the SCE. Recently, fiber-like fillers have been used to improve the ionic conductivity of the polymer-SCE, in which the fibers created a conduction network, ${ }^{[181,187]}$ and novel methods, e.g., spray coating have
Table 6. Some typical polymer-SCEs.

\begin{tabular}{lcccc}
\hline Composite electrolyte & $\begin{array}{c}\sigma \text { of polymer- } \\
\text { SCE }\left[\mathrm{S} \mathrm{cm}^{-1}\right]\end{array}$ & $\begin{array}{c}\sigma \text { of polymer } \\
\text { electrolyte } \\
\text { ref. }\left[\mathrm{S} \mathrm{cm}^{-1}\right]\end{array}$ & $\begin{array}{c}\text { Temperature } \\
{\left[{ }^{\circ} \mathrm{C}\right]}\end{array}$ & Ref \\
\hline $\mathrm{PEO} / \mathrm{Lil} / \mathrm{Al}_{2} \mathrm{O}_{3}$ & $1 \times 10^{-4}$ & $0.5 \times 10^{-4}$ & 40 & {$[177]$} \\
$\mathrm{PEO} / \mathrm{LiClO}_{4} / \mathrm{Al}_{2} \mathrm{O}_{3}$ & $1 \times 10^{-5}$ & $\approx 8 \times 10^{-7}$ & 25 & {$[81]$} \\
$\mathrm{PEO} / \mathrm{LiClO}_{4} / \mathrm{SiO}_{2}$ & $8 \times 10^{-6}$ & $2 \times 10^{-7}$ & 30 & {$[196]$} \\
$\mathrm{PEO} / \mathrm{LiClO}_{4} / \mathrm{TiO}_{2}$ & $2 \times 10^{-5}$ & $2 \times 10^{-6}$ & 30 & {$[196]$} \\
$\mathrm{PEO} / \mathrm{LiN}\left(\mathrm{SO}_{2} \mathrm{CF}_{3}\right)_{2} / \mathrm{SiO}_{2}$ & $1.4 \times 10^{-4}$ & $1.5 \times 10^{-5}$ & $\mathrm{RT}$ & {$[191]$} \\
$\mathrm{PEO} / \mathrm{LiClO}_{4} / \mathrm{Al}_{2} \mathrm{O}_{3}$ & $\approx 10^{-5}$ & $\approx 10^{-7}$ & $\mathrm{RT}$ & {$[197]$} \\
$\mathrm{PEO} / \mathrm{LiBF}_{4} / \mathrm{ZrO}_{2}$ & $4 \times 10^{-8}$ & $2 \times 10^{-8}$ & 25 & {$[198]$} \\
\hline
\end{tabular}

been applied to fabricate SCE with intimated polymer/filler interface. ${ }^{[188,189]}$

\subsection{Interface Interaction in Polymer-SCEs}

The conductivity enhancement in polymer-SCEs is also believed to be at least in part a result of interface interactions. The interaction between the inorganic particles can suppress the crystallinity of the polymer thus lowering the $T_{\mathrm{g}}$ of the polymer as supported by nuclear magnetic resonance (NMR), ${ }^{[4]} \mathrm{X}$-ray powder diffraction (XRD), ${ }^{[199]}$ and differential scanning calorimetry (DSC) ${ }^{[200,201]}$ results. A polymer can consist of crystal and/or amorphous parts.[202] The segmental motion of the crystal polymer is typically slower than that of the amorphous one ${ }^{[203]}$ and thus a higher fraction of amorphous to crystalline polymer results in higher ion conductivity. ${ }^{[176]}$ Therefore, as the polymer is mostly in amorphous state near the oxide particles, the conduction of $\mathrm{Li}^{+}$in the polymer-SCE increases with an increasing oxide particle surface area. Obviously, there will an optimum since a larger inactive volume fraction is introduced with higher oxide particle content. Alternatively, Lewis acid-base interactions between the inorganic particles, the Li-salt, and the polymer have been postulated to be responsible for enhanced ion conduction. ${ }^{[34,35,81,84,204-206]}$ In this explanation, $\mathrm{Li}^{+}$is considered as Lewis acid, and the anions and the solvating groups on the polymers, e.g. $-\mathrm{O}-$, are considered as Lewis bases, while the acidity/basicity of the inorganic particles depend on their surface chemistry. As such, a more conductive ion motion path can be created, e.g., near an oxide particle, where the $\mathrm{Li}^{+}$ can hop also from a surface site on the particles to and from the polymer. ${ }^{[207]}$ An acidic surface can attract anions or the solvating groups, freeing the associated $\mathrm{Li}^{+}$cations; whereas a basic surface attract cations which are then weakly bonded to the surface. In both cases a $\mathrm{Li}^{+}$rich layer is formed, respectively, near and on the particle interface which will affect the overall ion conductivity. ${ }^{[84,206,208]}$

The effect of the Lewis acid-base interaction is supported by the observed change in transference number of $\mathrm{Li}^{+}\left(t_{\mathrm{Li}^{+}}\right)$ for the polymer-SCE. Indeed, in the case where the anions are immobilized on the particle surface, the contribution of $\mathrm{Li}^{+}$ motion to the total conduction will be augmented. The transference number can be determined using $\mathrm{NMR}^{[47]}$ or electrochemical techniques ${ }^{[209]}$ such as dc-ac measurement, ${ }^{[210]}$ where the 
Table 7. $\mathrm{Li}^{+}$transference number $\left(\mathrm{L}_{\mathrm{L}^{+}}\right)$and conductivity (measured at RT) of some polymer-SCEs and the polymer electrolyte references. P(EO/ $\left.E_{2}\right)$ : poly[ethylene oxide-co-2-(2-methoxyethoxy) ethyl glycidyl ether.

\begin{tabular}{lcccc}
\hline Polymer-SCE & $\begin{array}{c}\text { Surface } \\
\text { property } \\
\text { of particles }\end{array}$ & $\begin{array}{c}t_{\mathrm{L}^{+}} / \text {conductivity } \\
{\left[\mathrm{S} \mathrm{cm}^{-1}\right] \text { of the }} \\
\text { composite }\end{array}$ & $\begin{array}{c}t_{\mathrm{L}^{+}} / \text {conductivity } \\
{\left[\mathrm{S} \mathrm{cm}^{-1}\right] \text { of }} \\
\text { the ref. }\end{array}$ & Ref \\
\hline $\mathrm{PEO} / \mathrm{LiClO}_{4} / \mathrm{TiO}_{2}$ & Acidic & $0.65 / 2 \times 10^{-5}$ & $0.25 / 1 \times 10^{-6}$ & {$[204]$} \\
$\mathrm{PEO} / \mathrm{LiClO}_{4} / \mathrm{Al}_{2} \mathrm{O}_{3}$ & Acidic & $0.3 / 1 \times 10^{-5}$ & $0.25 / 1 \times 10^{-6}$ & {$[204]$} \\
$\mathrm{P}\left(\mathrm{EO} / \mathrm{EM}_{2}\right) / \mathrm{LiClO}_{4} / \mathrm{TiO}_{2}$ & Acidic & $0.3 / 1.4 \times 10^{-5}$ & $0.14 /<10^{-5}$ & {$[213]$} \\
$\mathrm{PEO} / \mathrm{LiClO}_{4} / \mathrm{Al}_{2} \mathrm{O}_{3}$ & Acidic & $0.77 /-$ & $0.31 /-$ & {$[81]$} \\
$\mathrm{PEO} / \mathrm{LiClO}_{4} / \mathrm{BaTiO}_{3}$ & - b) & $0.37 / 1.2 \times 10^{-3 a)}$ & $0.2 / 2.4 \times 10^{-4}$ & {$[214]$} \\
$\mathrm{PEO} / \mathrm{LiN}\left(\mathrm{SO}_{2} \mathrm{CF}_{3}\right)_{2} / \mathrm{SiO}_{2}$ & $-\mathrm{OH}$ & $0.22 / 5.1 \times 10^{-5}$ & $0.12 / 1.5 \times 10^{-5}$ & {$[204]$} \\
$\mathrm{PEO} / \mathrm{LiClO}_{4} / \mathrm{SiO}_{2}$ & $-\mathrm{OH}$ & $0.19 / 9.7 \times 10^{-6}$ & $0.11 / 9.7 \times 10^{-7}$ & {$[204]$} \\
\hline
\end{tabular}

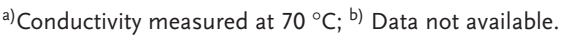

$\mathrm{Li}^{+}$-motion current is separated from the total current by nonblocking electrodes for $\mathrm{Li}^{+}{ }^{+}{ }^{[211]}$ The change of the transference number of some polymer-SCEs as compared to the pure polymer electrolyte is listed in Table 7. For example, Croce et al. ${ }^{[204]}$ reported that the change in the $t_{\mathrm{Li}^{+}}$value for a $\mathrm{PEO} / \mathrm{LiClO}_{4}$ based polymer SCE was consistent with the change in Lewis acid/base character of the inorganic particles added into the electrolyte. Acidic $\mathrm{TiO}_{2}$ particles increased the transference number of the polymer-SCE from 0.25 to $0.5-0.6$ while the less acidic $\mathrm{Al}_{2} \mathrm{O}_{3}$ particles only gave a modest increase from 0.25 to 0.3 . Similarly, Scrosati and co-worker ${ }^{[198]}$ showed that adding a sulfate promoted super-acid zirconia into $\mathrm{PEO} / \mathrm{LiBF}_{4}$ enhanced the $t_{\mathrm{Li}^{+}}$ from 0.42 to 0.81 because of the strong interaction between the super acidic surface and the anion. Also, they ${ }^{[212]}$ demonstrated that a small organic molecule like calixarene has such a large anion trapping property that it enhanced the $t_{\mathrm{Li}^{+}}$of a PEO/LiI based composite electrolyte from 0.25 to $0.8-1$.

However, studies showed that the effect of the acid-base interaction on the conductivity of the polymer-SCE was not straightforward, indicating the presence of multiple effects or conduction mechanisms existing in parallel. For example, Marcinek et al. ${ }^{[215]}$ showed a clear change in the ion conductivity for poly(ethylene glycol)(PEG)/ $\mathrm{LiClO}_{4} / \mathrm{Al}_{2} \mathrm{O}_{3}$ SCE where the alumina surface chemistry was modified to be neutral, acidic, or basic. In all cases, a conductivity enhancement was observed compared to the pure polymer electrolyte. The ion conductivity of the alumina composites was found to be similar for acidic and basic surfaces, and both higher than that of the composite with the neutral alumina surface. However, when also the relative fraction of ion pairs (i.e., the inverse of free or solvated ions) was measured, ${ }^{[216]}$ it did not follow the same trend: the ion pair fraction was indeed the highest in the pure polymer electrolyte, as expected from the conductivity difference, but for the composites it decreased from acidic $>$ neutral $>$ basic surface. In another example, Croce et al. ${ }^{[207]}$ found that the conductivity enhancement of the $\mathrm{PEO} / \mathrm{LiCF}_{3} \mathrm{SO}_{3}$ polymer electrolyte by adding $\mathrm{Al}_{2} \mathrm{O}_{3}$ with acid, basic, and neutral surface was in the order of acidic $>$ neutral $>$ reference $>$ basic. Interestingly, all the $\mathrm{PEO} / \mathrm{LiCF}_{3} \mathrm{SO}_{3} / \mathrm{Al}_{2} \mathrm{O}_{3}$ composite electrolytes showed a higher $t_{\mathrm{Li}^{+}}$than the pure $\mathrm{PEO} / \mathrm{LiCF}_{3} \mathrm{SO}_{3}$ polymer electrolyte reference. The authors suggested that next to Lewis acid-base interactions, structural changes also occur to the polymer itself, where the modified PEO promoted the $\mathrm{Li}^{+}$conduction (cf. similar to the change in the fraction of amorphous to crystalline polymer as discussed above). Similar ambiguity in conductivity trends have been found for polymer composites with silica particles. For example, Fan et al. ${ }^{[217]}$ found no conductivity enhancement for PEO polymer electrolyte mixed with silica for which the surface was modified with nonpolar alkyl moieties or polar polyethylene glycol. Kim et al. ${ }^{[218]}$ on the other hand, reported a conductivity enhancement for composites of $\mathrm{PEO} / \mathrm{LiN}\left(\mathrm{SO}_{2} \mathrm{CF}_{2} \mathrm{CF}_{3}\right)_{2}$ with $\mathrm{SiO}_{2}$ particles modified with nonpolar trimethylsilyl or $-\left[-\mathrm{Si}\left(\mathrm{CH}_{3}\right)_{2}-\mathrm{O}-\right]_{4}-\mathrm{H}$ group.

In conclusion, the effect of interface interactions on the conductivity of the polymer-SCE is far from straightforward as several mechanisms are at play. Three main mechanisms have been discussed: 1) structural changes in the polymer and their effect on motion of polymer moieties, 3) synergetic action between cation surface sites on the inorganic particle and polymer sites (solvating functional groups) which facilitate the hopping of $\mathrm{Li}^{+}$along the interface, and 3) complex surface chemistry which controls the concentration of free, associated, and solvated species at/near the heterogeneous interface. This complexity is further deepened by the fact that these effects can be interdependent of each other. It is however noted, that some of the conflicting findings could be also partially the result of unintended experimental differences. For example, the dispersion of the particles in the polymer-SCE has been rarely checked, even though different surface acidity/basicity can, for example, result in different levels of agglomeration. To disperse inorganic particles evenly in the polymer phase, the polymer has been chemically bonded to the surface of the particles. For example, silica has been bonded with various polymers such as PEG terminated trimethoxysilane, ${ }^{[219,220]}$ amine terminated PEO, ${ }^{[221]}$ and 3-(trihydroxysilyl)-1-propane sulfonic acid. ${ }^{[222]}$

\subsection{Polymer-SCEs with Porous Matrix}

As for the solid/solid interfaces discussed in Section 2, mesoporous particles can also be used for polymer-SCE to increase the interface portion and thus the total ion conductivity.

Some polymer-SCEs with porous particle matrices are listed in Table 8. The composites are typically fabricated by impregnating the polymer electrolyte in the porous particles. ${ }^{[223,224]}$ For this purpose, the polymer is first dissolved in a volatile solvent, such as acetonitrile, which is then removed by drying. The fraction of polymer remaining in the pores is determined by the starting concentration. The successful dispersion of the polymer electrolyte in the porous matrix is indicated by an increase of $T_{\mathrm{g}}$ of the polymer. ${ }^{[225]}$ As for the solid-solid SCE, the conductivity of these polymer-SCEs with mesoporous matrices typically exceeds that of similar SCEs with a solid matrix. For example, the conductivity of a composite with mesoporous $\mathrm{SiO}_{2}$ (5.8 $\mathrm{nm}$ pore size) was reported to be three times that of the composite with $10 \mathrm{~nm} \mathrm{SiO}$ particles. $^{[226]}$ In these porous SCEs, $\mathrm{Li}^{+}$ions can conduct via the bulk polymer electrolyte phase, the external particle surface, and the internal pore surface, as was shown by the different relaxation times and activation energies for $\mathrm{Li}^{+}$conduction by NMR (Figure 6). ${ }^{[223,227-230]}$ These results 
Table 8. Polymer-SCEs with mesoporous particles as matrix. PVDF: poly(vinylidene fluoride). The listed properties of the porous particles include the pore size, the surface area, and the surface acidity/basicity.

\begin{tabular}{|c|c|c|c|c|}
\hline Polymer electrolyte & Porous particles and their properties & $\sigma$ of the composite $\left[\mathrm{S} \mathrm{cm}^{-1}\right]$ & $\sigma$ of the reference $\left[\mathrm{S} \mathrm{cm}^{-1}\right]$ & Ref. \\
\hline $\mathrm{PEO} / \mathrm{LiBF}_{4}$ & Zeolite & $\approx 10^{-6}$ & $\approx 10^{-9}$ & {$[225]$} \\
\hline $\mathrm{PVDF} / \mathrm{LiPF}_{6}$ & $\mathrm{TiO}_{2}$ tube, $12-15 \mathrm{~nm}, 284 \mathrm{~m}^{2} \mathrm{~g}^{-1}$ & $2 \times 10^{-5}$ & $3 \times 10^{-6}$ & [232] \\
\hline $\mathrm{PEO} / \mathrm{LiClO}_{4}$ & $\mathrm{SiO}_{2}(\mathrm{MCM}-41), 3 \mathrm{~nm}, 1030 \mathrm{~m}^{2} \mathrm{~g}^{-1}$ & $4 \times 10^{-5}$ & $1 \times 10^{-5}$ & [229] \\
\hline $\mathrm{PEO} / \mathrm{LiClO}_{4}$ & $\mathrm{ZrO}_{2}$ & $1 \times 10^{-4}$ & $2 \times 10^{-6}$ & [237] \\
\hline $\mathrm{PEO} / \mathrm{LiClO}_{4}$ & $\mathrm{LiAlO}_{2}, 3 \mathrm{~nm}, 124 \mathrm{~m}^{2} \mathrm{~g}^{-1}$ & $2 \times 10^{-5}$ & $2 \times 10^{-7}$ & [238] \\
\hline PEO/LiTFSI & $\mathrm{Al}_{2} \mathrm{O}_{3}, 5.8 \mathrm{~nm}, 155 \mathrm{~m}^{2} \mathrm{~g}^{-1}$ & $2 \times 10^{-4}$ & $5 \times 10^{-5}$ & [231] \\
\hline $\mathrm{PEO} / \mathrm{LiClO}_{4}$ & $\mathrm{SiO}_{2}(\mathrm{MCM}-41), 3 \mathrm{~nm}, 1030 \mathrm{~m}^{2} \mathrm{~g}^{-1}$ surface modified with ether group & $7 \times 10^{-6}$ & $2 \times 10^{-6}$ & [223] \\
\hline $\mathrm{PEO} / \mathrm{LiClO}_{4}$ & $\mathrm{SiO}_{2}(\mathrm{MCM}-41), 2.6 \mathrm{~nm}, 803 \mathrm{~m}^{2} \mathrm{~g}^{-1}$ weak acid surface & $1 \times 10^{-4}$ & $3 \times 10^{-7}$ & [224] \\
\hline $\mathrm{PEO} / \mathrm{LiClO}_{4}$ & $\mathrm{SiO}_{2}(\mathrm{MCM}-41), 4 \mathrm{~nm}, 965 \mathrm{~m}^{2} \mathrm{~g}^{-1}$ & $5 \times 10^{-5}$ & $2 \times 10^{-7}$ & [234] \\
\hline $\mathrm{PEO} / \mathrm{LiClO}_{4}$ & $\mathrm{SiO}_{2}$ (MCM-41), $4 \mathrm{~nm}, 965 \mathrm{~m}^{2} \mathrm{~g}^{-1}$; EC/PC modified surface & $5 \times 10^{-4}$ & $2 \times 10^{-7}$ & {$[234]$} \\
\hline $\mathrm{PEO} / \mathrm{LiClO}_{4}$ & $\mathrm{SiO}_{2}(\mathrm{SBA}-15)$ & $3 \times 10^{-5}$ & $5 \times 10^{-6}$ & [227] \\
\hline $\mathrm{PEO} / \mathrm{LiCF}_{3} \mathrm{SO}_{3}$ & $\mathrm{SiO}_{2}, 7.1 \mathrm{~nm}$ & $9 \times 10^{-7}$ & $7 \times 10^{-8}$ & [235] \\
\hline $\mathrm{PEO} / \mathrm{LiCF}_{3} \mathrm{SO}_{3}$ & $\mathrm{SiO}_{2}, 6 \mathrm{~nm} ;[\mathrm{EMI}]\left[\mathrm{BF}_{4}\right]$ modified surface & $4 \times 10^{-5}$ & $7 \times 10^{-8}$ & [236] \\
\hline $\mathrm{PEO} / \mathrm{LiClO}_{4}$ & $\mathrm{SiO}_{2}(\mathrm{SBA}-15), 6 \mathrm{~nm}, 1012 \mathrm{~m}^{2} \mathrm{~g}^{-1}$ & $7 \times 10^{-7}$ & $\approx 10^{-8}$ & [239] \\
\hline $\mathrm{PEO} / \mathrm{LiClO}_{4}$ & $\mathrm{SiO}_{2}(\mathrm{SBA}-15), 6 \mathrm{~nm}, 1012 \mathrm{~m}^{2} \mathrm{~g}^{-1}, \gamma$-aminopropyltriethoxysilane modified surface & $1 \times 10^{-6}$ & $\approx 10^{-8}$ & [239] \\
\hline $\mathrm{PEO} / \mathrm{LiClO}_{4}$ & $\mathrm{SiO}_{2}(\mathrm{SBA}-15), 6 \mathrm{~nm}, 600 \mathrm{~m}^{2} \mathrm{~g}^{-1}$ & $2 \times 10^{-5}$ & $1 \times 10^{-7}$ & [240] \\
\hline $\mathrm{PEO} / \mathrm{LiClO}_{4}$ & $\mathrm{SiO}_{2}(\mathrm{MCM}-41), 3.4 \mathrm{~nm}, 650 \mathrm{~m}^{2} \mathrm{~g}^{-1}$ & $1.5 \times 10^{-5}$ & $10^{-7}$ & [233] \\
\hline $\mathrm{PEO} / \mathrm{LiClO}_{4}$ & $\mathrm{SiO}_{2}$ (HMS-41), $4.4 \mathrm{~nm}, 670 \mathrm{~m}^{2} \mathrm{~g}^{-1}$ & $1.5 \times 10^{-5}$ & $10^{-7}$ & [233] \\
\hline $\mathrm{PEO} / \mathrm{LiClO}_{4}$ & $\mathrm{SiO}_{2}(\mathrm{SBA}-15), 5.8 \mathrm{~nm}, 600 \mathrm{~m}^{2} \mathrm{~g}^{-1}$ & $2 \times 10^{-5}$ & $10^{-7}$ & [233] \\
\hline $\mathrm{PEO} / \mathrm{LiClO}_{4}$ & $\mathrm{SiO}_{2}(\mathrm{SBA}-15), 6 \mathrm{~nm}, 600 \mathrm{~m}^{2} \mathrm{~g}^{-1}$, loaded with $\mathrm{P} 123$ & $3 \times 10^{-5}$ & $1 \times 10^{-7}$ & [226] \\
\hline $\mathrm{P}\left(\mathrm{EO} / \mathrm{EM}_{2}\right) / \mathrm{LiClO}_{4}$ & $\mathrm{TiO}_{2}, 220 \mathrm{~m}^{2} \mathrm{~g}^{-1}$ & $1.4 \times 10^{-5}$ & - & [213] \\
\hline $\mathrm{P}\left(\mathrm{EO} / \mathrm{EM}_{2}\right) / \mathrm{LiClO}_{4}$ & $\mathrm{SiO}_{2}, 830 \mathrm{~m}^{2} \mathrm{~g}^{-1}$ & $1 \times 10^{-5}$ & - & [213] \\
\hline $\mathrm{P}\left(\mathrm{EO} / \mathrm{EM}_{2}\right) / \mathrm{LiClO}_{4}$ & $\mathrm{Al}_{2} \mathrm{O}_{3}, 265 \mathrm{~m}^{2} \mathrm{~g}^{-1}$ & $7 \times 10^{-6}$ & - & [213] \\
\hline $\mathrm{PEO} / \mathrm{LiClO}_{4}$ & $\mathrm{Zn}_{4} \mathrm{O}(1,4 \text {-benzenedi-carboxylate })_{3} \mathrm{MOF}$ & $3 \times 10^{-5}$ & $7 \times 10^{-6}$ & [241] \\
\hline PEO/LiTFSI & Mg-1,3,5-benzenetricarboxylic MOF & $1 \times 10^{-4}$ & $1 \times 10^{-7}$ & [242] \\
\hline
\end{tabular}

prove that there is interface conduction in the polymer-SCEs, and that the polymer electrolyte fill the pores. Similar $\mathrm{Li}^{+}$conduction mechanisms have been proposed for the polymer-SCE with porous $\mathrm{Al}_{2} \mathrm{O}_{3}{ }^{[231]}$ and $\mathrm{TiO}_{2} \cdot{ }^{[232]}$

Interestingly, it seems that the material composition of the porous matrix has a lesser effect on the conductivity enhancement than the surface chemistry. For example, Tominaga et al. ${ }^{[202]}$ found not more than a two-fold difference in the conductivity for a polymer composite electrolyte with polyethylene oxide-co-2-(2-methoxyethoxy)ethylglycidylether) mixed with $\mathrm{LiClO}_{4}$ and impregnated in mesoporous titania > silica $>$ alumina. ${ }^{[213]}$ Also, Xi et al. reported no significant difference between the conductivities of polymer electrolytes with different mesoporous silica such as Santa Barbara number 15 (SBA-15), mobile composition of matter number 41 (MCM41) and hexagonal mesoporous silica (HMS) $\left(5 \times 10^{-5} \mathrm{~S} \mathrm{~cm}^{-1} \mathrm{vs}\right.$ $\left.2 \times 10^{-5} \mathrm{~S} \mathrm{~cm}^{-1}\right) \cdot{ }^{[233]}$ In contrast, surface modification of porous particles is shown to be an effective approach to modify the Lewis acid-base interaction in the polymer-SCE thus tuning the conductivity. For example, Nan et al. reported that modifying the surface of MCM-41 with ethylene carbonate (EC)/propylene carbonate (PC) enlarged the conductivity of the $\mathrm{PEO} / \mathrm{LiClO}_{4} /$ MCM-41 electrolyte from $10^{-5}$ to $10^{-4} \mathrm{~S} \mathrm{~cm}^{-1}$. ${ }^{234]}$ The author assumed that the $\mathrm{Li}^{+}$conducted through the EC/PC functionalized nanochannels. Also, Tominaga et al. ${ }^{[235,236]}$ observed a 200-time conductivity enhancement in the $\mathrm{PEO} / \mathrm{LiCF}_{3} \mathrm{SO}_{3} /$ silica electrolyte where the silica surface was modified with 1-ethyl-3-methylimidazolium tetrafluoroborate ([EMI][BF $]$ ).

\section{ILE-SCEs}

\subsection{Ionic liquid Electrolytes for LIBs}

Room temperature ionic liquids (ILs) are materials that are solely comprised of ions and have a melting point below $100-150{ }^{\circ} \mathrm{C} \cdot{ }^{[88]}$ "Ionic liquid" is now the most generally accepted term but in the literature, they have been termed also "fused salts," "pure liquid electrolyte," "liquid salt," "ionophore," "organic room temperature molten salt," "low temperature molten salt," "ambient temperature molten salt," "ionic fluid," and "liquid organic salt," etc. ${ }^{[8,243]}$ Good thermal, chemical, and electrochemical stabilities of ILs allow them to be used as reaction media for applications such as aluminum plating where conventional aqueous electrolyte solutions and even most organic solvents cannot be used. The development of ILs can be traced back to $\mathrm{LiCl}-\mathrm{KCl}$, a eutectic 
(a)
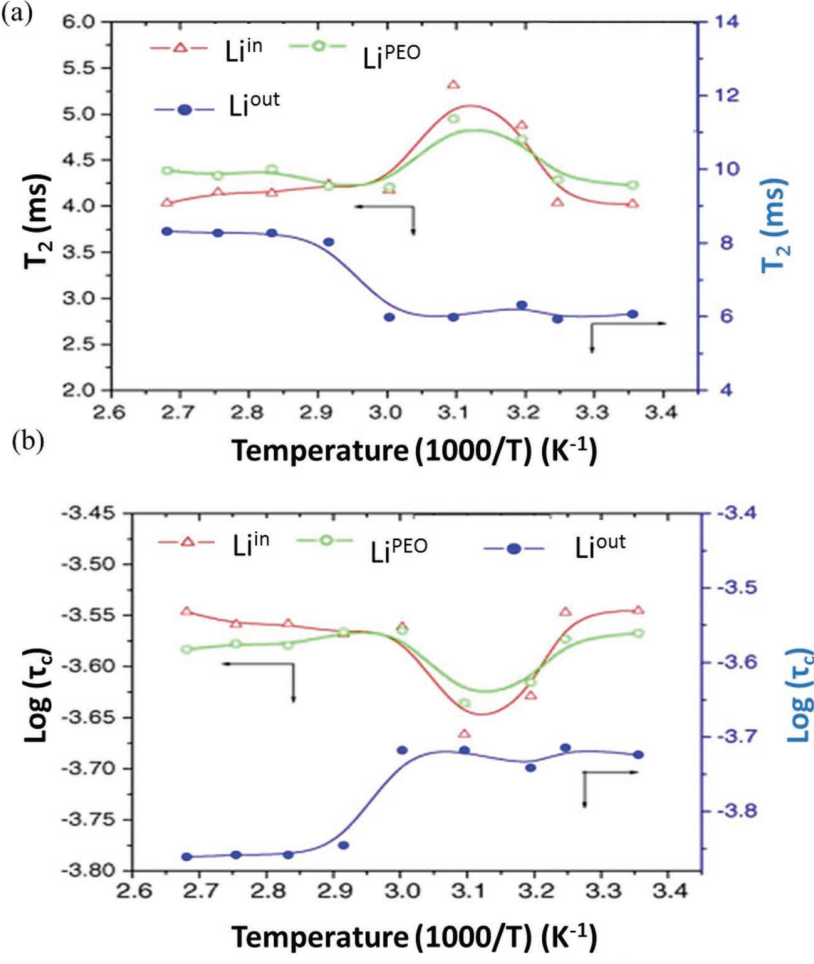

Figure 6. Reported NMR characterization of the $\mathrm{PEO} / \mathrm{LiClO}_{4} /$ porous material (SBA-15) polymer-SCE. a) Variable temperature spin-spin relaxation time $\left(T_{2}\right)$ of lithium species; b) variable temperature motional correlation time $\left(\tau_{c}\right)$ of lithium species; three types of lithium ion responses are detected, corresponding to lithium ions inside the pores (red), outside the pores but still near the surface of the matrix (green), and in the PEO bulk (blue). Reproduced with permission. ${ }^{[228]}$ Copyright 2006, Elsevier.

mixture with a melting point of $355^{\circ} \mathrm{C}^{[244]}$ which was considered to be a "low temperature" one compared to the classical high temperature molten salts which were difficult to handle and needed specialized equipment. ${ }^{[243]}$ Soon after the LiCl-KCl mixture, $\mathrm{NaCl}-\mathrm{AlCl}_{3}$ was found to have a lower melting pointing of $107^{\circ} \mathrm{C} \cdot[243]$ Then a 1-butylpyridinium chloride- $\mathrm{AlCl}_{3}$ mixture (m.p. $\left.40{ }^{\circ} \mathrm{C}\right)^{[245]}$ was developed based on previous research into the lowering of the melting point of $\mathrm{AlCl}_{3}$ mixtures for $\mathrm{Al}$ plating by the addition of organic molecules. This, in turn, might have been inspired by earlier work on the ionic liquid ethylammonium nitrate (m.p. $\left.12{ }^{\circ} \mathrm{C}\right) .{ }^{[246]}$ This 1-butylpyridinium chloride- $\mathrm{AlCl}_{3}$ mixture, however, has a limited cathodic stability and is prone to hydrolysis. To address these issues and to further reduce the melting temperature, the pyridinium ion was replaced by other quaternary N-containing cations, such as dialkylimidazolium, and the moisture sensitive $\mathrm{AlCl}_{3}$ was replaced by stable anions such as bis(trifluoromethane)sulfonimide $\left(\mathrm{TFSI}^{-}\right), \mathrm{NO}_{3}^{-}$, and $\mathrm{SO}_{4}^{2-}$, etc. ${ }^{[243]}$ Nowadays, state-of-the-art ILs have melting points below $0{ }^{\circ} \mathrm{C}$, can be handled in humid air, and are cathodically stable to plate even lithium. Theoretical work ${ }^{[247]}$ showed that the large size and conformational flexibility of the ions of the IL lead to small lattice enthalpies and large entropy changes that favor the liquid state.

ILs have been considered as promising solvents for electrolytes for LIBs. ${ }^{[48]}$ An ILE is a solution where lithium salts
Table 9. Physicochemical properties of some ILEs used for LIB electrolytes. [BMP][FSI]: 1-butyl-7-methylpyrrolidinium bis(fluorosulfonyl)imide; [EMI][FSI]: 7 -ethyl-3-methyllmidazolium bis (fluorosulfonyl)imide; Li[FSI]: lithium bis(fluorosulfonyl)imide.

\begin{tabular}{|c|c|c|c|c|}
\hline ILE & $\begin{array}{l}\text { Thermal } \\
\text { stability }\left[{ }^{\circ} \mathrm{C}\right]\end{array}$ & $\sigma\left[\mathrm{S} \mathrm{cm}^{-1}\right]$ & $\begin{array}{l}\text { Electrochemical } \\
\text { window }\end{array}$ & Ref. \\
\hline Li[TFSI]/[BMP][TFSI] & $378(0.5 \mathrm{M})$ & $\begin{array}{c}1.7 \times 10^{-3} \\
(0.5 \mathrm{M})\end{array}$ & $\begin{array}{c}1-5 \mathrm{~V} \text { vs Li } \mathrm{i}^{+} / \mathrm{Li} \\
(0.5 \mathrm{M}) \text { glassy carbon }\end{array}$ & {$[281,282]$} \\
\hline Li[FSI]/[BMP][FSI] & $300(0.1 \mathrm{M})$ & $\begin{array}{c}3.2 \times 10^{-3} \\
(0.1)\end{array}$ & $\begin{array}{l}0.03-5.37 \mathrm{~V} \mathrm{vs} \mathrm{Li+} / \mathrm{Li} \\
(0 \mathrm{~m}) \text { platinum }\end{array}$ & {$[283,284]$} \\
\hline Li[FSI]/[EMI][FSI] & 307 (0 M) & $\begin{array}{c}1.1 \times 10^{-2} \\
(0.7 \mathrm{M})\end{array}$ & $\begin{array}{c}0.2 \mathrm{~V} \mathrm{vs} \mathrm{Li}^{+} / \mathrm{Li} \\
\left(0.32 \mathrm{~kg} \mathrm{~mol}^{-1}\right) \text { graphite }\end{array}$ & {$[285,286]$} \\
\hline Li[TFSI]/[BMI][TFSI] & 465 (0 м) & $\begin{array}{l}2 \times 10^{-3} \\
(1 \mathrm{~m})\end{array}$ & $\begin{array}{c}-2.7 \text { to } 3.2 \mathrm{Vvs} \mathrm{Fc}^{+} / \\
\mathrm{Fc}(0 \mathrm{M})\end{array}$ & {$[287,288]$} \\
\hline $\mathrm{LiBF}_{4} /[\mathrm{EMI}] \mathrm{BF}_{4}$ & 350 (1 M) & $\begin{array}{c}8 \times 10^{-3} \\
(1 \mathrm{M})\end{array}$ & $\begin{array}{l}1.1-5.1 \mathrm{~V} \mathrm{vs} \mathrm{Li}^{+} / \mathrm{Li} \\
(0 \mathrm{M}) \text { platinum }\end{array}$ & [289] \\
\hline
\end{tabular}

are dissolved in the ILs. ILEs can have large electrochemical windows (up to $9 \mathrm{~V}^{[246]}$ with a high oxidation limit ${ }^{[249,250]}$ ), high thermal stability (decomposition at $300-400{ }^{\circ} \mathrm{C}$ ), ${ }^{[251]}$ nonflammability ${ }^{[252]}$ (which improves the battery safety), and reasonable conductivity ranging from $0.1 \mathrm{mS} \mathrm{cm}^{-1}$ up to tens of $\mathrm{mS} \mathrm{cm}^{-1}{ }^{[16]}$ comparable to that of commercial organic liquid electrolytes. ${ }^{[13]}$ Physical chemical properties of some typically ILEs are listed in Table 9. Ionic liquids used for LIB electrolytes generally have cyclic amine cations such as dialkylpyrrolidinium ${ }^{[253]}$ and dialkylimidazolium, ${ }^{[254]}$ and large electron withdrawing anions such as TFSI and bis(fluorosulfonyl) imide $(\text { FSI })^{[255]}$ (Figure 7a).

The structure of ILs is determined by the intermolecular forces such as van der Waals forces, Coulombic or dipole interactions, hydrogen bonding, etc. IL molecules have polar and nonpolar parts. ${ }^{[88]}$ For example, the anion and the positively charged atoms on the cation such as the $\mathrm{N}$ on the imidazolium ring are polar whereas the alkyl chains on cation are nonpolar. When ILs solidify, they can form a crystal where the polar and nonpolar parts segregate into a bilayer structure. ${ }^{[88]}$ For example, the structure of 1-alkyl-3-methylimidazolium halide ILs with more than 12 carbons on the alkyl chain can be described as sheets of imidazolium rings and anions, separated by a domain of interdigitated alkyl chains. ${ }^{[256]}$ When these crystalline ILs melt, some organization through intermolecular forces may remain even in the liquid phase. ${ }^{[257]}$ The liquid structures of many ILs have been described at the molecular and mesoscopic level. At the molecular level, the cations and anions are proposed to exist mostly as free ions rather than ion pairs, as high as $90 \%$ according to some work ${ }^{[258]}$ based on molecular dynamics simulations, ${ }^{[259]}$ dielectric spectroscopy measurements, ${ }^{[258]}$ and NMR measurements. ${ }^{[260]}$ Others, however, postulated that the IL molecules form clusters at the molecular level. For example, for most aprotic ILs, clusters with a composition of $[\mathrm{C}]_{\mathrm{a}}[\mathrm{A}]_{\mathrm{b}}(\mathrm{C}=$ cation, $\mathrm{A}=$ anion with $a$ and $b$ values between 2 and 5) have been detected by electrospray ionization mass spectrometry. ${ }^{[88]}$ The existence of clusters has also been observed by X-ray reflectivity (XRR) ${ }^{[261]}$ and NMR. ${ }^{[260]}$ At the mesoscopic level, ILs are believed to hold a similar segregation structure as their solid crystalline form, as supported by MD simulation and evidenced by small-angle X-ray scattering 
(a)

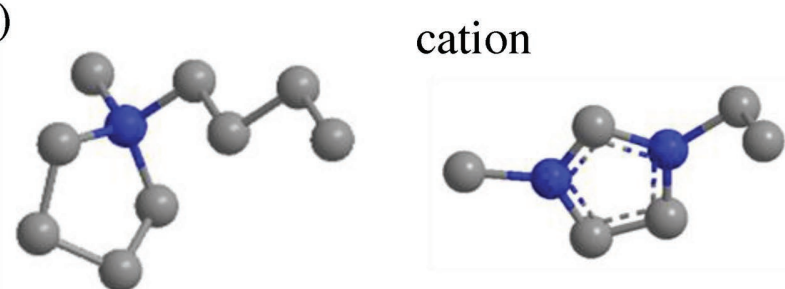

(b)

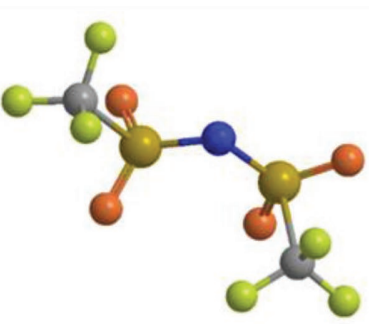

anion

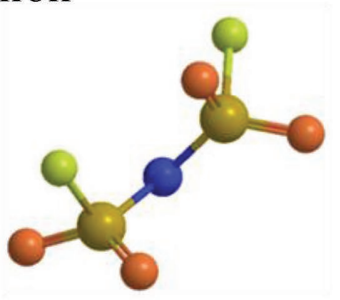

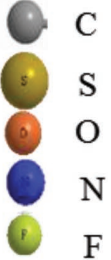

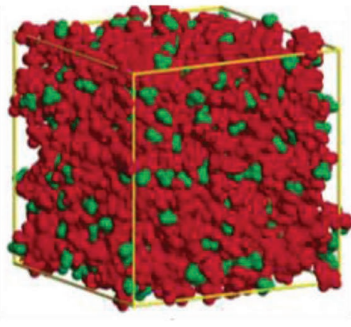

$\mathrm{n}=2$

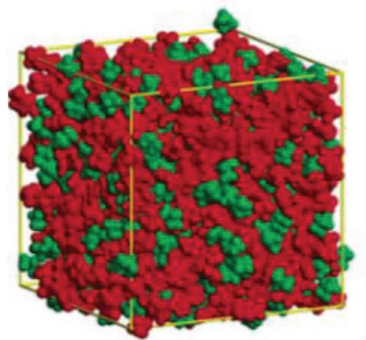

$\mathrm{n}=4$

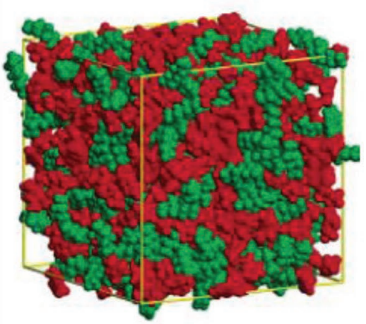

$\mathrm{n}=8$

Figure 7. a) Molecular structures of some typical cations and anions in ionic liquids used for LIB electrolytes: 1-butyl-1-methyl-pyrrolidinium [BMP] (top right), 1-ethyl-3-methyl-imidazolium [BMI] (top left), bis(trifluoromethane)sulfonimide [TFSI] (low left), and bis(fluorosulfonyl) imide [FSI] (low right); gray, dark yellow, orange, blue, and green balls represent carbon, sulfur, oxygen, nitrogen, and fluorine atoms, respectively; for clarity, $\mathrm{H}$ atoms on the molecules are not shown; b) snapshots of simulated mesoscopic structure of 1-alkyl-3-methylimidazolium $\mathrm{PF}_{6}$ which shows the polar (red) and nonpolar domains (green), with carbon number of alkyl chain, $n$, of 2 (left), 4 (middle), and 8 (right). Adapted with permission. ${ }^{[263]}$ Copyright 2006, American Chemical Society.

(SAXS), XRD, NMR results. ${ }^{[88]}$ The anions can solvate the charge-bearing cation head via Coulombic attraction to form interconnected ionic domains (also termed as polar network, or ionic channel) ${ }^{[88]}$ and the alkyl chains on the cation are oriented outward forming nonpolar domains separating adjacent ionic domains, a bit similar to micelles. ${ }^{[262]}$ It is proposed that the nonpolar domains formed by short alkyl chains (with less than 4 carbon) are isolated small, globular "islands" within the polar network, while the nonpolar domains formed by long alkyl chain form an interconnected nanostructure (Figure 7b). ${ }^{[263]}$

ILs can dissolve lithium salts with the same anion or different anion as themselves up to several mol $\mathrm{L}^{-1} \cdot{ }^{[264]}$ The structure of the ILE is lesser studied as compared to ILs. ${ }^{[264]}$ Theoretical calculation showed that for many ILEs, $\mathrm{Li}^{+}$ions are solvated by two anions forming $\left[\operatorname{Li}(\text { anion })_{2}\right]^{-}$when the molar ratio of the lithium salt to IL is low $(\approx 0.2) \cdot{ }^{[265]}$ The solvation of $\mathrm{Li}^{+}$was also experimentally observed by spectroscopic techniques such as NMR, ${ }^{[266,267]}$ Fourier-transform infrared spectroscopy (FTIR), ${ }^{[268]}$ and Raman. ${ }^{[269]}$ For example, using Raman spectroscopy and density function theory calculations, Lassegues et al. ${ }^{[69]}$ reported that lithium ions in Li[TFSI] spiked ionic liquids based on dialkylimidazolium cations and [TFSI] were solvated by 4 oxygens from two anions when lithium salt to IL ratio was $0.08-0.2$. The authors also showed that the solvation number of $\mathrm{Li}^{+}$was less than two when the lithium salt to IL ratio is high $(>0.2)$. In ILE, it was proposed that the $\mathrm{Li}^{+}$ ions are located in the ionic domain of the IL structure, with an effect of increasing the size of the ionic domain. ${ }^{[88]}$

The conductivity of ILs follows the empirical Walden rule. ${ }^{[16,266,270,271]}$ According to this rule, the molar conductivity of ILs is inversely proportional to the viscosity of ILs. A socalled "hole theory" has been developed to account for such molar conductivity-viscosity behavior. ${ }^{[272]}$ This theory proposes that in ILs, ions are conducted through holes or voids bigger than themselves. The Walden rule is considered to also hold for the ILE. The conductivity of the ILE can be described as following ${ }^{[16]}$

$\sigma=\sum \frac{q^{2} c_{i}}{6 \pi r_{i} \eta}$

where $\mathrm{q}$ is the charge of ions in Coulomb, $c_{i}$ is the charge carrier concentration, $r_{i}$ is the effective radius of the ion, and $\eta$ is the viscosity of the ILE which relates to the intermolecular forces in 


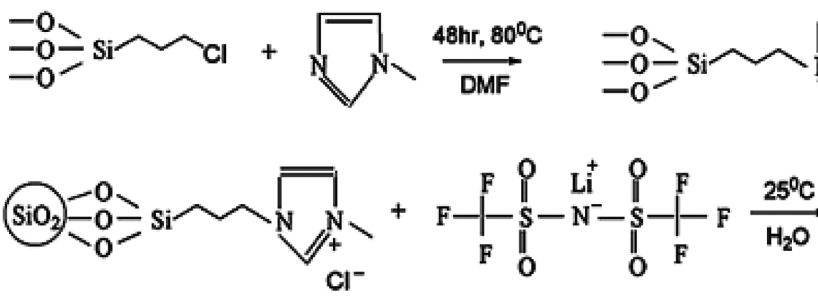

IL-particles

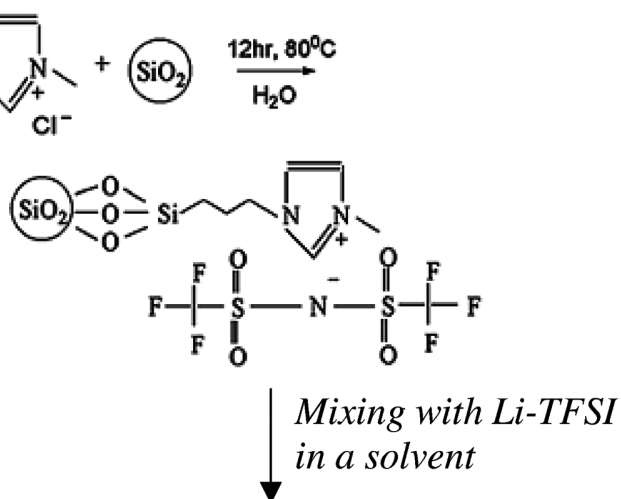

\section{Evaporation}

of the solvent

\section{ILE-SCE}

Figure 8. Schematic of tethering an IL to silica particles to synthesize an ILE-SCE. Reprinted with permission. ${ }^{[279]}$ Copyright 2012 , Royal Society of Chemistry.

the ILE. The temperature dependence of the ILE conductivity follows the Vogel-Tammann-Fulcher (VTF) behavior. ${ }^{[273,274]}$

\subsection{Preparation of ILE-SCES}

A solid composite electrolyte based on ionic liquid electrolytes (ILE-SCE) is made up of an ionic liquid, a lithium salt, an inorganic matrix, typically an oxide, and optionally some additives such as polymers. The synthesis of ILE-SCEs can be categorized into three classes. In the first approach, called "direct mixing" in the following text, an ILE and matrix particles are mechanically mixed by, e.g., ball milling. ${ }^{[275-277]}$ The second method involves covalently tethering an IL to the surface of the particles to form IL-tethered particles, to which a lithium salt is added. ${ }^{[278]}$ This tethering is typically carried out using reactions between ILs and functional groups on the particle surface, such as condensation between $-\mathrm{NH}_{2}$ or $-\mathrm{OH}$ and carboxylic acid, silanization between trimethoxysilyl- and - $\mathrm{OH}$, and complexation between thiol group and transitional metals, all of which have been extensively applied to surface modification of materials. Figure 8 shows a classic multistep tethering process developed by Archer and co-workers, where an IL is tethered to silica. ${ }^{[279]}$ In the first step, an ionic liquid with a chloride anion and a cation containing a trimethoxysilyl group is synthesized by alkylation of the cation, a typical approach used to synthesize ILs. ${ }^{[20]}$ Then, this ionic liquid containing the trimethoxysilyl group is tethered to $-\mathrm{OH}$ terminated silica, forming IL-particle composites.

Note: numbers with $\mathrm{M}$ in the round brackets denote the concentration of the lithium salt in the ILE in morality or molar ratio. $\mathrm{M}$ stands for $\mathrm{mol} \mathrm{L} \mathrm{L}^{-1}$, e.g., $0.5 \mathrm{~m}$ in the first row means $0.5 \mathrm{~mol} \mathrm{~L}^{-1}$. Pure numbers in the round brackets are the molar ratio between the lithium salt and ionic liquid in ILE, e.g., "0.1" in the second row means the ratio between the numbers of lithium salt and ionic liquid is $1: 10 . \mathrm{Fc}^{+} / \mathrm{Fc}$ stands for ferrocene redox couple. The working electrodes used to determine the electrochemical window are listed in the column.
Afterward, the chloride ion in the IL-particles is replaced by a desired anion $\mathrm{X}^{-}$by metathesis reaction between the ionic liquid and a LiX (Li-TFSI for the example in Figure 8). Finally, the IL-particles with the $\mathrm{X}$ anion are then mixed with LiX in a solvent, e.g., acetone, to increase the Li-salt concentration after evaporation by which, the final ILE-SCE is synthesized. As such, ILE-SCEs with an imidazolium $^{[290]}$ or piperidinium ${ }^{[291]}$ cation tethered to $\mathrm{SiO}_{2}$ or $\mathrm{ZrO}_{2}$ have been reported. [278] These ILESCEs showed enhanced $\mathrm{Li}^{+}$transference number as compared to the ILE reference. ${ }^{[278,292,293]}$ So far, only ILE-SCEs with cation tethered to particles have been reported, although methods for bonding anions to solid surfaces are also known. ${ }^{[294,295]}$

The final preparation method for ILE-SCE which will be described here is one which is started from a homogenous liquid mixture, i.e., without the addition of solid particle fraction as in the methods above. In this case, an ionic liquid electrolyte is added to a sol-gel solution for the synthesis of the oxide matrix. In this method, the ILE and matrix form a composite in an "in situ" manner: the precursors in the solution react to form a continuous matrix encapsulating the ILE in the process. Hence, the IL may act as a template. Indeed, under certain synthesis conditions, the prepared ILE-SCE can be in the form of a monolith with the ILE embedded in a continuous nanoporous inorganic oxide network. So far, mostly silica based ILE-SCEs have been prepared in this way. Most reported sol-gel formulations contain an ILE, an alkyl-silicate such as TEOS as silica precursor, and formic acid as reactant and solvent. ${ }^{[296,297]}$ According to a proposed mechanism ${ }^{[298]}$ for this sol-gel process, silica is mainly produced by the reaction between TEOS and the formic acid, although water is generated during the sol-gel process, which could also react with TEOS to form silica. Besides these formic acid based "nonaqueous" mixtures, aqueous sol-gel formulations with $\mathrm{HCl}$ as catalyst and $\mathrm{H}_{2} \mathrm{O}$ as reactant have also been described, however, for the synthesis of a composite with only the IL and silica. ${ }^{[299,300]}$ Such solutions typically contains an IL, an alkylsilicate, $\mathrm{H}_{2} \mathrm{O}, \mathrm{HCl}$, and optionally an alcohol as a solvent. ${ }^{[301,302]}$ In these solutions, 


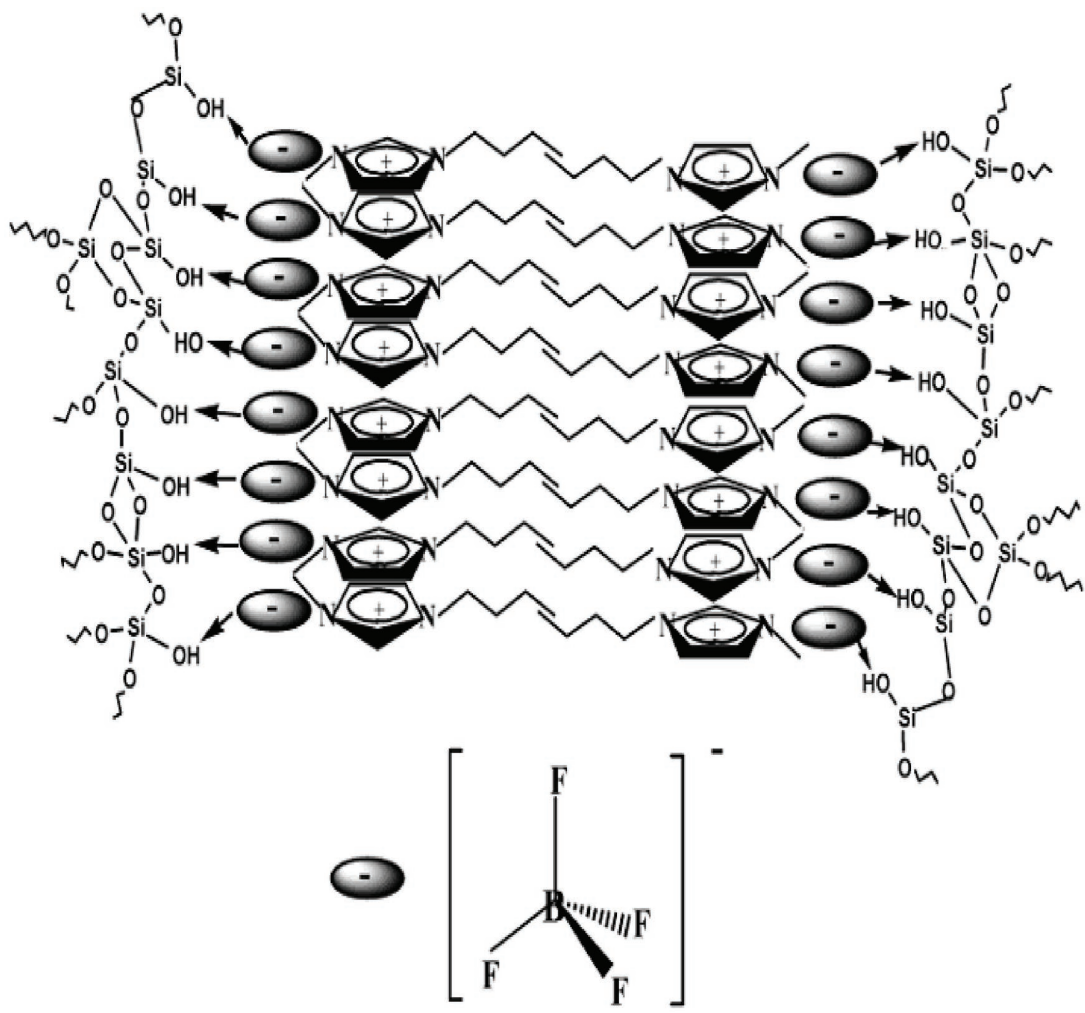

Figure 9. A proposed micelle formation mechanism for [ $\mathrm{BMI}^{\mathrm{B}} \mathrm{BF}$ ionic liquid in a sol-gel solution for mesoporous silica. Reprinted with permission. ${ }^{[300]}$ Copyright 2004, American Chemical Society.

the IL was proposed to form micelles ${ }^{[300]}$ which can then act as a template (see Section 2.3). It was postulated that the anion formed hydrogen bonds with the silica surface and interacted with the cation on its other side pointing toward the solution. The cations were stacked together by $\pi-\pi$ interactions between the imidazolium rings. As such, an elongated "micelle-like" structure formed guiding the growth of the silica matrix nanoporous structure (Figure 9). ${ }^{[300]}$

Table 10 summarizes the reported ILE-SCEs with particles by direct mixing, chemically tethered particles and sol-gel monoliths. The ILE-SCEs have conductivities up to $10 \mathrm{mS} \mathrm{cm}$, orders of magnitude higher than that of solid composites with only particles and a lithium salt, demonstrating the effect of the "solvent-like surface" on the conductivity. Among the ILE-SCEs prepared from the three methods, the sol-gel derived ones show the highest conductivities, proving the advantage of using a porous matrix for the conductivity as it was also the case for polymer composite (see Section 3.2). However, the conductivity of the ILE-SCEs is typically lower than that of the ILE reference, although some ILE-SCEs with conductivity exceeding that of ILE reference have been reported very recently. ${ }^{[51,86,87,303]}$

\subsection{Interface of ILE-SCES}

At the interface of the ILE-SCEs, ILE molecules generally exist as a layered phase different from the bulk due to interface interactions between the ILE and the particle surface. ${ }^{[8,316]}$
The interactions can include Coulombic interactions, ion-dipole interactions, van der Waals interactions, hydrogen bonding, covalent bonding (as in the case of tethered ILESCEs), and so-called steric interaction due to the increased entropy generated during the rearrangement of the molecules. ${ }^{[317]}$ In general, IL molecules are layered in the direction perpendicular to the interface, but still distributed randomly in domains along the interface. ${ }^{[88]}$ As a consequence of the change in the molecular arrangement, ionic liquids at the interface can have different physicochemical properties as compared to their bulk phases. For example, [EMI][TFSI] confined in $1 \mathrm{~nm}$ pores, which is about the size of the IL molecule, showed increased electrical double layer capacity. ${ }^{[318,319]}$ This confined [EMI][TFSI] was proposed to be in a superionic state. ${ }^{[320]}$ As for the SCE with solid-solid interface, the interface of the ILE-SCE has been typically investigated using a planar model, i.e., an ILE thin-film deposited on a planar matrix substrate. So far, most literature focuses on ionic liquid films on planar substrates, but models of ILE film/planar substrate have rarely been investigated. However, research on ionic liquid film/planar substrate models can still shed light on the understanding of the ILE-SCE interface. An ionic liquid film/substrate model is typically prepared by drop-casting a solution containing an ionic liquid and a volatile solvent such as methanol on a substrate. ${ }^{[321]}$ However, it is noted that deposition of a continuous thin-film IL could be difficult due to strong cohesion in the liquid which easily can result in dewetting of the surface. In the following, physicochemical properties of the IL at the interface of IL film/ substrate model, and the used characterization techniques are summarized and discussed.

Direct observation of the layered structure at the ionic liquid/ solid interface can be realized by atomic force microscopy (AFM). ${ }^{[322]}$ For example, Yokota et al. ${ }^{[322]}$ detected a single layer of 1-butyl-3-methylimidazolium bis(trifluoromethylsulfonyl) imide ([BMI][TFSI]), with a thickness of $0.81 \mathrm{~nm}$, on highly oriented pyrolytic graphite, which agreed well with the thickness of a IL monolayer calculated using density data. Also with AFM, Liu et al. ${ }^{[321]}$ observed the coexistence of a liquid and solid phase in a 1-butyl-3-methylimidazolium hexafluoro-phosphate ([BMI] $\left.\left[\mathrm{PF}_{6}\right]\right)$ film on mica. Basically, they observed that the adsorbed ionic liquid molecules seemed to follow the mica crystal structure similar to epitaxial growth. Indeed, Figure 10 shows that the arrangement of this "solid-like" ionic liquid layer matches well with the mica lattice.

The ordering of the interface layer can be characterized with XRR. ${ }^{[323]}$ For example, Mezger et al. ${ }^{[324]}$ observed a $\approx 5-6$ layer thick interface layer between 1-butyl-1-methylpyrrolidinium tris(pentafluoroethyl) trifluorophosphate ionic liquid film and a sapphire substrate. By fitting the electron density data, the authors claimed that the first layer directly on top of 
Table 10. Reported ILE-SCEs for lithium ion batteries. [DEME][TFSI]: $N, N$-diethyl- $N$-methyl- $N$-(2-methoxyethyl)ammonium bis (trifluoromethylsulfonyl) imide; [HMI][TFSI] 1-hexyl-3-methyl imidazolium bis(trifluoromethylsulfonyl)imide; [MMI][TFSI]: 1-methyl-3-methylimidazolium bis (trifluoromethylsulfonyl)imide; [MPPp][TFSI]: 1-methyl-1-propylpiperidinium bis (trifluoromethylsulfonyl)imide; [PMI][TFSI]: 1-propyl-3-methylimidazolium bis(trifluoromethylsulfonyl)imide; [PYR1201][TFSI]: N-methoxyethyl-N-methyl-pyrrolidinium bis (trifluoromethylsulfonyl)imide; PVdF-HFP: poly(vinylidene fluoride-hexafluoropropylene).

\begin{tabular}{|c|c|c|c|c|c|c|}
\hline Ionic liquid electrolyte ${ }^{\text {a) }}$ & Particle properties ${ }^{\text {b) }}$ & Preparationc) & $\begin{array}{c}\sigma \text { of the ILE-SCEd) } \\
{\left[\mathrm{S} \mathrm{cm}^{-1}\right]}\end{array}$ & $\begin{array}{c}\sigma \text { of the ILE ref. } \\
{\left[\mathrm{S} \mathrm{cm}^{-1}\right]}\end{array}$ & Cell studies ${ }^{\mathrm{e}}$ & Ref. \\
\hline [EMI][TFSI] & $\mathrm{SiO}_{2}, 12 \mathrm{~nm},-\mathrm{OH}$ & Direct mixing & $<10^{-2}(5 \mathrm{wt} \%)$ & $10^{-2}$ & - & [276] \\
\hline 1 м Li[FSI]/[EMI][TFSI] & $\mathrm{SiO}_{2}, 54.8 \mathrm{~m}^{2} \mathrm{~g}^{-1}$ & Direct mixing & $2 \times 10^{-3}(50$ vol\%) & $9 \times 10^{-3}$ & - & [304] \\
\hline 1 м Li[FSI]/[EMI][TFSI] & $\mathrm{Al}_{2} \mathrm{O}_{3}, 13 \mathrm{~m}^{2} \mathrm{~g}^{-1}$ & Direct mixing & $5 \times 10^{-3}(50$ vol $\%)$ & $9 \times 10^{-3}$ & - & [304] \\
\hline 1 м Li[FSI]/[EMI][TFSI] & $\mathrm{TiO}_{2}$ anatase, $49.2 \mathrm{~m}^{2} \mathrm{~g}^{-1}$ & Direct mixing & $1 \times 10^{-3}(40$ vol $\%)$ & $9 \times 10^{-3}$ & - & [304] \\
\hline 1 м Li[FSI]/[EMI][TFSI] & $\mathrm{TiO}_{2}$ rutile, $49.1 \mathrm{~m}^{2} \mathrm{~g}^{-1}$ & Direct mixing & $1 \times 10^{-3}$ (40 vol\%) & $9 \times 10^{-3}$ & - & [304] \\
\hline 1 м Li[FSI]/[EMI][TFSI] & $3 Y S Z, 17.0 \mathrm{~m}^{2} \mathrm{~g}^{-1}$ & Direct mixing & $7 \times 10^{-3}(50$ vol $\%)$ & $9 \times 10^{-3}$ & - & [304] \\
\hline $0.3 \mathrm{~mol} \mathrm{~kg}^{-1}$ Li[TFSI]/[EMI][FSI] & $0.75 \mathrm{Li}_{2} \mathrm{~S}-0.25 \mathrm{P}_{2} \mathrm{~S}_{5}, \mu \mathrm{m}$ sized & Direct mixing & $1 \times 10^{-3}(90 \mathrm{~mol} \%)$ & - & - & [305] \\
\hline 1 м Li[TFSI]/[EMI][TFSI] & $\mathrm{SiO}_{2}, 10 \mathrm{~nm}$ & Direct mixing & - & - & $\begin{array}{c}\mathrm{Li} / \mathrm{SCE} / \mathrm{LCO} 120 \mathrm{mAh} \mathrm{g}^{-1} @ \\
0.1 \mathrm{C}, 65^{\circ} \mathrm{C}\end{array}$ & [306] \\
\hline 1 м Li[TFSI]/[DEME][TFSI] & $\mathrm{SiO}_{2}, 7 \mathrm{~nm}$ & Direct mixing & $7 \times 10^{-4}(25$ vol\%) & $1 \times 10^{-3}$ & $\begin{array}{c}\mathrm{Li} / \mathrm{SCE} / \mathrm{LCO} 130 \mathrm{mAh} \mathrm{g}^{-1} @ \\
0.1 \mathrm{C} \text { rate, } 35^{\circ} \mathrm{C}\end{array}$ & [307] \\
\hline Li[TFSI]/[MPPp][TFSI] & $\mathrm{SiO}_{2}, 7 \mathrm{~nm}$ & Direct mixing & $5 \times 10^{-4}(25$ vol\%) & $1 \times 10^{-3}$ & - & [307] \\
\hline 50 mol\% Li[TFSI]/tetraglyme & $\mathrm{SiO}_{2}, 7 \mathrm{~nm}$ & Direct mixing & - & - & $\begin{array}{c}\text { Li/SCE/PAN-S, } \\
400 \mathrm{mAh} \mathrm{g}^{-1} @ 0.1 \mathrm{C}, 35^{\circ} \mathrm{C}\end{array}$ & [308] \\
\hline 1 м Li[TFSI]/[MMI][TFSI] & $\begin{array}{l}\text { Porous } \mathrm{SiO}_{2} \text {, pore size } 10 \mathrm{~nm} \text {, with various } \\
\text { surface groups; and } 80 \mathrm{~nm} \text { nonporous } \mathrm{SiO}_{2} \\
\text { with various surface groups }\end{array}$ & Direct mixing & - & - & - & [309] \\
\hline 1 m Li[TFSI]/[EMI][TFSI] & & & - & - & - & [309] \\
\hline 1 м Li[TFSI]/[PMI][TFSI] & & & - & - & - & [309] \\
\hline 1 м Li[TFSI]/[BMI][TFSI] & & & - & - & - & [309] \\
\hline 1 м Li[TFSI]/[HMI][TFSI] & & & - & - & - & [309] \\
\hline 1 м Li[TFSI]/[BMP][TFSI] & & & - & - & - & [309] \\
\hline $\begin{array}{l}0.6 \mathrm{~mol} \mathrm{~kg}^{-1} \mathrm{Li}[\mathrm{TFSI}] /[\mathrm{PYR} 1201] \\
\text { [TFSI] }\end{array}$ & $\begin{array}{l}\text { SBA-15, pore size 7-9 nm, } \\
550-600 \mathrm{~m}^{2} / \mathrm{g}\end{array}$ & Direct mixing & $\begin{array}{c}3 \times 10^{-4}(22 \mathrm{wt} \%) \\
\text { with } 2 \mathrm{wt} \% \text { of } \\
\text { PVdF-HFP }\end{array}$ & $1 \times 10^{-3}$ & $\begin{array}{c}\text { Li/SCE/LFP } \\
150 \mathrm{mAh} \mathrm{g}^{-1} @ 0.1 \mathrm{C} \\
25^{\circ} \mathrm{C}\end{array}$ & [310] \\
\hline 1 м Li[TFSI]/[EMI][TFSI] & Silica, pore size $15 \mathrm{~nm}$ & Direct mixing & $1 \times 10^{-3}(50 w t \%)$ & $8 \times 10^{-3}$ & - & [311] \\
\hline 2 wt\% Li[TFSI]/[EMI][TFSI] & $\mathrm{TiO}_{2}, 70 \mathrm{~nm}$ & Direct mixing & $1 \times 10^{-3}(45 w t \%)$ & $2 \times 10^{-3}$ & $\begin{array}{c}\text { Li/SCE/LFP } \\
150 \mathrm{mAh} \mathrm{g}^{-1} @ 0.1 \mathrm{C} \\
\text { RT }\end{array}$ & [312] \\
\hline $\begin{array}{l}1 \text { m Li[TFSI]/1-undecyltrime- } \\
\text { thoxysilane-3-butyl } \\
\text { imidazolium [TSFI] }\end{array}$ & $\mathrm{ZrO}_{2}, 86 \pm 2 \mathrm{~nm}$ & Tethering & $10^{-5}(10 w t \%)$ & $10^{-3}$ & - & [278] \\
\hline $\begin{array}{l}\text { Li[TFSI]/ 1-methyl-3- } \\
\text { propylimidazolium[TFSI] }\end{array}$ & $\mathrm{SiO}_{2}, 7 \mathrm{~nm}$ & Tethering & $10^{-4}$ (86.6 wt\% LiTFSI) & $>10^{-3}$ & - & [279] \\
\hline $\begin{array}{l}\text { Li[TFSI]/1-methyl- 3-(propyl) } \\
\text { trimethoxysilane) piperidinium } \\
\text { [TFSI] }\end{array}$ & $\mathrm{SiO}_{2}, 10 \mathrm{~nm}$ & Tethering & $\begin{array}{l}6 \times 10^{-3}(11 \mathrm{wt} \%) \\
\text { with } 1 \mathrm{~m} \mathrm{Li}[\mathrm{TFSI}] / \mathrm{PC}\end{array}$ & $10^{-2}$ & $\begin{array}{c}\text { Li/SCE/LTO } \\
170 \mathrm{mAh} \mathrm{g}^{-1} @ 3 \mathrm{C}\end{array}$ & [291] \\
\hline $\begin{array}{l}\text { Li[TFSI]/1-butyl- 3-((propyl) } \\
\text { trimethoxysilane) piperidinium } \\
\text { [TFSI] }\end{array}$ & $\mathrm{SiO}_{2}, 52 \mathrm{~nm}$ & Tethering & $\begin{array}{c}1 \times 10^{-6}(0.16 \mathrm{mmol} \\
\left.\mathrm{IL} \mathrm{g}^{-1} \mathrm{SiO}_{2}\right)\end{array}$ & - & - & [293] \\
\hline $\begin{array}{l}0.6 \mathrm{~mol} \mathrm{~kg}{ }^{-1} \\
\text { Li[TFSI]/[PYR1201][TFSI] }\end{array}$ & Porous $\mathrm{SiO}_{2}$ & $\begin{array}{l}\text { Sol-gel } \\
\text { Formic acid }\end{array}$ & $6 \times 10^{-4}(30 w t \%)$ & - & $\begin{array}{c}\mathrm{Li} / \mathrm{SCE} / \mathrm{LFP} 150 \mathrm{mAh} \mathrm{g}^{-1} @ \\
0.2 \mathrm{C}, 25^{\circ} \mathrm{C}\end{array}$ & [313] \\
\hline (0.5) Li[TFSI]/(0.2)[BMI][BFF & Porous $\mathrm{SiO}_{2}$ & $\begin{array}{l}\text { Sol-gel } \\
\text { Formic acid }\end{array}$ & $5 \times 10^{-3}$ & - & - & [314] \\
\hline 1 м Li[TFSI]/[BMP][TFSI] & $\begin{array}{c}\text { Porous } \mathrm{SiO}_{2} \\
7 \mathrm{~nm} \text { pore, } 1078 \mathrm{~m}^{2} \mathrm{~g}^{-1}\end{array}$ & $\begin{array}{l}\text { Sol-gel } \\
\text { Formic acid }\end{array}$ & $\begin{array}{l}3 \times 10^{-4} \\
10 w t \%\end{array}$ & $1 \times 10^{-3}$ & $\begin{array}{c}\text { Li/SCE/LFP } 150 \mathrm{mAh} \mathrm{g} \mathrm{g}^{-1} @ \\
0.1 \mathrm{C} 25^{\circ} \mathrm{C}\end{array}$ & [297] \\
\hline
\end{tabular}


Table 10. Continued.

\begin{tabular}{|c|c|c|c|c|c|c|}
\hline Ionic liquid electrolyte ${ }^{\text {a) }}$ & Particle properties ${ }^{b)}$ & Preparation ${ }^{c}$ & $\begin{array}{c}\sigma \text { of the ILE-SCEd) } \\
{\left[\mathrm{S} \mathrm{cm}^{-1}\right]}\end{array}$ & $\begin{array}{c}\sigma \text { of the ILE ref. } \\
{\left[\mathrm{S} \mathrm{cm}^{-1}\right]}\end{array}$ & Cell studies ${ }^{\mathrm{e})}$ & Ref. \\
\hline (0.5) Li[TFSI]/ (0.2)[BMP][TFSI] & $\begin{array}{c}\text { Porous } \mathrm{SiO}_{2} \\
7 \mathrm{~nm} \text { pore, } 1078 \mathrm{~m}^{2} \mathrm{~g}^{-1}\end{array}$ & $\begin{array}{l}\text { Sol-gel } \\
\text { Formic acid }\end{array}$ & $\begin{array}{l}1.5 \times 10^{-3}(15 \mathrm{wt} \% \\
\text { PVDF-co-HEA) }\end{array}$ & $3 \times 10^{-3}$ & $\begin{array}{c}\text { Li/SCE/LFP } \\
140 \mathrm{mAh} \mathrm{g}{ }^{-1} @ \\
0.05 \mathrm{C}, 25{ }^{\circ} \mathrm{C}\end{array}$ & {$[296]$} \\
\hline (0.25) Li[TFSI]/(1)[BMI][TFSI] & $\begin{array}{c}\text { Porous } \mathrm{SiO}_{2} \\
12 \mathrm{~nm} \text { pore, } 860 \mathrm{~m}^{2} \mathrm{~g}^{-1}\end{array}$ & $\begin{array}{l}\text { Sol-gel } \\
\text { Formic acid }\end{array}$ & $\begin{array}{c}4 \times 10^{-3} \\
\text { 1:2 mol ratio of ILE } \\
\text { to } \mathrm{SiO}_{2}\end{array}$ & $5 \times 10^{-3}$ & $\begin{array}{c}\mathrm{MCMB} / \mathrm{SCE} / \mathrm{LFP} \\
150 \mathrm{mAh} \mathrm{g}^{-1} @ 0.1 \mathrm{C} \\
30^{\circ} \mathrm{C} \\
\mathrm{MCMB} / \mathrm{SCE} / \mathrm{LCO} \\
140 \mathrm{mAh} \mathrm{g}^{-1} @ 0.1 \mathrm{C}\end{array}$ & [315] \\
\hline (0.25) Li[TFSI]/(1)[BMI][TFSI] & $\begin{array}{c}\text { Porous } \mathrm{SiO}_{2} \\
12 \mathrm{~nm} \text { pore, } 860 \mathrm{~m}^{2} \mathrm{~g}^{-1}\end{array}$ & $\begin{array}{l}\text { Sol-gel } \\
\text { Formic acid }\end{array}$ & $\begin{array}{c}4 \times 10^{-3}, \text { (IL to silica } \\
\text { molar ratio } 0.5)\end{array}$ & $5 \times 10^{-3}$ & $\begin{array}{c}\mathrm{MCMB} / \mathrm{SCE} / \mathrm{LFP} \\
150 \mathrm{mAh} \mathrm{g}^{-1} @ 0.1 \mathrm{C}, 30^{\circ} \mathrm{C} \\
\mathrm{MCMB} / \mathrm{SCE} / \mathrm{LCO} \\
140 \mathrm{mAh} \mathrm{g}^{-1} @ 0.1 \mathrm{C}, 30^{\circ} \mathrm{C} \\
\mathrm{MCMB} \mathrm{SCE} / \\
\mathrm{LiNi}_{1 / 3} \mathrm{Co}_{1 / 3} \mathrm{Mn}_{1 / 3} \mathrm{O}_{2} \\
140 \mathrm{mAh} \mathrm{g}^{-1} @ 0.1 \mathrm{C}, 30^{\circ} \mathrm{C}\end{array}$ & [315] \\
\hline (0.6 M) Li[TFSI]/[Py13][T-FSI] & Silica, surface group glycidyloxypropyl & $\begin{array}{l}\text { Sol-gel } \\
\text { Formic acid }\end{array}$ & $\begin{array}{c}1.9 \times 10^{-3} \text { (IL to silica } \\
\text { molar ratio } 0.75)\end{array}$ & $<1.9 \times 10^{-3}$ & $\begin{array}{c}\text { Li/SCE/LFP } \\
155 \text { mAh g }{ }^{-1} @ 0.1 \mathrm{C}, 30{ }^{\circ} \mathrm{C} \\
\text { Li/SCE } / \text { LTO } \\
150 \mathrm{mAh} \mathrm{g}^{-1} @ 0.1 \mathrm{C}, 30{ }^{\circ} \mathrm{C}\end{array}$ & [303] \\
\hline (0.34) Li[TFSI]/[BMP][T-FSI] & Porous silica & $\begin{array}{c}\text { Sol-gel } \\
\mathrm{Li}^{+}\end{array}$ & $\begin{array}{c}1 \times 10^{-3} \text { (IL to silica } \\
\text { molar ratio } 10.5)\end{array}$ & $6 \times 10^{-4}$ & - & [51] \\
\hline
\end{tabular}

a) Numbers with $\mathrm{M}$ in the round brackets label the concentration of lithium salt in the ILE in morality or molar ratio. $\mathrm{M}$ stands for mol $\mathrm{L}^{-1}$. Pure numbers in the brackets are the molar ratio between the lithium salt and the ionic liquid; b) The listed properties of the particles include the particles size, the pore size, the surface area, and the surface groups; ${ }^{c}$ In the sol-gel method, the solvent and the catalyst are mentioned; d) In the conductivity column, the ratio of the particles in the ILE-SCE is listed ether in weight percent (wt\%) or in volume percent (vol\%), unless otherwise noted; e) The capacity, rate, and the temperature of the charge-discharge test are listed.

the sapphire consists of cations upon which an anion layer is stacked, and as such some 5-6 cation/anion layers alternatively stacked at the interface (Figure 11).

The orientation of the ionic liquid molecules and the interacting functional groups at the interface can be revealed using sum frequency generation spectroscopy (SFG) which can detect the strong nonlinear optical signal (sum frequency) of the vibration of the groups at the very interface, where noninverse symmetry exists. ${ }^{[325]}$ For example, Baldelli ${ }^{[326,327]}$ extracted a thickness of $0.33 \mathrm{~nm}$ for the interface layer at the 1-butyl-3-methylimidazolium tetrafluoroborate $\left([\mathrm{BMI}]\left[\mathrm{BF}_{4}\right]\right)$ film/Pt stack, in accordance with the thickness calculated using impedance spectra. The authors managed to quantify the change in the orientation of the cation on the substrate from $60^{\circ}$ to $35^{\circ}$ when they applied different potentials on the underlying substrate. With SFG, they observed the interaction between $-\mathrm{SiOH}$ groups on $\mathrm{SiO}_{2}$ surface and the imidazolium of the IL from the change in vibration of the $-\mathrm{CH}$ on the ring $\left(3150-3180 \mathrm{~cm}^{-1}\right)$.

The fluid dynamics of the interface can be revealed by surface force apparatus (SFA). ${ }^{[328]}$ In the measurement using SFA, the ionic liquid is confined between two atomically flat substrates, and the thickness of the ionic liquid layers is determined by means of multiple beam interferometry with fast spectral correction. The force perpendicularly applied to the opposing substrates is recorded as a function of the thickness of the IL, and a measure of the rigidity of the IL layer. The viscosity of the ionic liquid can be determined from the shearing of the ionic liquid induced between the two parallel substrate plates of the apparatus. With SFA, Bou-Malham and Bureau ${ }^{[329]}$ postulated that two imidazolium-based ionic liquids, $[\mathrm{BMI}]\left[\mathrm{BF}_{4}\right]$ and $[\mathrm{BMI}]$ $\left[\mathrm{PF}_{6}\right]$, exhibited molecular layering when they were confined between charge-bearing mica surfaces. Such layering dramatically affected the fluid dynamics of the ILs. As the confinement increased from 20 to $5 \mathrm{~nm}$, the viscosity of the ILs increased over several orders of magnitude until the ILs were eventually immobilized and exhibited a solid-like response. In strong contrast, the same ILs confined between noncharged methyl-terminated surfaces displayed no such layering and displayed fluidic properties with similar viscosity as the bulk IL when confined even down to two monolayers thick $(<2 \mathrm{~nm})$.

In summary, techniques such as AFM, XRR, SFG, and SFA have been used to characterize the interface of IL/substrate model stacks. Ionic liquid molecules show a clear tendency to order at the interface with a solid surface. The molecular ordering can extend up to several monolayers thick. The surface interaction can strongly affect the fluidity of the IL even to the solid phase. The characterization and interpretation of the IL/solid interfaces of particle-based ILE-SCEs are far from straight forward, as these many nonplanar interfaces are spatially oriented in all directions. However, some techniques can still provide indirect information about the interface interactions and structure as discussed below.

An indication for the existence of an interface structure can be found from a change in the phase transition behavior of the IL which is typically characterized using DSC. ILs can experience phase transitions such as glass transition, crystallization, and melting as the temperature is changed. ${ }^{[330]}$ For example, melting and crystallization of ILs confined in a porous matrix 
(a)
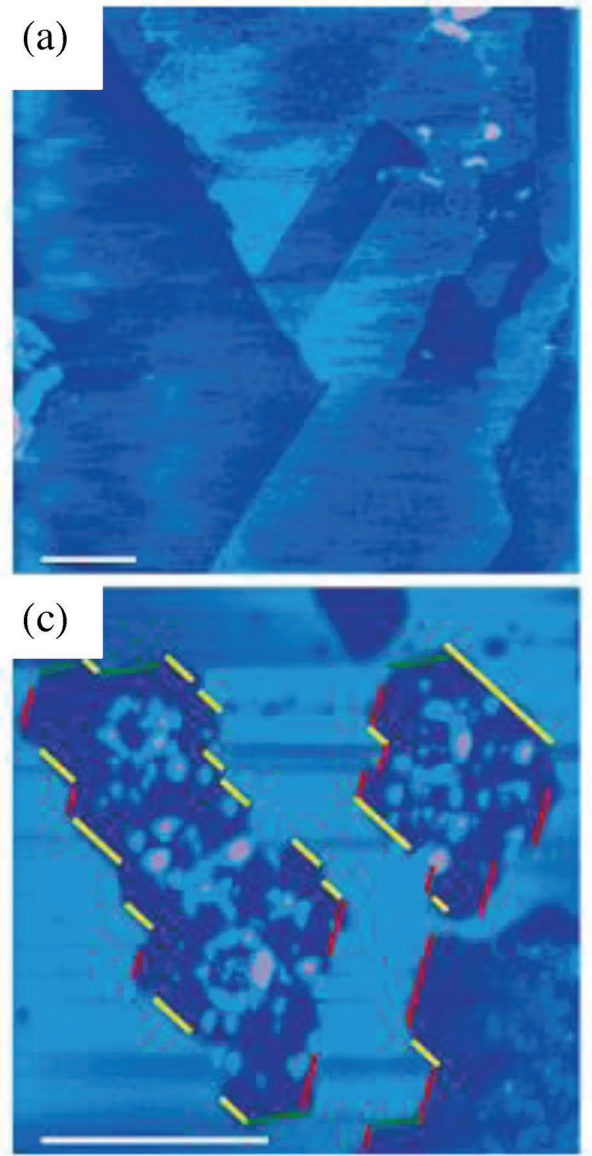

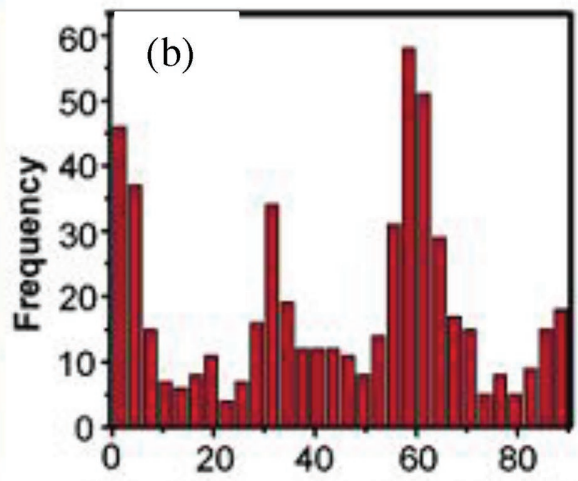

Angle between edges (degree)

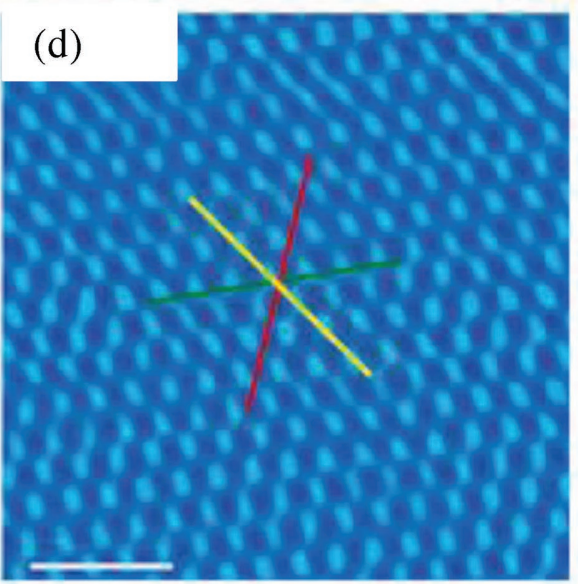

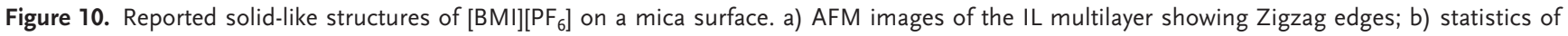
the angles between zigzag edges and a randomly selected edge in AFM images; $c, d$ ) the edges of the solid-like IL structures which match well with the mica lattice; the bars are $500 \mathrm{~nm}$ in (a) and (c) and $2 \mathrm{~nm}$ in (d). Reprinted with permission. ${ }^{[321]}$ Copyright 2006, American Chemical Society.

can disappear, as Néouze et al. observed for [BMI][TFSI] confined in silica with 12 and $5 \mathrm{~nm}$ pores. ${ }^{[90,331]}$ The explanation for this phenomenon has not been given yet but the ionic compound seems to be in a state between liquid and solid, i.e., in a mesophase state. The change of the phase behaviors of ILs is similar to that of confined $\mathrm{H}_{2} \mathrm{O} \cdot{ }^{[332]}$ For example, a $0.35 \mathrm{~nm}$ water layer in porous MCM-41 ${ }^{[333]}$ (pore size $\approx 5 \mathrm{~nm}$ ) was found to be nonfreezing, i.e., similar as for the confined IL above. The authors suggested that the size of the pores might be too small for the nucleation of the solid phase. However, it may be also related to fact that water strongly adsorbs on $\mathrm{Si}-\mathrm{OH}$ terminated silica forming solid or so-called ice layers. Indeed, based on FTIR results, it is observed that $\mathrm{H}_{2} \mathrm{O}$ layers adsorbed on silica film terminated with silanol groups are in different states. ${ }^{[334]}$ As those in solid state, $\mathrm{H}_{2} \mathrm{O}$ molecules in the first layers at the $\mathrm{H}_{2} \mathrm{O}$ /silica interface are on average bonded by 4 hydrogen bonds; while $\mathrm{H}_{2} \mathrm{O}$ molecules in the layers above these solid layers are bonded by about 2.5 hydrogen bonds, as water in its liquid state. In addition, the structure of the adsorbed interface layer is thought to be different from both its liquid and solid $\mathrm{H}_{2} \mathrm{O}$ counterpart in bulk form. For example, it was found that the $\mathrm{H}_{2} \mathrm{O}$ confined in a hydrophilic glass with $5 \mathrm{~nm}$ pores was in the cubic phase rather than the hexagonal bulk phase at low temperature. ${ }^{[335]}$
The change of the melting point of the confined liquid can be predicted by Equation (34) as ${ }^{[90]}$

$\frac{T_{\mathrm{m}}^{\prime}-T_{\mathrm{m}}}{T_{\mathrm{m}}}=-\frac{2\left(\gamma_{\mathrm{p} / \mathrm{s}}-\gamma_{\mathrm{p} / 1}\right) V_{\mathrm{m}}}{\mathrm{d} \lambda_{\mathrm{f}}}$

where $T_{m}^{\prime}$ is the melting point of the confined liquid; $T_{m}$ is the melting point of the bulk liquid; $\gamma_{\mathrm{p} / \mathrm{s}}$ is the pore/solid interface energy; $\gamma_{\mathrm{p} / \mathrm{l}}$ is the pore/liquid interface energy; $V_{\mathrm{m}}$ is the molar volume of the liquid; $d$ is the size of the pore; and $\lambda_{\mathrm{f}}$ is the latent heat of melting. According to Equation (34), the change in the melting point is expected to be larger for smaller pore sizes, which was indeed experimentally observed. ${ }^{[31]}$ Moreover, it was suggested that an increase in the melting temperature indicates an attractive interface interaction, while depression of the melting point means a repulsive interface interaction. Besides the melting point, the glass transition temperature, $T_{\mathrm{g}}$, of the ionic liquid, which relates to its viscosity, has been reported to increase when the ionic liquid was confined. ${ }^{89,336]}$

The decomposition temperature, which indicates the thermal stability of the ionic liquid, can also be affected by the interface interaction. For example, it was observed that the decomposition temperature of the $[\mathrm{BMI}]\left[\mathrm{PF}_{6}\right]$ decreased by $80{ }^{\circ} \mathrm{C}$ when the IL was confined in a nonthermal conducting porous silica with 
(a)

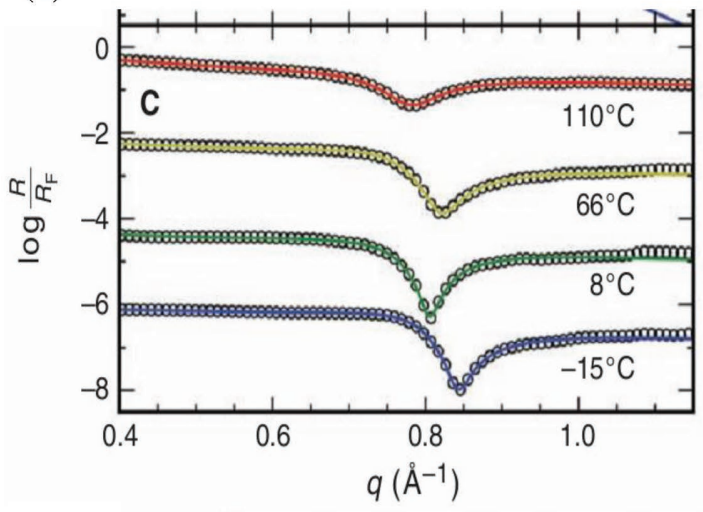

(b)

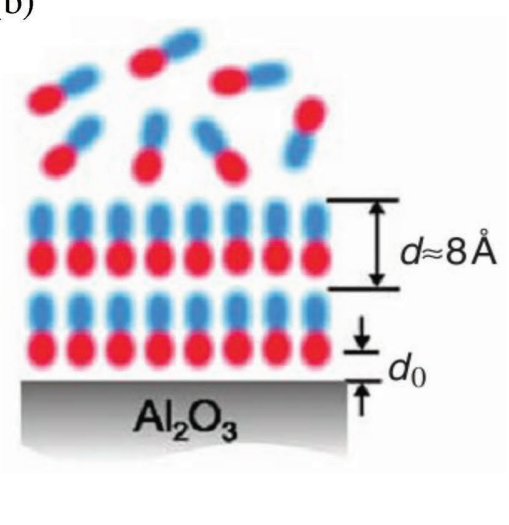

(c)

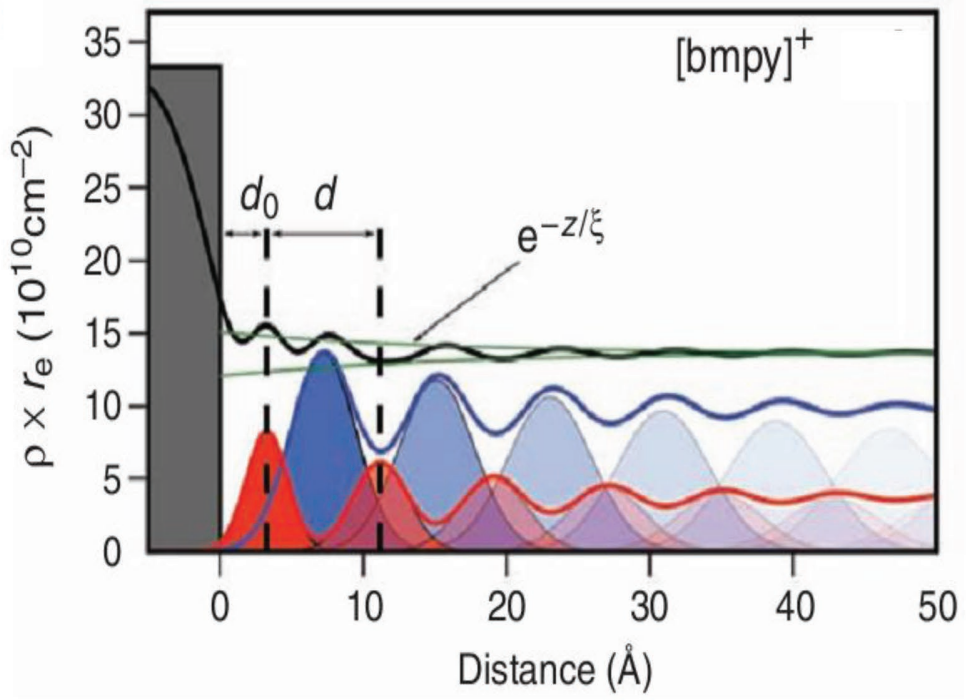

Figure 11. Reported XRR characterization of the 1-butyl-1-methylpyrrolidinium tris (pentafluoroethyl)-trifluorophosphate ionic liquid layer on $\mathrm{Al}_{2} \mathrm{O}_{3}$; a) normalized reflectivities (symbols) together with best fits at different temperatures; b) the layering arrangements of the ionic liquid on $\mathrm{Al}_{2} \mathrm{O}_{3}$ formulated from the data; c) cation (red), anion (blue), and total (black) electron densities obtained from the fit; red and blue lines indicate cation and anion' Gaussian distributions contributing to the respective partial electron density profiles; and gray bar represents electron density of the sapphire substrate without roughness. Reprinted with permission. ${ }^{[324]}$ Copyright 2008, American Association for the Advancement of Science.

pore size less than $10 \mathrm{~nm} \cdot{ }^{[337]}$ The reason for this decrease is yet unclear. However, it has been found that also the mechanism of thermal decomposition of the ILs can change. For example, Singh et al. ${ }^{[338,339]}$ reported that ILs with a 1-butyl-3-methylimidazoulium cation confined in a silica matrix decomposed in more than one step, while the bulk IL counterparts decompose in only one step. For the confined IL, it was proposed that the aliphatic tail was removed from the adsorbed cation at lower temperature than the removal of the aromatic ring from the silica wall.

The functional groups engaging in the interaction and the strength of their interaction in the ILE-SCE can be determined using FTIR and Raman spectroscopy. The interaction can change the force constant of the vibration of the bonds in the functional groups, thus shifting the corresponding vibration peaks in the spectra to different wavenumbers. For example, the $\mathrm{C}-\mathrm{H}$ vibration peaks of the on imidazolium cation shift when the IL is confined in silica. ${ }^{[340,341]}$ For the anion, a shift of the vibration of the functional group is often observed due to hydrogen bonding with the $\mathrm{Si}-\mathrm{OH}$ on the silica pore surface. ${ }^{[336]}$ This indicates that both the cation and anion of the imidazolium ionic liquid can interact with the silica surface, and exist in the very first monolayers at the interface. These techniques are also very useful for monitoring the solvation of $\mathrm{Li}^{+}$in the ionic liquid, which could introduce new peaks or shift peak positions in the corresponding spectra. ${ }^{[342]}$

The effect of the interface on the ionic mobility in the ILESCEs can be evaluated with electrical impedance spectroscopy and NMR. As a general trend, the ion conductivity of the ILESCE composite is lower than that of the ILE bulk reference (Table 10). ILE-SCEs synthesized by direct-mixing have a moderate conductivity drop. For example, Uemo et al. ${ }^{[304]}$ systematically studied conductivities of particle ILE-SCEs with on average 1 to $20 \mathrm{~nm}$ ILE coatings thick layer around $\mathrm{SiO}_{2}$, $\mathrm{Al}_{2} \mathrm{O}_{3}, \mathrm{TiO}_{2}$, and $\mathrm{Y}_{2} \mathrm{O}_{3}$ stabilized $\mathrm{ZrO}_{2}$ nanoparticles (ILE $=1 \mathrm{M}$ Li[TFSI] in [EMI][TFSI]). The conductivities of these ILE-SCEs were typically one order of magnitude lower than that of the ILE reference. The diffusion coefficients of the ions determined from NMR were $20-70 \%$ of those of the ILE reference. The $\mathrm{Li}^{+}$transference numbers of the ILE-SCEs were similar to 


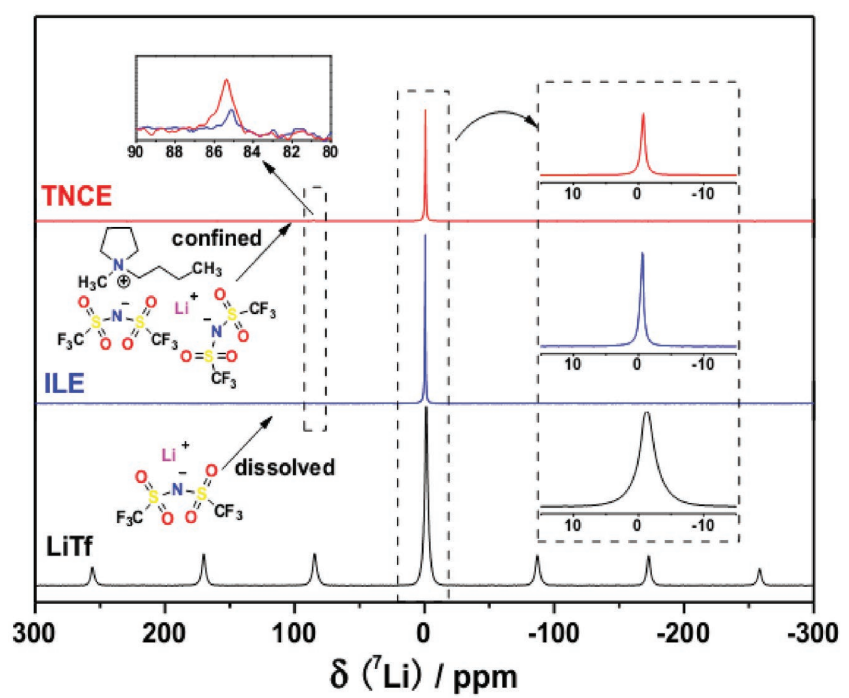

Figure 12. ${ }^{7} \mathrm{Li}$-magic angle spinning (MAS) NMR spectra of a sol-gel derived ILE-SCE consisting of Li[BMP][TFSI]_ILE and silica (red), of the ILE reference (blue), and of Li[TFSI] reference (black); $\mathrm{Li}^{+}$in the SCE shows liquid-like dynamic. Reprinted with permission. ${ }^{[297]}$ Copyright 2011 , John Wiley \& Sons.

that of the ILE references, while the [EMI] cation transference number of the ILE-SCEs increased due to the enhanced dissociation of the ion pairs. Krawczyk, ${ }^{[309]}$ in his thesis, investigated the conductivity of ILE-SCEs with Li[TFSI]/[BMP][TFSI] as the ILE and various functionalized $\mathrm{SiO}_{2}$ particles as the matrix. The surfaces of $80 \mathrm{~nm}$ solid $\mathrm{SiO}_{2}$ nanoparticle and also $50 \mu \mathrm{m}$ mesoporous $\mathrm{SiO}_{2}$ particles with $10 \mathrm{~nm}$ pores were functionalized with $-\mathrm{CH}_{3},-\mathrm{C}_{3} \mathrm{H}_{6}-\mathrm{NH}_{2}$, or $-\mathrm{C}_{3} \mathrm{H}_{6}-\mathrm{SO}_{3} \mathrm{Li}$ groups. All the SCEs showed lowered conductivities compared to the ionic liquid electrolyte reference. In this work, no conclusion on the effect of the surface group on the conductivity could be drawn due to the complexity of the interaction in the ILE-SCE systems, as the author explained.

The tethered ILE-SCEs show a conductivity drop typically larger than one order of magnitude, the largest drop for the three types of ILE-SCEs summarized in this work (Table 10). However, since the cation of the ionic liquid is covalently bonded to the particles, the $\mathrm{Li}^{+}$transference numbers of the SCEs are about $0.3-0.5$, significantly higher than those of the ILEs $(\approx 0.1)$. ${ }^{[278,279,291,292,312,343]}$

The ILE-SCEs synthesized by sol-gel methods have conductivities comparable to those of the ILEs but typically still somewhat lower. NMR results indicate that $\mathrm{Li}^{+}$ions in these sol-gel derived SCEs still have "liquid-like" mobility, as the $\mathrm{Li}^{+}$spectra of the ILE-SCEs and ILE reference gave ${ }^{7}$ Li peaks with similar width ${ }^{[297]}$ (Figure 12). Also, the activation energy of the $\mathrm{Li}^{+}$ mobility of the ILE-SCEs is comparable to that of the ILE reference. Interestingly, the activation energy for $\mathrm{Li}^{+}$diffusion in the ILE-SCE made by direct-mixing is also typically comparable to that of the ILE reference. This indicates that the high conductivity of the sol-gel derived ILE-SCE benefits very likely from the continuous conduction paths along the interconnected pores and silica in the porous matrix.

One of the key factors that influences the $\mathrm{Li}^{+}$ion conductivity in the ILE-SCE is the interface interaction. The interaction can change the solvation state of $\mathrm{Li}^{+}$and the association of the ionic liquid itself, thus changing the concentrations of the free charge carriers. Also, the activation energy of ion diffusion can change as a result of the molecular ordering at the interface. The interaction in the ILE-SCEs, however, can be even more complex as compared to that of the polymer-SCE (see Conclusion in Section 3.1). Unlike the polymer where the interactions are mainly attributed to van der Waals forces, the ionic liquid itself bears charges that can generate Coulombic and iondipole interactions with the matrix surface. Since most of the ILE-SCEs are particle based, the interpretation of the interface conduction is further complicated by the distribution of the particles and the associated ion percolation paths. Therefore, the conductivity models for the solid-solid particle SCE are not actually applicable for the ILE-SCE. Nevertheless, two reasonable models for the conductivity of the ILE-SCE have been considered. They are discussed in the following.

\subsection{Conductivity Models for ILE-SCEs}

So far, to the best of our knowledge, only a few papers ${ }^{[279,293,343]}$ have mentioned conductivity models for the ILE-SCE, yet the models have not been applied to analyze data. One of the models is the one proposed by Maier et al. ${ }^{[344]}$ to describe the so-called "soggy-sand electrolyte" which applies to composites with a solid phase, such as $\mathrm{SiO}_{2}$ particles and a salt dissolved in solvent, such as tetrahydrofuran (THF), i.e., a nonionic liquid electrolyte. In these electrolytes, the cation and anion are dissociated in the solvent to some extent (i.e., some ions may still exist as ion pairs, depending on the concentration of the salt). One type of ion is adsorbed on the surface of the particles, e.g., the anion is expected to be adsorbed on $\mathrm{SiO}_{2}$, and the counter ion accumulates next to the surface to form an electrical double layer. As such, the dissociation of the salt is promoted. The overall conductivity of the electrolyte is the sum of that of the interface and the bulk solution according to Equation (35) as ${ }^{[344]}$

$\sigma=\beta_{\mathrm{b}}\left(1-x_{\mathrm{v}}\right) \sigma_{\mathrm{b}}+\beta_{\text {in }} x_{\mathrm{v}, \text { in }}\left\langle\sigma_{\text {in }}\right\rangle$

where $\sigma$ is the overall conductivity; $\sigma_{\mathrm{b}}$ and $\sigma_{\text {in }}$ are the conductivities of the bulk electrolyte and interface, respectively; $\beta_{\mathrm{b}}$ and $\beta_{\text {in }}$, respectively, refer to the proportion of the bulk and the interface contribution; $x_{\mathrm{v}}$ and $x_{\mathrm{v}, \text { in }}$ are the volume fractions of the second phase and the effective fraction of the interface, respectively. The $\sigma_{\text {in }}$ is expressed as

$\sigma_{\text {in }}=2 \sigma_{\mathrm{b}} \frac{\Theta}{1-\Theta}$

where $\Theta$ is a measure of the strength of the ion adsorption on the oxide. With this expression, the conductivity of the electrolyte can be described by measurable parameters as

$\sigma=\beta_{\infty}\left(1-x_{\mathrm{v}}\right) \sigma_{\infty}+\beta_{\text {in }} x_{\mathrm{v}, \text { in }} u B \Sigma$

with $u$ the mobility of the ion, $B$ the surface to volume ratio of second phase particles, which is related to the BET surface area of the particles, and $\Sigma$ the charge density on the second 


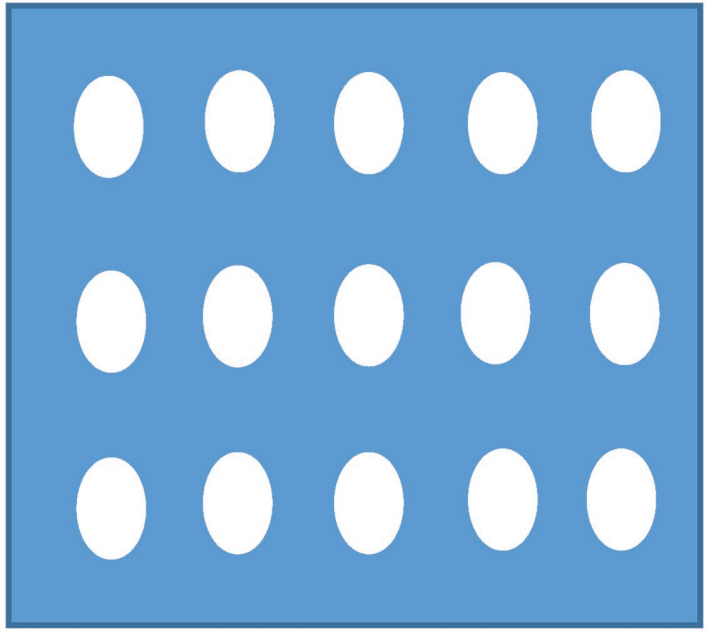

Figure 13. Schematic of a dispersion consisting of a second phase distributed in a liquid phase, used to explain the conductivity reduction in the Maxwell model.

phase particles, which can be extracted using the ion exchange capacity of the particles. The transference number, $t_{+}^{\prime}$, of cation in the electrolyte is then defined as ${ }^{[34]}$

$t_{+}^{\prime} \cong \frac{t_{+}+\left(\sigma-\sigma_{\infty}\right) / \sigma_{\infty}}{\left(\sigma-\sigma_{\infty}\right) / \sigma_{\infty}+1}$

with $t_{+}$the transference number of the cation in the bulk electrolyte.

This model has been applied to explain the conductivity enhancement and transference number of a $\mathrm{LiClO}_{4} / \mathrm{THF} / \mathrm{SiO}_{2}$ electrolyte. ${ }^{[345]}$

Applying this model to the ILE-SCE faces some issues. The model simplifies the conductivity by omitting the decrease of the counter ion conductivity at the interface, and the influence of this is not well estimated yet. As the ILE-SCEs are solely comprised of ions, the error caused by this simplification can be more problematic as compared to the soggy-sand electrolyte. Moreover, the contribution factor of the surface conduction, $\beta$, is arbitrary. Maier and co-workers found an empirically fitted value of 0.67 for $\beta .^{[344]}$

The other proposed model for describing the overall conductivity of the ILE-SCE is the Maxwell model, which is similar to the effective medium model ${ }^{[346]}$ for the solid-solid SCE. The model was used to describe the conductivity of a dispersion or composite where gas bubbles, or spherical solid particles are distributed in a conductive liquid phase (Figure 13), ${ }^{[347,348]}$ similar to the ILE-SCE where the ILE is mixed with a solid matrix. This model was based on early work by Maxwell[ ${ }^{[349]}$ to describe the electrical conductivity of a two-phase medium. Lemlich ${ }^{[350]}$ modified the model to describe the electrolytes where the liquid fraction, $1-x_{v}$, is either very large or very small $\left(1-x_{v} \rightarrow 1\right.$, or 0$)$. Feitosa et al. ${ }^{[351]}$ proposed an improved empirical equation to extend the application of the model to the whole liquid fraction range as

$\sigma=\frac{2\left(1-x_{\mathrm{v}}\right)\left(1+12\left(1-x_{\mathrm{v}}\right)\right)}{6+29\left(1-x_{\mathrm{v}}\right)-9\left(1-x_{\mathrm{v}}\right)^{2}}$ with $\sigma$ the conductivity of the composite normalized to that of the liquid reference. This extension enables the model to fit the conductivity of a dispersion with a second phase of different sizes and shapes. Basically, the model formulates the effect of volume occupation of the second phase in the dispersion on the conductivity of the dispersion, i.e., the volume reduction effect, with an assumption that no interface conduction is present at the interface. This model can fit a series of widely cited conductivity data sets. ${ }^{[351]}$ As can been seen in this figure, the normalized conductivity of the dispersion is less than 1 , which means the dispersion conductivity is lower than the corresponding liquid conductivity, demonstrating the volume reduction effect.

Comparing the measured normalized conductivity of ILESCE to the Maxwell model projected conductivity can tell whether interface conduction is present in the composite. Higher than Maxwell model predicted conductivities indicate the existence of interface conduction in the ILE-SCE, as conductivity enhancement at interface can counteract the conductivity drop caused by the volume reduction effect, resulting in higher than model projected conductivities of the dispersion.

\section{Conclusions and Outlook}

The development of solid composite electrolytes or SCEs consisting of an ionic conductor and a dielectric matrix offers an elegant strategy to enhance the ionic conductivity of electrolytes by engineering the interface conduction. At the conductor/ matrix interface, the ionic conductivity can be enhanced by the enriched charge carrier concentration and/or the changed molecular structure of the conductor. For nanomaterial composites where the matrix surface to volume ratio is larger, the enhanced interface conductivity could lead to higher ion conductivity for the composite than for the isolated ionic conductor by itself. For lithium ion conductive SCEs, the conductor can be an inorganic electrolyte, polymer electrolyte or ILE. With these types of electrolytes, particle inorganic-based SCEs (inorganic-SCE) with solid-solid interfaces, and polymer-based SCEs (polymer-SCE) as well as ILE-based SCEs (ILE-SCE) having solvent-like interfaces have been developed.

For inorganic-SCEs, the interface conduction mechanism has been investigated using layered conductor/matrix thin-film SCE models. In this way it was indeed shown that higher ion conductivity is obtained at oxide/Li-compound interfaces as compared to the bulk conductor. However, the interpretation of these observations was limited by the practical deposition of continuous films with sufficient thinness. Further investigation of the interface effect on the conductivity relies on advanced techniques for the fabrication of atomically flat layers such as ALD and MBE. Compared to the thin-film models, the inorganic-SCEs composed of particles have more complex ion conduction paths, as their interfaces are randomly distributed. However, despite the complexity, several conductivity models have been proposed for the description of the conductivity in particle-based SCEs. The main factors influencing the conductivity of the composite next to the bulk conductivity of the ionic conductor and the interface interactions giving rise to the interface enhancement are a high-volume fraction of interface (i.e., high surface to volume ratio) and low volume fraction of 
the matrix with a proper distribution of the conductor to matrix phases in order to optimize the ionic transport path in the SCEs.

Unlike the inorganic SCE with solid-solid interface, the polymer-SCE, and the ILE-SCE have "solvent-like" interfaces where the lithium ions are solvated as in a liquid. The "solvent-like" interface increases the conductivity of the composite by orders of magnitude compared to the inorganic SCE. In these two types of SCEs, the interface interaction is also vital for the ion conduction. For the polymer-SCE, it is proposed that besides the change of the structure of the polymer at the interface, which can improve the conductivity, Lewis acid-base interactions are present between the surface of the matrix particles, the polymer, and the lithium salt. The interaction can affect the solvation of $\mathrm{Li}^{+}$in the polymer, resulting in higher lithium concentration for conduction; and/or make $\mathrm{Li}^{+}$ions hopping between the polymer and the surface sites on the matrix particles, creating fast conduction paths. As a result, the conductivity and $\mathrm{Li}^{+}$transference number of the polymer-SCE can be tuned by engineering the surface properties, i.e., the acidity/basicity of the matrix particles.

To form solvent like interfaces for ILE-SCEs, different preparation methods have been developed, i.e., direct-mixing in which the ILE are mechanically mixed with particles; tethering where the cations of IL are chemically bonded to the particles, and sol-gel methods in which the ILE is added to the precursor solution for oxide particles. At the interface of the ILE-SCE, the ionic liquid molecule can rearrange to form layered structures, and this ordering has been revealed by techniques such as XRR, SFG, AFM, DSC, and FTIR. Effects of the surface polarity of particles and the chemistries of ionic liquid molecules on the conductivity of the ILE-SCE are not clear yet. Also, models need to be developed to describe the conductivity of the ILE-SCE.

With an effect of increasing the volumetric proportion of the interface in the SCE, using a nanoporous matrix for SCE can effectively enhance the conductivity of the SCE. Indeed, SCES containing nanoporous matrices have shown higher conductivities as compared to those SCEs with nonporous matrices. So far, conventional nanoporous materials with relatively low surface area $\left(\approx 1000 \mathrm{~m}^{2} \mathrm{~g}^{-1}\right)$, such as silica and alumina, are typically used for SCEs. Novel nanoporous materials with large surface area and easy-to-modify surface such as MOFs are encouraged to be used in the SCE. The porous matrices used for SCEs are typically microsized particles where $\mathrm{Li}^{+}$ions still need to hop between the particles. This means that the interface conduction thus the conductivity of the SCE can be compromised by the limited connectivity between the particles. A "perfect" porous matrix should have a porous network extending through the whole electrolyte, e.g., a porous monolith where the $\mathrm{Li}^{+}$ion can conduct in the entire electrolyte without interruption. This idea of having a monolith as matrix can be realized in the ILE-SCE prepared by the sol-gel method. Indeed, the sol-gel derived ILE-SCEs have shown conductivities higher than those of the ILE-SCEs prepared by direct-mixing and tethering, where the matrixes are solid or porous particles.

In summary, all types of SCEs, i.e., inorganic-SCE, polymerSCE, and ILE-SCE can show conductivity enhancement which can be further enlarged by using porous matrices. Among these SCEs, ILE-SCEs have the highest conductivity up to
$10^{-2} \mathrm{~S} \mathrm{~cm}^{-1}$, while inorganic-SCEs show lowest conductivity, typically below about $10^{-6} \mathrm{~S} \mathrm{~cm}^{-1}$. Besides improving the conductivity of these SCEs, applying them in all-solid-state lithium ion batteries (ASSLIB) is also fascinating. ASSLIB can be classified into thin-film microbatteries and powder-based batteries. Thin-film microbatteries are typically fabricated by depositing micrometer-thick electrodes and electrolyte sequentially on substrates in vapor phases. While allowing the electrolyte to be somewhat resistive $\left(\approx 10^{-6} \mathrm{~S} \mathrm{~cm}^{-1}\right)$, the short conduction path in the thin-film batteries keeps the resistance of the electrolyte below an acceptable value (e.g., $<50 \Omega \mathrm{cm}^{-2}$ ). Functional thin-film batteries with $\mu \mathrm{m}$-thick LiPON film, which has a conductivity of about $10^{-6} \mathrm{~S} \mathrm{~cm}^{-1}$, have been investigated and even commercialized. To be implemented in microbatteries, SCEs have to be made in thin-film format. In SCE thin-films, the matrix and the ionic conductor need to be evenly dispersed within $\mu \mathrm{m}$-ranged, and the conductor should contact the electrodes to ensure the ionic conduction within the batteries. The fabrication of such SCE thin-films could be difficult especially for composites based on ILEs and polymers which can be rarely deposited in vapor phases. However, in spite of this difficulty, some interesting deposition techniques for thin film SCEs have been reported. For example, ILE-SCEs with silica as matrix have been developed by spin-coating sol-gel solutions for silica containing ILEs. ${ }^{[352]}$ Polymer-SCEs have been fabricated by first depositing a porous silica matrix and then filling pores in the silica with polymer electrolytes. ${ }^{[179]}$ As ceramics, inorganicSCE thin-films are more difficult to fabricate than ILE-SCE and polymer SCE thin films. However, recently, thin-films of inorganic-SCE were deposited using the pore-filling approach for the polymer-SCE thin films. ${ }^{[353]}$ In the fabrication, a socalled alucone film where organoaluminium molecules, such as trimethylaluminium, were interconnected by organic molecules, e.g., ethylene glycol, was deposited by molecular layer deposition (MLD). Then, the organic parts in the alucone were etched away, resulting in a porous alumina which was afterward filled with a lithium conductor by ALD. MLD and ALD employed in this process enable coating composite film on electrode of high aspect ratio.

Limited by the mass of the electrode materials, thin-film batteries can only delivery relatively lower capacity compared to conventional LIBs with liquid electrolyte. In contrast, powderbased ASSLIBs typically containing electrode and electrolyte layers of dozens- $\mu \mathrm{m}$ thick can output high capacity. With such thickness, the electrolyte in the powder-based battery should be highly conductive $\left(>10^{-4} \mathrm{~S} \mathrm{~cm}^{-1}\right)$. Therefore, ILE-SCEs are more promising candidates for these batteries compared to the other two types of SCEs. Moreover, unlike the conventional LIBs where the liquid electrolyte can wet the porous electrodes, powder-based ASSLIBs have "composite electrodes" where the electrode and electrolyte particles are mixed to ensure the ionic conduction. In a typical fabrication procedure for these solid batteries, ${ }^{[25]}$ the active electrode material, carbon black, and electrolyte powders (typically more than $30 \mathrm{wt} \%$ ) are mixed. Then this mixture is pressed into composite electrode pellet, and the obtained composite electrode pellets are pressed toget0her with the electrolyte pellet to build the cell. There are three types of contacts in the prepared solid-state batteries: between the electrode and the electrolyte particles in the composite electrode, 

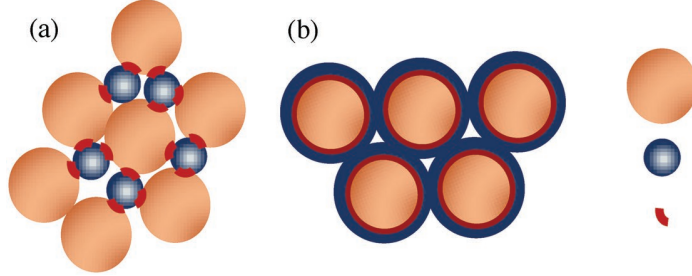

Electrode particle

Electrolyte particle Interface

Figure 14. Schematic of electrode (orange)-electrolyte (blue) particles contacts in all-solid-state batteries prepared by the conventional way a), and prepared by the sol-gel method in which the ILE-SCE can cover the surface of the electrode particles b). Red lines represent the interface.

between the electrolyte particles in the electrolyte pellet, and between the pellets of composite electrode and the electrolyte. These contacts are mainly point-to-point type, as illustrated in Figure 14a (for the contacts between the particles in the composite electrolyte, but other contacts are similar to this case), resulting in limited $\mathrm{Li}^{+}$ion conduction. Fabrication of solidstate batteries with intimate ionic contacts are considered as a prime objective for the future development of solid-state batteries. ${ }^{[354]}$

To improve the contact in the batteries, the pellets are usually hot-pressed, ${ }^{[355]}$ a process similar to the ceramic fabrication, or sintered at about $60 \%$ of the melting point of the materials to chemically bond the particles. ${ }^{[356]}$ For example, according to literature, $\mathrm{Li}_{10} \mathrm{GeP}_{2} \mathrm{~S}_{12}$ and $\mathrm{Li}_{7} \mathrm{La}_{3} \mathrm{Zr}_{2} \mathrm{O}_{12}$ pellets were sintered at $500{ }^{\circ} \mathrm{C}^{[37]}$ and about $1000{ }^{\circ} \mathrm{C},{ }^{[357]}$ respectively. This high temperature treatment can be incompatible with other battery components. For example, the aluminum current collector melts at $660{ }^{\circ} \mathrm{C}^{[358]}$ and carbon will be reduced by the cathode at such high temperatures. In fact, more expensive platinum current collectors instead of aluminum are used in thin-film batteries with $\mathrm{LiCoO}_{2}$ as electrode, because the synthesis of $\mathrm{LiCoO}_{2}$ requires temperature up to $700{ }^{\circ} \mathrm{C} .{ }^{[359]}$ Moreover, high temperature treatment can introduce a blocking interface between the electrolyte and electrodes, as the atoms in the electrodes and electrolyte can cross the interface to diffuse into other materials (or battery components). ${ }^{[360]}$ Buffer layers are, therefore, generally introduced in all-solid-state batteries to reduce the interface resistance. A conductive buffer layer that can be processed at low temperature is preferred. For example, $\mathrm{LiNbO}_{3}$ is typically used as buffer layer between the $\mathrm{LiCoO}_{2}$ electrode and the sulfide electrolyte, ${ }^{[32]}$ because glassy $\mathrm{LiNbO}_{3}$, which needs no high temperature treatment, has a conductivity of up to $10^{-5} \mathrm{~S} \mathrm{~cm}^{-1}$. ${ }^{[361]}$

In summary, a low temperature process that can form intimate ionic contact between the battery components is required for the fabrication of high-performance powder-based batteries. Recently, wet processes at low temperatures for the fabrication of all-solid-state batteries have been shown. ${ }^{[354,362-364]}$ In these processes, porous electrode films were soaked in a solution containing the precursors for the synthesis of the solid electrolyte, and then the soaked electrodes were heated below $300{ }^{\circ} \mathrm{C}$ to form the electrolyte inside the electrode film. The solid electrolyte is believed to be brought into contact with the electrode particles by the liquid.

Besides its significance on the conductivity of the ILE-SCEs, the sol-gel method can also enable novel battery fabrication processes similar to those low-temperature wet processes. An intimate contact (Figure 14b) between the electrode and electrolyte can be formed by wetting the particles with the sol-gel solution, and as the ILE-SCE is a monolith, the ionic contact within the electrolyte layer is intrinsically optimal. Moreover, it is even possible to form the whole battery stack by one step, i.e., the contact between the composite electrode and electrolyte "pellets" forms without a pressing step, which is needed in the conventional fabrication. More importantly, the process can be done at room temperature which can mitigate the formation of a detrimental interface layer.

The mainstream sol-gel formulations for the ILE-SCEs, however, contain formic acid with a $\mathrm{p} K_{\mathrm{a}}$ of 3.7. This acidity will damage the lithium ion battery electrodes. ${ }^{[365]}$ The incompatibility between the electrode materials and the ingredients in these sol-gel methods means that with these sol-gel formulations, the above discussed benefits of a using sol-gel approach for the fabrication of all-solid-state battery cannot be realized. Hence, it is necessary to develop a new sol-gel recipe for the synthesis of ILE-SCEs. Sol-gel methods with neutral aqueous or nonaqueous solution are known. ${ }^{[366,367]}$ They can be adapted to synthesize the ILE-SCEs.

\section{Conflict of Interest}

The authors declare no conflict of interest.

\section{Keywords}

interfacial conduction, ionic liquid, solid electrolyte, solid-state batteries

Received: June 12, 2018

Revised: October 7, 2018

Published online:

[1] G. E. Blomgren, J. Electrochem. Soc. 2017, 164, A5019.

[2] China Industrial Association of Power Sources, http://www.cbea. com/yjbg/201712/396984.html (accessed: December 2017).

[3] P. R. C. Ministry of Industry and Information, http://www.escn. com.cn/news/show-450656.html (accessed: December 2017).

[4] K. Ozawa, Solid State Ionics 1994, 69, 212.

[5] A. Yamada, S. C. Chung, K. Hinokuma, J. Electrochem. Soc. 2001, 148, A224.

[6] B. Lang, B. Ziebarth, C. Elsässer, Chem. Mater. 2015, 27, 5040.

[7] J. W. Fergus, J. Power Sources 2010, 195, 939.

[8] N. Nitta, F. Wu, J. T. Lee, G. Yushin, Mater. Today 2015, 18, 252.

[9] N. L. Franco, D. Persio, L. Boon-Brett, Lithium Ion Battery Value Chain and Related Opportunities for Europe, European Commission, Petten 2016.

[10] T. F. Yi, L. J. Jiang, J. Shu, C. B. Yue, R. S. Zhu, H. Bin Qiao, J. Phys. Chem. Solids 2010, 71, 1236.

[11] R. Van Noorden, Nature 2014, 507, 26.

[12] M. M. Doeff, Batteries for Sustainability: Selected Entries from the Encyclopedia of Sustainability Science and technology, Springer, New York 2012

[13] K. Xu, Chem. Rev. 2014, 114, 11503.

[14] D. Aurbach, Y. Talyosef, B. Markovsky, E. Markevich, E. Zinigrad, L. Asraf, J. S. Gnanaraj, H.-J. Kim, Electrochim. Acta 2004, 50, 247.

[15] K. Xu, Chem. Rev. 2004, 104, 4303. 
[16] M. Galiński, A. Lewandowski, I. Stępniak, Electrochim. Acta 2006, 51, 5567.

[17] E. Quartarone, P. Mustarelli, Chem. Soc. Rev. 2011, 40, 2525.

[18] B. Put, P. M. Vereecken, J. Meersschaut, A. Sepúlveda, A. Stesmans, ACS Appl. Mater. Interfaces 2016, 8, 7060.

[19] X. Yu, J. B. Bates, G. E. Jellison, F. X. Hart, J. Electrochem. Soc. 1997, 144, 524.

[20] N. J. Dudney, Mater. Sci. Eng., B 2005, 116, 245.

[21] C. Lethien, M. Zegaoui, P. Roussel, P. Tilmant, N. Rolland, P. A. Rolland, Microelectron. Eng. 2011, 88, 3172.

[22] Y. Kato, S. Hori, T. Saito, K. Suzuki, M. Hirayama, A. Mitsui, M. Yonemura, H. Iba, R. Kanno, Nat. Energy 2016, 1, 16030.

[23] S. Abada, G. Marlair, A. Lecocq, M. Petit, V. Sauvant-Moynot, F. Huet, J. Power Sources 2016, 306, 178.

[24] Q. Wang, B. Jiang, B. Li, Y. Yan, Renewable Sustainable Energy Rev. 2016, 64, 106.

[25] N. J. Dudney, W. C. West, J. Nanda, Handbook of Solid State Battries, 2nd ed., World Scientific, Singapore 2015.

[26] J. Li, C. Ma, M. Chi, C. Liang, N. J. Dudney, Adv. Energy Mater. 2015, 5, 1401408 .

[27] W. D. Richards, L. J. Miara, Y. Wang, J. C. Kim, G. Ceder, Chem. Mater. 2016, 28, 266.

[28] H. G. Jung, M. W. Jang, J. Hassoun, Y. K. Sun, B. Scrosati, Nat. Commun. 2011, 2, 515.

[29] J. Guo, W. Zuo, Y. Cai, S. Chen, S. Zhang, J. Liu, J. Mater. Chem. A 2015, 3, 4938 .

[30] X. Huang, J. Solid State Electrochem. 2011, 15, 649.

[31] J. G. Kim, B. Son, S. Mukherjee, N. Schuppert, A. Bates, O. Kwon, M. J. Choi, H. Y. Chung, S. Park, J. Power Sources 2015, 282, 299.

[32] Y. Zhu, X. He, Y. Mo, ACS Appl. Mater. Interfaces 2015, 7, 23685.

[33] J. C. Bachman, S. Muy, A. Grimaud, H. H. Chang, N. Pour, S. F. Lux, O. Paschos, F. Maglia, S. Lupart, P. Lamp, L. Giordano, Y. Shao-Horn, Chem. Rev. 2016, 116, 140.

[34] R. C. Agrawal, G. P. Pandey, J. Phys. D: Appl. Phys. 2008, 41, 223001.

[35] L. Long, S. Wang, M. Xiao, Y. Meng, J. Mater. Chem. A 2016, 4, 10038.

[36] D. T. Hallinan, N. P. Balsara, Annu. Rev. Mater. Res. 2013, 43, 503.

[37] N. Kamaya, K. Homma, Y. Yamakawa, M. Hirayama, R. Kanno, M. Yonemura, T. Kamiyama, Y. Kato, S. Hama, K. Kawamoto, A. Mitsui, Nat. Mater. 2011, 10, 682.

[38] J. W. Fergus, J. Power Sources 2010, 195, 4554.

[39] A. K. Ivanovshits, S. E. Sigaryov, Solid State lonics 1988, 27, 89.

[40] J. Wu, L. Chen, T. Song, Z. Zou, J. Gao, W. Zhang, S. Shi, Funct. Mater. Lett. 2017, 10, 1730002

[41] N. J. J. De Klerk, I. Rosłoń, M. Wagemaker, Chem. Mater. 2016, 28, 7955.

[42] V. Thangadurai, S. Narayanan, D. Pinzaru, Chem. Soc. Rev. 2014, 43, 4714.

[43] M. Tatsumisago, F. Mizuno, A. Hayashi, J. Power Sources 2006, 159, 193.

[44] J. Trevey, J. S. Jang, Y. S. Jung, C. R. Stoldt, S. H. Lee, Electrochem. Commun. 2009, 11, 1830.

[45] S. Q. Zhang, S. Xie, C. H. Chen, Mater. Sci. Eng., B 2005, 121, 160.

[46] I. Seo, S. W. Martin, J. Electrochem. Soc. 2011, 158, A465.

[47] W. Gorecki, R. Andreani, C. Berthier, M. Armand, M. Mali, J. Roos, D. Brinkmann, Solid State Ionics 1986, 18-19, 295.

[48] B. Kumar, J. D. Schaffer, M. Nookala, L. G. Scanlon, J. Power Sources 1994, 47, 63.

[49] A. Magistris, P. Mustarelli, E. Quartarone, C. Tomasi, Solid State Ionics 2000, 136-137, 1241.

[50] W. Goreckit, M. Jeannint, E. Belorizkyt, C. Roux, M. Armand, Education 1995, 7, 6823.

[51] X. Chen, P. Vereecken, Presented at Solid State Ionics, Padua, Italy 2017.

[52] J. B. Goodenough, Annu. Rev. Mater. Res. 2003, 33, 91.
[53] P. G. Bruce, Chemistry of Solid State Materials, Cambridge University Press, Cambridge 1995.

[54] S. W. Martin, C. A. Angell, J. Non-Cryst. Solids 1986, 83, 185.

[55] D. K. McElfresh, D. G. Howitt, J. Am. Ceram. Soc. 1986, 69, C-237.

[56] H. Mehrer, Diffusion in Solids, Springer, Berlin 2007.

[57] R. D. Shannon, B. E. Taylor, A. D. English, T. Berzins, Electrochim. Acta 1977, 22, 783.

[58] Y.-W. Hu, J. Electrochem. Soc. 1977, 124, 1240.

[59] N. F. Uvarov, J. Solid State Electrochem. 2011, 15, 367.

[60] W. Jande, Z. Angew. Chem. 1929, 42, 462.

[61] C. C. Liang, J. Electrochem. Soc. 1973, 120, 1289.

[62] H. Yamada, A. J. Bhattacharyya, J. Maier, Adv. Funct. Mater. 2006, 16, 525.

[63] J. Maier, Nat. Mater. 2005, 4, 805.

[64] C. F. Holmes, J. Power Sources 2001, 97-98, 739.

[65] C. C. Liang, A. V. Joshi, L. Barnette, US Patent 4127708, 1978.

[66] C. C. Liang, C. F. Holmes, W. Greatbatch, W. Drive, J. Power Sources 1980, 5, 3 .

[67] J. B. Phipps, D. H. Whitmore, Solid State Ionics 1983, 9-10, 123.

[68] H. Mat, N. S. Mohamed, R. H. Yahaya Subban, Adv. Mater. Res. 2011, 415-417, 442

[69] N. H. Kaus, A. H. Ahmad, lonics 2009, 15, 197.

[70] N. F. Uvarov, V. P. Isupov, V. Sharma, A. K. Shukla, Solid State lonics 1992, 51, 41.

[71] R. C. Agrawal, R. K. Gupta, J. Mater. Sci. 1999, 34, 1131.

[72] P. Gopalan, S. Bhandari, A. R. Kulkarni, V. R. Palkar, Mater. Res. Bull. 2002, 37, 2043.

[73] J. Mejerovich, J. Power Sources 1992, 38, 345.

[74] N. F. Uvarov, A. S. Ulihin, A. B. Slobodyuk, V. Y. Kavun, S. D. Kirik, ECS Trans. 2008, 11, 9.

[75] F. W. Poulsen, J. Power Sources 1987, 20, 317.

[76] A. S. Ulihin, N. F. Uvarov, Y. G. Mateyshina, L. I. Brezhneva, A. A. Matvienko, Solid State lonics 2006, 177, 2787.

[77] A. S. Ulihin, a. B. Slobodyuk, N. F. Uvarov, O. a. Kharlamova, V. P. Isupov, V. Y. Kavun, Solid State lonics 2008, 179, 1740.

[78] M. N. T. Nishino, Solid State lonics 1994, 70-71, 96.

[79] L. Chen, Z. Zhao, C. Wang, L. Zir, Acta Phys. Sin. 1985, 34, 1027.

[80] F. Capuano, F. Croce, B. Scrosati, J. Electrochem. Soc. 1991, 138, 1918.

[81] W. Wieczorek, J. R. Stevens, Z. Florjańczyk, Solid State lonics 1996, 85, 67.

[82] E. Quartarone, P. Mustarelli, A. Magistris, Solid State lonics 1998, $110,1$.

[83] M. Marcinek, A. Zalewska, G. Zukowska, W. Wieczorek, 2000, 137, 1175.

[84] A. Manuel Stephan, K. S. Nahm, Polymer 2006, 47, 5952.

[85] J. L. Schaefer, D. A. Yanga, L. A. Archer, Chem. Mater. 2013, 25, 834.

[86] X. Chen, K. B. Gandrud, M. Mees, P. Vereecken, presented at The 58th Battery Symp. in Japan, Fukuoka, November 2017.

[87] X. Chen, K. Gandrud, M. Mees, A. Sagaraa, M. Muratac, M. Tomiyama, M. Shimada, P. M. Vereecken, paper presented at The 58th Battery Symp. in Japan, Fukuoka, November 2017.

[88] R. Hayes, G. G. Warr, R. Atkin, Chem. Rev. 2015, 115, 6357.

[89] J. Le Bideau, L. Viau, A. Vioux, Chem. Soc. Rev. 2011, 40, 907.

[90] M. Ne, J. Le Bideau, P. Gaveau, U. M. R. Cnrs, I. C. Gerhardt, V. Uni, R. V. March, V. Re, M. Recei, V. June, Chem. Mater. 2006, 18, 3931.

[91] P. Knauth, J. Electroceram. 2000, 5, 111.

[92] N. F. Uvarov, Russ. Chem. Rev. 2007, 76, 415.

[93] N. F. Uvarov, V. G. Ponomareva, G. V. Lavrova, Russ. J. Electrochem. 2010, 46, 722.

[94] J. Maier, J. Phys. Chem. Solids 1985, 46, 309.

[95] J. Maier, Solid State lonics 1987, 23, 59.

[96] J. Maier, Prog. Solid State Chem. 1995, 23, 171. 
[97] U. Lauer, J. Maier, W. Göpel, Sens. Actuators, B 1990, 2, 125.

[98] X. Guo, J. Maier, Adv. Mater. 2009, 21, 2619.

[99] X. X. Guo, J. Maier, Surf. Sci. 2004, 549, 211.

[100] E. Schreck, K. Läuger, K. Dransfeld, Z. Phys. B: Condens. Matter $1986,62,331$.

[101] N. Sata, K. Eberman, K. Eberl, J. Maier, Nature 2000, 408, 946.

[102] D. Lubben, F. A. Modine, J. Appl. Phys. 1996, 80, 5150.

[103] F. A. Modine, D. Lubben, J. B. Bates, J. Appl. Phys. 1993, 74, 2658

[104] S. Mühlherr, K. Läuger, E. Schreck, K. Dransfeld, N. Nicoloso, Solid State lonics 1988, 28-30, 1495.

[105] N. Schichtel, C. Korte, D. Hesse, N. Zakharov, B. Butz, D. Gerthsen, J. Janek, Phys. Chem. Chem. Phys. 2010, 12, 14596.

[106] S. Furusawa, H. Tabuchi, T. Tsurui, Solid State lonics 2007, 178, 1033.

[107] N. J. Dudney, J. Am. Ceram. Soc. 1985, 68, 538.

[108] J. C. Wang, N. J. Dudney, Solid State lonics 1986, 18-19, 112.

[109] H. E. Roman, M. Yussouff, Phys. Rev. B 1987, 36, 4

[110] H. E. Roman, A. Bunde, W. Dieterich, Phys. Rev. B 1986, 34, 3439.

[111] A. Bunde, W. Dieterich, E. Roman, Phys. Rev. Lett. 1985, 55, 5.

[112] S. Indris, P. Heitjans, H. E. Roman, A. Bunde, Phys. Rev. B 2000, 84, 2889.

[113] S. Indris, P. Heitjans, M. Ulrich, A. Bunde, Z. Phys. Chem. 2005 $219,89$.

[114] H. E. Roman, J. Phys.: Condens. Matter 1990, 2, 3909.

[115] S. Jiang, J. B. Wagner, J. Phys. Chem. Solids 1995, 56, 1113.

[116] A. M. Stoneham, E. Wade, J. A. Kilner, Mater. Res. Bull. 1979, 14, 661.

[117] S. Fujitsu, H. Kobayashi, K. Koumoto, H. Yanagida, J. Electrochem. Soc. 1986, 133, 1497.

[118] C.-W. Nan, D. M. Smith, Mater. Sci. Eng., B 1991, 10, 99.

[119] I. V. Belova, G. E. Murch, J. Phys. Chem. Solids 2005, 66, 722.

[120] R. Landauer, J. Appl. Phys. 1952, 23, 779.

[121] M. Chang, K. Shahi, J. B. Wagner, J. Electrochem. Soc. 1984, 131, 1213.

[122] A. R. Petosa, D. P. Jaisi, I. R. Quevedo, M. Elimelech, N. Tufenkji, Environ. Sci. Technol. 2010, 44, 6532.

[123] J. Jiang, G. Oberdörster, P. Biswas, J. Nanopart. Res. 2009, 11, 77.

[124] J. Wang, W. B. White, J. H. Adair, J. Am. Ceram. Soc. 2006, 89, 2359.

[125] W. Yao, G. Guangsheng, W. Fei, W. Jun, Powder Technol. 2002, 124 , 152.

[126] E. M. Hotze, T. Phenrat, G. V. Lowry, J. Environ. Qual. 2010, 39, 1909.

[127] W. Koch, S. K. Friedlander, J. Colloid Interface Sci. 1990, 140, 419.

[128] H. H. Hahn, J. L. Logas, R. S. Averback, J. Mater. Res. 1990, 5, 609.

[129] J. H. Smått, S. Schunk, M. Lindén, Chem. Mater. 2003, 15, 2354.

[130] N. Melosh, P. Lipic, F. S. Bates, F. Wudl, G. D. Stucky, G. H. Fredrickson, B. F. Chmelka, Macromolecules 1999, 32, 4332.

[131] Y. Wan, D. Zhao, Chem. Rev. 2007, 107, 2821.

[132] A. Soleimani Dorcheh, M. H. Abbasi, J. Mater. Process. Technol. 2008, 199, 10.

[133] A. Taguchi, F. Schüth, Microporous Mesoporous Mater. 2005, 77, 1.

[134] D. Gu, F. Schüth, Chem. Soc. Rev. 2014, 43, 313.

[135] M. E. Davis, R. F. Lobo, Chem. Mater.4, 1992, 756.

[136] C. S. Cundy, P. Cox, Chem. Rev. 2003, 103, 663.

[137] S. T. Meek, J. Greathouse, M. D. Allendorf, Adv. Mater. 2011, 23, 249.

[138] J.-P. Zhang, Y.-B. Zhang, J.-B. Lin, X.-M. Chen, Chem. Rev. 2012 $112,1001$.

[139] H.-C. Zhou, J. R. Long, O. M. Yaghi, Chem. Rev. 2012, 112, 673.

[140] C. J. Brinker, G. W. Scherer, Sol-Gel Science: The physics and Chemistry of Sol-Gel Processing, Academic Press, Boston, MA 1990.

[141] M. Kruk, M. Jaroniec, C. H. Ko, R. Ryoo, Chem. Mater. 2000, 12, 1961.

[142] M. H. Lim, C. F. Blanford, A. Stein, Chem. Mater. 1998, 10, 467.

[143] R. Winter, J. Chan, R. Frattini, J. Jonas, J. Non-Cryst. Solids 1988, 105, 214.

[144] M. Morpurgo, D. Teoli, M. Pignatto, M. Attrezzi, F. Spadaro, N. Realdon, Acta Biomater. 2010, 6, 2246.

[145] D. Zhao, J. Sun, Q. Li, G. D. Stucky, S. Barbara, Chem. Mater. 2000, 12, 275.
[146] D. Zhao, J. Feng, Q. Huo, N. Melosh, G. H. Fredrickson, B. F. Chmelka, G. D. Stucky, Science 1998, 279, 548.

[147] T. Yu, H. Zhang, X. Yan, Z. Chen, X. Zou, P. Oleynikov, D. Zhao, J. Phys. Chem. B 2006, 110, 21467.

[148] J. Eastoe, R. F. Tabor, Surfactants and Nanoscience, Elsevier, Berlin 2014.

[149] G. J. D. A. A. Soler-Illia, C. Sanchez, B. Lebeau, J. Patarin, Chem Rev. 2002, 102, 4093.

[150] U. Ciesla, F. Schu, Microporous Mesoporous Mater. 1999, 27, 131.

[151] C. T. Kresge, M. E. Leonowicz, W. J. Roth, J. C. Vartuli, J. S. Beck, Nature 1992, 359, 710.

[152] A. Hozumi, Y. Yokogawa, T. Kameyama, K. Hiraku, H. Sugimura, O. Takai, M. Okido, Adv. Mater. 2000, 12, 985.

[153] R. P. Bagwe, L. R. Hilliard, W. Tan, Langmuir 2006, 22, 4357.

[154] P. Sutra, F. Fajula, D. Brunel, P. Lentz, G. Daelen, J. B. Nagy, Colloids Surf. A 1999, 158, 21.

[155] L. A. Belyakova, A. M. Varvarin, Colloids Surf. A 1999, 154, 285.

[156] B. Lynch, J. D. Glennon, C. Tröltzsch, U. Menyes, M. Pursch, K. Albert, Anal. Chem. 1997, 69, 1756.

[157] J. S. Bradshaw, R. L. Bruening, K. E. Krakowiak, B. J. Tarbet, M. L. Bruening, R. M. Izatt, J. J. Christensen, J. Chem. Soc., Chem. Commun. 1988, 812

[158] I. Park, Z. Wang, T. J. Pinnavaia, Chem. Mater. 2005, 17, 383.

[159] P. T. Tanev, T. J. Pinnavaia, Science. 1995, 267, 865.

[160] R. Ryoo, J. M. Kim, C. H. Ko, C. H. Shin, J. Phys. Chem. 1996, 100, 17718

[161] M. J. Kim, R. Ryoo, Chem. Mater. 1999, 11, 487.

[162] H. Furukawa, N. Ko, Y. B. Go, N. Aratani, S. B. Choi, E. Choi, A. Ö. Yazaydin, R. Q. Snurr, M. O'Keeffe, J. Kim, O. M. Yaghi, Science 2010, 329, 424

[163] A. C. Khandkar, J. B. Wagner Jr., Solid State Ionics 1986, 18-19, 1100.

[164] H. Maekawa, R. Tanaka, T. Sato, Y. Fujimaki, T. Yamamura, Solid State lonics 2004, 175, 281.

[165] G. Lavrova, V. G. Ponomareva, N. F. Uvarov, Solid State lonics 2000, 136-137, 1285

[166] S. Albert, N. Frolet, P. Yot, A. Pradel, M. Ribes, Solid State lonics 2006, 177, 3009.

[167] S. Albert, N. Frolet, P. G. Yot, A. Pradel, M. Ribes, Mater. Sci. Eng., B 2008, 150, 199

[168] H. Yamada, I. Moriguchi, T. Kudo, Solid State lonics 2005, 176, 945.

[169] S. V. Baryshnikov, C. Tien, E. V. Charnaya, M. K. Lee, D. Michel, W. Böhlmann, N. P. Andriyanova, J. Phys.: Condens. Matter 2008, 20, 025214.

[170] A. M. Stephan, Eur. Polym. J. 2006, 42, 21.

[171] Q. Wang, W. L. Song, L. Wang, Y. Song, Q. Shi, L. Z. Fan, Electrochim. Acta 2014, 132, 538.

[172] Z. Osman, M. I. Mohd Ghazali, L. Othman, K. B. Mdisa, Results Phys. 2012, 2, 1.

[173] R. Bouchet, S. Lascaud, M. Rosso, J. Electrochem. Soc. 2003, 150 , A1385.

[174] A. Vallée, S. Besner, J. Prud'Homme, Electrochim. Acta 1992, 37, 1579.

[175] P. G. Bruce, C. A. Vincent, J. Chem. Soc., Faraday Trans. 1993, 89, 3187.

[176] D. F. Shriver, P. G. Bruce, in Chemistry of Solid State Materials: Solid State Electrochemistry, Cambridge University Press, Cambridge 1995.

[177] D. Golodnitsky, G. Ardel, E. Peled, Solid State lonics 2002, 147, 141.

[178] L. Persi, F. Croce, B. Scrosati, E. Plichta, M. A. Hendrickson, J. Electrochem. Soc. 2002, 149, A212.

[179] X. Chen, P. M. Vereecken, Adv. Mater. Interfaces 2017, 4, 1600877.

[180] S. Skaarup, K. West, B. Zachau-Christiansen, Solid State lonics 1988, 28-30, 975 
[181] X. Tao, Y. Liu, W. Liu, G. Zhou, J. Zhao, D. Lin, C. Zu, O. Sheng, W. Zhang, H. W. Lee, Y. Cui, Nano Lett. 2017, 17, 2967.

[182] Y. Inda, T. Katoh, M. Baba, J. Power Sources 2007, 174, 741.

[183] H. Aono, E. Sugimoto, J. Electrochem. Soc. 1990, 137, 1023.

[184] L. Chen, Y. Li, S. P. Li, L. Z. Fan, C. W. Nan, J. B. Goodenough, Nano Energy 2018, 46, 176.

[185] C. Wang, X.-W. Zhang, A. J. Appleby, J. Electrochem. Soc. 2005, 152, A205.

[186] W. E. Tenhaeff, K. A. Perry, N. J. Dudney, J. Electrochem. Soc. 2012, 159, A2118.

[187] W. Liu, N. Liu, J. Sun, P. C. Hsu, Y. Li, H. W. Lee, Y. Cui, Nano Lett. 2015, 15, 2740.

[188] A. S. Pandian, X. C. Chen, J. Chen, B. S. Lokitz, R. E. Ruther, G. Yang, K. Lou, J. Nanda, F. M. Delnick, N. J. Dudney, J. Power Sources 2018, 390, 153.

[189] S. Kalnaus, W. E. Tenhaeff, J. Sakamoto, A. S. Sabau, C. Daniel, N. J. Dudney, J. Power Sources 2013, 241, 178.

[190] J. R. Maccallum, M. J. Smith, C. A. Vincent, Solid State Ionics 1984, 11, 307.

[191] C. Capiglia, P. Mustarelli, E. Quartarone, C. Tomasi, A. Magistris, Solid State lonics 1999, 118, 73.

[192] G. Chiodelli, P. Ferloni, A. Magistris, M. Sanesi, Solid State lonics 1988, 28-30, 1009.

[193] P. Mustarelli, E. Quartarone, C. Tomasi, A. Magistris, Solid State Ionics 2000, 135, 81.

[194] M. Watanabe, J. Ikeda, I. Shinohara, Polym. J. 1983, 15, 65.

[195] C. Roux, J. Y. Sanchez, Solid State lonics 1994, 72, 160.

[196] B. Scrosati, F. Croce, L. Persi, J. Electrochem. Soc. 2000, 147, 1718.

[197] F. Croce, L. Persi, F. Ronci, B. Scrosati, Solid State lonics 2000, $135,47$.

[198] F. Croce, L. Settimi, B. Scrosati, Electrochem. Commun. 2006, 8, 364.

[199] N. Lago, O. Garcia-Calvo, J. M. Lopezdelamo, T. Rojo, M. Armand, ChemSusChem 2015, 8, 3039.

[200] G. B. Appetecchi, W. Henderson, P. Villano, M. Berrettoni, S. Passerini, J. Electrochem. Soc. 2001, 148, A1171.

[201] T. Caruso, S. Capoleoni, E. Cazzanelli, R. G. Agostino, P. Villano, S. Passerini, lonics 2002, 8, 36.

[202] Z. Gadjourova, Y. G. Andreev, D. P. Tunstall, P. G. Bruce, Nature 2001, 412, 520.

[203] J. R. Fried, Polymer Science and Technology, Prentice Hall, New Jersey 1995.

[204] F. Croce, R. Curini, a. Martinelli, L. Persi, F. Ronci, B. Scrosati, R. Caminiti, J. Phys. Chem. B 1999, 103, 10632.

[205] S. Panero, B. Scrosati, H. H. Sumathipala, W. Wieczorek, J. Power Sources 2007, 167, 510.

[206] J. Zhou, P. S. Fedkiw, Solid State lonics 2004, 166, 275.

[207] F. Croce, L. L. Persi, B. Scrosati, F. Serraino-Fiory, E. Plichta, M. A. Hendrickson, Electrochim. Acta 2001, 46, 2457.

[208] S. Srivastava, J. L. Schaefer, Z. Yang, Z. Tu, L. A. Archer, Adv. Mater. 2014, 26, 201.

[209] S. Zugmann, M. Fleischmann, M. Amereller, R. M. Gschwind, H. D. Wiemhöfer, H. J. Gores, Electrochim. Acta 2011, 56, 3926.

[210] J. Evans, C. A. Vincent, P. G. Bruce, Polymer. 1987, 28, 2324.

[211] P. G. Bruce, C. a. Vincent, J. Electroanal. Chem. Interfacial Electrochem. 1987, 225, 1.

[212] A. Blazejczyk, W. Wieczorek, R. Kovarsky, D. Golodnitsky, E. Peled, L. G. Scanlon, G. B. Appetecchi, B. Scrosati, J. Electrochem. Soc. 2004, 151, A1762.

[213] Y. Tominaga, M. Endo, Electrochim. Acta 2013, 113, 361.

[214] H.-Y. Sun, J. Electrochem. Soc. 1999, 146, 1672.

[215] M. Marcinek, A. Bac, P. Lipka, A. Zalewska, R. Borkowska, W. Wieczorek, J. Phys. Chem. B 2000, 104, 11088.

[216] W. Wieczorek, P. Lipka, H. Wycis, J. Phys. Chem. B 1998, 102, 6968.
[217] J. Fan, S. R. Raghavan, X. Y. Yu, S. A. Khan, P. S. Fedkiw, J. Hou, G. L. Baker, Solid State lonics 1998, 111, 117.

[218] J. H. Kim, B. R. Min, J. Won, Y. S. Kang, J. Phys. Chem. B 2003, 107, 5901.

[219] H. Zhang, P. Maitra, S. L. Wunder, Solid State lonics 2008, 178, 1975.

[220] A. Agrawal, S. Choudhury, L. A. Archer, RSC Adv. 2015, 5, 20800.

[221] N. J. Fernandes, J. Akbarzadeh, H. Peterlik, E. P. Giannelis, ACS Nano 2013, 7, 1265.

[222] R. Rodriguez, R. Herrera, L. A. Archer, E. P. Giannelis, Adv. Mater. 2008, 20, 4353.

[223] H. M. Kao, Y. Y. Tsai, S. W. Chao, Solid State lonics 2005, 176, 1261.

[224] S. Kim, S. J. Park, Electrochim. Acta 2007, 52, 3477.

[225] B. Kumar, L. G. Scanlon, Solid State Ionics 1999, 124, 239.

[226] J. Xi, X. Tang, Chem. Phys. Lett. 2004, 400, 68.

[227] M. J. Reddy, P. P. Chu, J. Power Sources 2004, 135, 1.

[228] M. J. Reddy, P. P. Chu, U. V. S. Rao, J. Power Sources 2006, 158, 614.

[229] P. P. Chu, M. J. Reddy, H. M. Kao, Solid State lonics 2003, 156, 141.

[230] H. J. Walls, P. S. Fedkiw, T. A. Zawodzinski, S. A. Khan, J. Electrochem. Soc. 2003, 150, E165.

[231] P. A. R. D. Jayathilaka, M. A. K. L. Dissanayake, I. Albinsson, B. Mellander, Electrochim. Acta 2002, 47, 3257.

[232] C. Y. Chiang, M. Jaipal Reddy, P. P. Chu, Solid State lonics 2004, 175,631 .

[233] J. Xi, X. Qiu, W. Zhu, X. Tang, Microporous Mesoporous Mater. 2006, $88,1$.

[234] C.-W. Nan, L. Fan, Y. Lin, Q. Cai, Phys. Rev. Lett. 2003, 91, 266104.

[235] Y. Tominaga, S. Asai, M. Sumita, S. Panero, B. Scrosati, J. Power Sources 2005, 146, 402.

[236] Y. Tominaga, S. Asai, M. Sumita, S. Panero, B. Scrosati, Electrochem. Solid-State Lett. 2005, 8, A22.

[237] G. Derrien, J. Hassoun, S. Sacchetti, S. Panero, Solid State lonics 2009, 180, 1267.

[238] L. Hu, Z. Tang, Z. Zhang, J. Power Sources 2007, 166, 226.

[239] X. L. Wang, A. Mei, M. Li, Y. Lin, C. W. Nan, Solid State lonics 2006, $177,1287$.

[240] J. Xi, X. Qiu, X. Ma, M. Cui, J. Yang, X. Tang, W. Zhu, L. Chen, Solid State lonics 2005, 176, 1249.

[241] C. Yuan, J. Li, P. Han, Y. Lai, Z. Zhang, J. Liu, J. Power Sources 2013, 240, 653.

[242] N. Angulakshmi, R. S. Kumar, M. A. Kulandainathan, A. M. Stephan, J. Phys. Chem. C 2014, 118, 24240.

[243] J. S. Wilkes, Green Chem. 2002, 4, 73.

[244] A. S. Basin, A. B. Kaplun, A. B. Meshalkin, N. F. Uvarov, Russ. J. Inorg. Chem. 2008, 53, 1509.

[245] R. T. Carlin, J. S. Wilkes, Chemistry of Nonaqueous Solutions, WileyVCH, New York 1994, pp. 277-306.

[246] P. Walden, Bull. Russ. Acad. Sci. 1914, 4, 405.

[247] I. Krossing, J. M. Slattery, C. Daguenet, P. J. Dyson, A. Oleinikova, H. Weingärtner, J. Am. Chem. Soc. 2006, 128, 13427.

[248] M. Armand, F. Endres, D. R. MacFarlane, H. Ohno, B. Scrosati, Nat. Mater. 2009, 8, 621.

[249] E. Jónsson, P. Johansson, Phys. Chem. Chem. Phys. 2015, 17, 3697.

[250] S. P. Ong, O. Andreussi, Y. Wu, N. Marzari, G. Ceder, Chem. Mater. 2011, 23, 2979.

[251] C. Maton, N. De Vos, C. V. Stevens, Chem. Soc. Rev. 2013, 42, 5963.

[252] L. P. N. Rebelo, J. N. Canongia Lopes, J. M. S. S. Esperança, E. Filipe, J. Phys. Chem. B 2005, 109, 6040.

[253] D. MacFarlane, P. Meakin, J. Phys. Chem. B 1999, 103, 4164.

[254] S. Seki, Y. Ohno, Y. Kobayashi, H. Miyashiro, A. Usami, Y. Mita, H. Tokuda, M. Watanabe, K. Hayamizu, S. Tsuzuki, M. Hattori, N. Terada, J. Electrochem. Soc. 2007, 154, A173.

[255] M. Kerner, N. Plylahan, J. Scheers, P. Johansson, Phys. Chem. Chem. Phys. 2015, 17, 19569. 
[256] C. M. Gordon, J. D. Holbrey, A. R. Kennedy, K. R. Seddon, J. Mater Chem. 1998, 8, 2627.

[257] G. J. Maximo, R. J. B. N. Santos, J. A. Lopes-da-Silva, M. C. Costa, A. J. A. Meirelles, J. A. P. Coutinho, ACS Sustainable Chem. Eng. 2014, 2, 672

[258] H. Weingärtner, A. Knocks, W. Schrader, U. Kaatze, J. Phys. Chem. A 2001, 105, 8646.

[259] W. Zhao, B. Heggen, S. Zahn, B. Kirchner, S. Balasubramanian, F. Mu, J. Am. Chem. Soc. 2009, 131, 15825.

[260] H. Weingärtner, Curr. Opin. Colloid Interface Sci. 2013, 18, 183.

[261] D. Wakeham, A. Nelson, G. G. Warr, R. Atkin, Phys. Chem. Chem. Phys. 2011, 13, 20828.

[262] R. Hayes, S. Imberti, G. G. Warr, R. Atkin, J. Phys. Chem. C 2014, $118,13998$.

[263] J. N. A. Canongia Lopes, A. A. H. Pádua, J. Phys. Chem. B 2006, $110,3330$.

[264] Z. P. Rosol, N. J. German, S. M. Gross, Green Chem. 2009, 11, 1453.

[265] K. Angenendt, P. Johansson, J. Phys. Chem. B 2011, 115, 7808.

[266] K. Hayamizu, Y. Aihara, H. Nakagawa, T. Nukuda, W. S. Price, J. Phys. Chem. B 2004, 108, 19527.

[267] Y. Saito, T. Umecky, J. Niwa, T. Sakai, S. Maeda, J. Phys. Chem. B 2007, 111, 11794.

[268] J. Lassègues, J. Grondin, D. Talaga, Phys. Chem. Chem. Phys. 2006 8, 5629

[269] J. Lasse, J. Grondin, C. Aupetit, P. Johansson, J. Phys. Chem. A $20092009,113,305$

[270] W. Xu, E. I. Cooper, C. A. Angell, J. Phys. Chem. B 2003, 107, 6170.

[271] B. Garcia, S. Lavallée, G. Perron, C. Michot, M. Armand, Electrochim. Acta 2004, 49, 4583.

[272] A. P. Abbott, ChemPhysChem 2005, 6, 2502.

[273] A. McEwen, H. L. Ngo, K. LeCompte, J. L. Goldman, J. Electrochem. Soc. 1999, 146, 1687.

[274] A. Lewandowski, M. Biegun, M. Galinski, Electrochim. Acta 2012, 63, 204.

[275] S. Shimano, H. Zhou, I. Honma, Chem. Mater. 2007, 19, 5216.

[276] K. Ueno, K. Hata, T. Katakabe, M. Kondoh, M. Watanabe, J. Phys. Chem. B 2008, 112, 9013.

[277] J. Nordström, L. Aguilera, A. Matic, Langmuir 2012, 28, 4080.

[278] S. S. Moganty, N. Jayaprakash, J. L. Nugent, J. Shen, L. A. Archer, Angew. Chem., Int. Ed. 2010, 49, 9158.

[279] Y. Lu, S. S. Moganty, J. L. Schaefer, L. A. Archer, J. Mater. Chem. 2012, 22, 4066.

[280] T. Welton, Chem. Rev. 1999, 99, 2071

[281] J. H. Shin, E. J. Cairns, J. Power Sources 2008, 177, 537.

[282] V. Borgel, E. Markevich, D. Aurbach, G. Semrau, M. Schmidt, J. Power Sources 2009, 189, 331.

[283] Q. Zhou, W. a. Henderson, G. B. Appetecchi, M. Montanino, S. Passerini, J. Phys. Chem. B 2008, 112, 13577.

[284] G. B. Appetecchi, M. Carewska, M. Montanino, F. Alessandrini, S. Passerini, ECS Trans. 2010, 25, 49.

[285] T. Sugimoto, Y. Atsumi, M. Kikuta, E. Ishiko, M. Kono, M. Ishikawa, J. Power Sources 2009, 189, 802.

[286] A. Guerfi, M. Dontigny, Y. Kobayashi, A. Vijh, K. Zaghib, J. Solid State Electrochem. 2009, 13, 1003.

[287] M. Ara, T. Meng, G.-A. Nazri, S. O. Salley, K. Y. Simon Ng, J. Electrochem. Soc. 2014, 161, A1969.

[288] A. M. O. Mahony, D. S. Silvester, L. Aldous, C. Hardacre, R. G. Compton, Engineering 2008, 2884.

[289] H. Nakagawa, S. Izuchi, K. Kuwana, T. Nukuda, Y. Aihara, J. Electrochem. Soc. 2003, 150, A695.

[290] B. Xin, J. Hao, Chem. Soc. Rev. 2014, 43, 7171.

[291] K. S. Korf, Y. Lu, Y. Kambe, L. A. Archer, J. Mater. Chem. A 2014, 2, 11866.

[292] S. S. Moganty, S. Srivastava, Y. Lu, J. L. Schaefer, S. A. Rizvi, L. A. Archer, Chem. Mater. 2012, 24, 1386.
[293] S. Delacroix, F. Sauvage, M. Reynaud, M. Deschamps, S. Bruyère, M. Becuwe, D. Postel, J. M. Tarascon, A. N. Van Nhien, Chem. Mater. 2015, 27, 7926

[294] V. I. Prâvulescu, C. Hardacre, Chem. Rev. 2007, 107, 2615.

[295] M. H. Valkenberg, C. deCastro, W. F. Hölderich, Green Chem. $2002,4,88$

[296] A. Guyomard, J. Abusleme, P. Soudan, B. Lestriez, D. Guyomard, J. Le Bideau, Adv. Energy Mater. 2014, 4, 1301570.

[297] F. Wu, G. Tan, R. Chen, L. Li, J. Xiang, Y. Zheng, Adv. Mater. 2011, 23, 5081.

[298] K. G. Sharp, J. Sol-Gel Sci. Technol. 1994, 2, 35.

[299] Y. Zhou, M. Antonietti, Chem. Mater. 2004, 16, 544.

[300] Y. Zhou, J. H. Schattka, M. Antonietti, Nano Lett. 2004, 4, 477.

[301] J. Zhang, Y. Ma, F. Shi, L. Liu, Y. Deng, Microporous Mesoporous Mater. 2009, 119, 97

[302] C. M. Wu, S. Y. Lin, H. L. Chen, Microporous Mesoporous Mater. 2012, 156, 189

[303] F. Wu, N. Chen, R. Chen, L. Wang, L. Li, Nano Energy. 2017, 31, 9.

[304] I. H. Unemoto, Y. Iwai, S. Mitani, S. Baek, S. Ito, T. Tomai, J. Kawamura, Solid State Ionics 2011, 201, 11.

[305] K. Minami, A. Hayashi, M. Tatsumisago, J. Electrochem. Soc. 2010, 157, A1296.

[306] S. Ito, A. Unemoto, H. Ogawa, T. Tomai, I. Honma, J. Power Sources 2012, 208, 271.

[307] A. Unemoto, H. Ogawa, S. Ito, I. Honma, J. Electrochem. Soc. 2013, 160, A138.

[308] A. Unemoto, Y. Gambe, D. Komatsu, I. Honma, Solid State lonics 2014, 262, 765 .

[309] N. Krawczyk, Effect of Nanostructured Silica Filler Material on Ionic Liquid-Based Lithium Electrolytes Systematic Characterization of Liquid and Gellified Electrolytes, Justus-Liebig-Universität, Gießen, Germany 2014.

[310] X. Li, Z. Zhang, K. Yin, L. Yang, K. Tachibana, S. I. Hirano, J. Power Sources 2015, 278, 128

[311] J. Zhang, Y. Bai, X. G. Sun, Y. Li, B. Guo, J. Chen, G. M. Veith, D. K. Hensley, M. P. Paranthaman, J. B. Goodenough, S. Dai, Nano Lett. 2015, 15, 3398.

[312] J. K. Kim, J. Scheers, T. J. Park, Y. Kim, ChemSusChem 2015, 8, 636.

[313] X. Li, S. Li, Z. Zhang, J. Huang, L. Yang, S. Hirano, J. Mater. Chem. A 2016, 4, 13822

[314] T. Ecelmeyer, H. W. Meyer, L. Van Wu, Chem. Mater. 2009, 21, 2280.

[315] G. Tan, F. Wu, C. Zhan, J. Wang, D. Mu, J. Lu, K. Amine, Nano Lett. 2016, 16, 1960.

[316] M. V. Fedorov, A. A. Kornyshev, Chem. Rev. 2014, 114, 2978.

[317] Z. He, P. Alexandridis, Phys. Chem. Chem. Phys. 2015, 17, 18238.

[318] C. Largeot, C. Portet, J. Chmiola, P. L. Taberna, Y. Gogotsi, P. Simon, J. Am. Chem. Soc. 2008, 130, 2730.

[319] J. Chmiola, G. Yushin, Y. Gogotsi, C. Portet, P. Simon, P. L. Taberna, Science 2006, 313, 1760.

[320] S. Kondrat, A. Kornyshev, J. Phys.: Condens. Matter 2011, 23, 022201

[321] Y. Liu, Y. Zhang, G. Wu, J. Hu, J. Am. Chem. Soc. 2006, 128, 7456.

[322] Y. Yokota, T. Harada, K. Fukui, Chem. Commun. 2010, 46, 8627.

[323] P. Taylor, A. J. Carmichael, C. Hardacre, K. R. Seddon, J. D. Holbrey, Mol. Phys. 2001, 99, 795

[324] M. Mezger, H. Shiröder, H. Reichert, S. Schramm, J. S. Okasinski, S. Schöder, V. Honkimäki, M. Deutsch, B. M. Ocko, J. Ralston, M. Rohwerder, M. Stratmann, H. Dosch, Science 2008, 322, 424.

[325] Y. R. Shen, J. Phys. Chem. C 2012, 116, 15505.

[326] S. Baldelli, J. Phys. Chem. Lett. 2013, 4, 244.

[327] S. Baldelli, Acc. Chem. Res. 2008, 41, 421.

[328] L. Bureau, Rev. Sci. Instrum. 2007, 78, 065110.

[329] I. Bou-Malham, L. Bureau, Soft Matter 2010, 6, 4062. 
[330] E. Gómez, N. Calvar, Á. Domínguez, lonic Liquids_Current State of the Art, InTech, 2015.

[331] M. Néouze, J. Le Bideau, F. Leroux, A. Vioux, Chem. Commun. 2005, 1082.

[332] H. K. Christenson, J. Phys.: Condens. Matter 2001, 13, R95.

[333] D. Akporiaye, E. W. Hansen, R. Schmidt, M. Stocker, J. Phys. Chem. 1994, 98, 1926.

[334] D. B. Asay, S. H. Kim, J. Phys. Chem. B 2005, 109, 16760.

[335] M. C. Bellissent-Funel, J. Lal, L. Bosio, J. Chem. Phys. 1993, 98, 4246.

[336] M. P. Singh, R. K. Singh, S. Chandra, Prog. Mater. Sci. 2014, 64, 73.

[337] S. Chen, Y. Liu, H. Fu, Y. He, C. Li, W. Huang, Z. Jiang, G. Wu, J. Phys. Chem. Lett. 2012, 3, 1052.

[338] A. K. Gupta, M. P. Singh, R. K. Singh, S. Chandra, Dalton Trans. 2012, 41, 6263.

[339] M. P. Singh, R. K. Singh, S. Chandra, J. Phys. D: Appl. Phys. 2010, 43, 092001

[340] Y. L. Verma, M. P. Singh, R. K. Singh, Mater. Lett. 2012, 86, 73.

[341] M. P. Singh, R. K. Singh, S. Chandra, J. Phys. Chem. B 2011, 115, 7505.

[342] Y. Umebayashi, T. Mitsugi, S. Fukuda, T. Fujimori, K. Fujii, R. Kanzaki, M. Takeuchi, S. I. Ishiguro, J. Phys. Chem. B 2007, 111, 13028

[343] J. L. Schaefer, S. S. Moganty, D. A. Yanga, L. A. Archer, J. Mater. Chem. 2011, 21, 10094

[344] C. Pfaffenhuber, M. Göbel, J. Popovic, J. Maier, Phys. Chem. Chem. Phys. 2013, 15, 18318.

[345] C. Pfaffenhuber, J. Maier, Phys. Chem. Chem. Phys. 2012, 2050.

[346] J. Przyluski, M. Siekierski, W. Wieczorek, Electrochim. Acta 1995, 40, 2101.

[347] H. Cheng, S. Torquato, Proc. R. Soc., London, Ser. A 1997, 453, 145.

[348] M. Pavlin, T. Slivnik, D. Miklavčič, IEEE Trans. Biomed. Eng. 2002, 49, 77.
[349] J. C. Maxwell, A Treatise on Electricity and Magnetism, 3rd ed., Oxford University Press, New York 1891.

[350] R. Lemlich, J. Colloid Interface Sci. 1978, 64, 107.

[351] K. Feitosa, S. Marze, A. Saint-Jalmes, D. J. J. Durian, J. Phys.: Condens. Matter 2005, 17, 6301.

[352] X. Chen, Solid Composite Electrolytes for Lithium Ion Batteries, Katholieke Universiteit Leuven, Leuven, Belgium 2018.

[353] K. Gandrud, S. Hollevoet, K. Kerckhove, B. Put, V. Creatore, A. Detavernier, C. Philippe, presented at Euromat Symp., Thessalonica, March 2017.

[354] K. H. Park, D. Y. Oh, Y. E. Choi, Y. J. Nam, L. Han, J. Y. Kim, H. Xin, F. Lin, S. M. Oh, Y. S. Jung, Adv. Mater. 2016, 28, 1874.

[355] A. Hayashi, M. Tatsumisago, Electron. Mater. Lett. 2012, 8, 199.

[356] R. W. Rice, AlChE J. 1990, 36, 481.

[357] I. Kokal, M. Somer, P. H. L. Notten, H. T. Hintzen, Solid State lonics 2011, 185, 42

[358] J. Mei, J. W. Davenport, Phys. Rev. B 1992, 46, 21.

[359] C. L. Liao, K. Z. Fung, J. Power Sources 2004, 128, 263.

[360] A. Sakuda, A. Hayashi, M. Tatsumisago, Chem. Mater. 2010, 22, 949.

[361] A. M. Glass, K. Nassau, T. J. Negran, J. Appl. Phys. 1978, 49, 4808.

[362] D. H. Kim, D. Y. Oh, K. H. Park, Y. E. Choi, Y. J. Nam, H. A. Lee, S. M. Lee, Y. S. Jung, Nano Lett. 2017, 17, 3013.

[363] X. Yao, D. Liu, C. Wang, P. Long, G. Peng, Y. S. Hu, H. Li, L. Chen, X. Xu, Nano Lett. 2016, 16, 7148

[364] E. Rangasamy, Z. Liu, M. Gobet, K. Pilar, G. Sahu, W. Zhou, H. Wu, S. Greenbaum, C. Liang, J. Am. Chem. Soc. 2015, 137, 1384.

[365] D. R. Simon, Characterization of $\mathrm{Li}_{4} \mathrm{Ti}_{5} \mathrm{O}_{12}$ and $\mathrm{LiMn}_{2} \mathrm{O}_{4}$ spinel materials treated with aqueous acidic solutions, University of Cincinnati, Cincinnati, OH 2007.

[366] C. Boissiere, A. Larbot, A. Van der Lee, P. J. Kooyman, E. Prouzet, Chem. Mater. 2000, 12, 2902.

[367] M. Niederberger, Acc. Chem. Res. 2007, 40, 793. 